\title{
Synthesis of $[c]$-Fused Bicyclic Proline Analogues
}

\author{
M. Isabel Calaza, Francisco J. Sayago, Pedro Laborda, and Carlos \\ Cativiela*
}

Departamento de Química Orgánica, Instituto de Síntesis Química y Catálisis Homogénea (ISQCH), Universidad de Zaragoza-CSIC, 50009 Zaragoza, Spain 


\title{
KEYWORDS:
}

Amino acids / Nitrogen heterocycles / Proline analogues / Diastereoselectivity / Enantioselectivity

\begin{abstract}
An overview of synthetic methods developed to build [c]-fused bicyclic proline analogues is presented. The focus is on the preparation of azabicycles that bear a carbocyclic ring fused to the $[c]$ face of the pyrrolidine unit. Attention is paid both to procedures that afford the desired compounds in racemic form and to asymmetric strategies. Procedures are organized according to the size of the carbocycle that is fused to the pyrrolidine moiety. Strategies able to provide multigram quantities of enantiopure compounds that have application in the synthesis of marketed drugs are highlighted.
\end{abstract}

\section{CONTENTS:}

1. Introduction

2. Synthesis of six-membered ring [c]-fused proline analogues

2.1. Synthesis of isoindoline-1-carboxylic acid derivatives

2.2. Synthesis of octahydroisoindole-1-carboxylic acid derivatives

3. Synthesis of five-membered ring [c]-fused proline analogues

4. Synthesis of four-membered ring [c]-fused proline analogues

5. Synthesis of three-membered ring [c]-fused proline analogues

6. Concluding remarks

7. Abbreviations and acronyms 


\section{Introduction}

In recent years important pharmacological properties have been described for compounds containing bicyclic proline residues that incorporate a carbocyclic ring fused to the $[c]$ face of the pyrrolidine unit (Figure 1).<smiles>O=C(O)C1NCC2=C1CCCC2</smiles><smiles>O=C(O)C1=C2CCCC2=C1C(=O)O</smiles>

Figure 1. General structures of $[c]$-fused bicyclic proline analogues. The positions of chiral carbons are indicated.

Among them, azabicycles $\mathbf{1}$ and $\mathbf{2}^{[1]}$ (Figure 2) have found application in the synthesis of Telaprevir, ${ }^{[2]}$ and Boceprevir, ${ }^{[3]}$ respectively; these are drugs in the market for the treatment of hepatitis $\mathrm{C}$ virus infection.
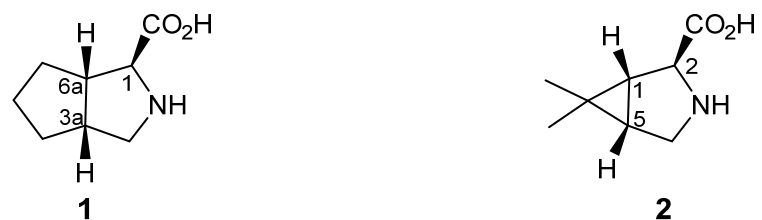

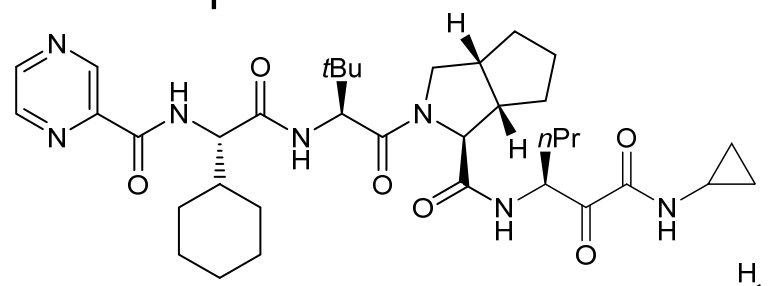

Telaprevir, Incivek ${ }^{\circledR}$

2

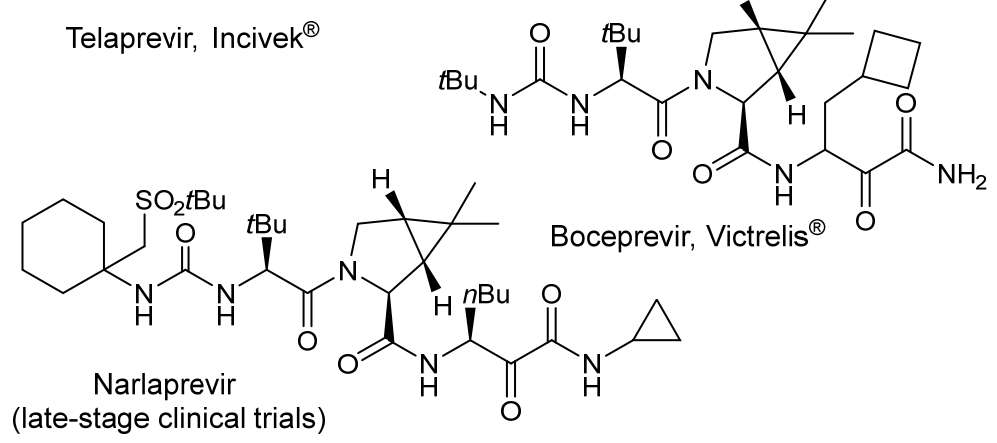

Figure 2. Marketed and new experimental hepatitis $\mathrm{C}$ protease inhibitors containing a $[c]-$ fused bicyclic proline moieties. 
In addition, the isoindoline-1-carboxylic acid scaffold forms part of the structures of compounds with potential applications as inhibitors of coagulation factor $\mathrm{Xa} .{ }^{[4]} \mathrm{It}$ is also found in the structure of a new class of specific inhibitors of the molecular chaperone Hsp90 with in vivo antitumour activity in human melanoma cells (Figure 3). ${ }^{[5]}$ Moreover, isoindoline-1-carboxylic acid has been useful in the design of analogues of indapamide, a diuretic agent used in the therapy of hypertension. ${ }^{[6]}$ Its sterically constrained structure has been valuable in structure-activity relationship studies for the design of inhibitors -or activators -of different receptors for the development of therapeutic approaches targeting hypertension, ${ }^{[7]}$ inflammation, ${ }^{[8]}$ or autoimmune ${ }^{[9]}$ and neurodegenerative diseases. ${ }^{[10]}$ Furthermore, its use as a surrogate of proline has contributed to enhancement of the selectivity properties of human PPAR $\delta$ agonists (Figure 3), which are considered promising leads for drugs for the treatment of diabetes, obesity or atherosclerosis. ${ }^{[11]}$
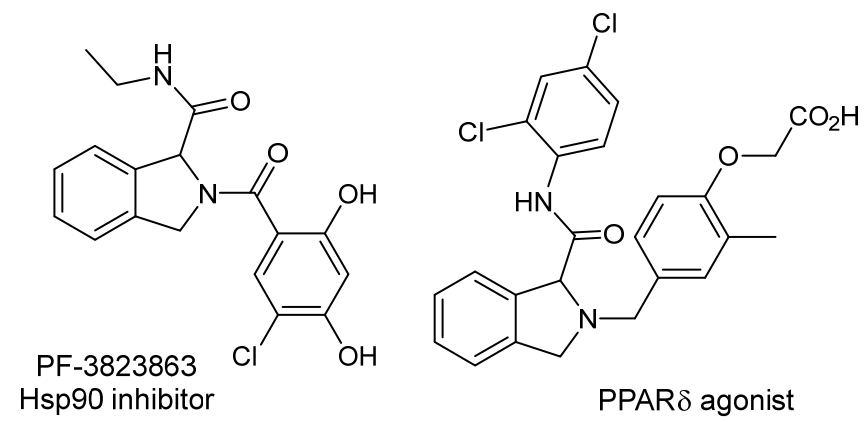

Figure 3. Isoindoline-1-carboxylic acid derivatives with pharmacologically important properties.

More lipophilic bicyclic proline analogues that bear a saturated ring fused to the $[c]$ face of the pyrrolidine make up the core structures of compounds under investigation for potential applications in diseases characterized by joint cartilage damage. ${ }^{[12]}$ These analogues have also found application in structure-activity relationship studies for the design of inhibitors of angiotensin converting enzyme, ${ }^{[13]}$ hepatitis C virus NS3 protease, ${ }^{[14]}$ and rhinovirus $3 \mathrm{C}$ protease, ${ }^{[15]}$ which are associated with hypertension, hepatitis, and human rhinovirus infections, respectively. In addition, cis-methano-Lproline is a component of peptidomimetic inhibitors of the transcription factor Stat3, an attractive target for anticancer drug design, ${ }^{[16]}$ and both stereoisomers of methano-Lproline are growth-inhibitory to bacteria. ${ }^{[17]}$ Moreover, cis-fused methano-L-proline bearing a carboxylic acid moiety attached to the cyclopropane ring is a known blocker of excitatory amino acid transporters that plays a major role in neurotransmission. ${ }^{[18]}$ 
In view of the enormous potential of proline analogues of this type and the growing interest in them, we wish to illustrate available methods for the synthesis of the family of $[c]$-fused bicyclic proline derivatives depicted in Figure 1. Attention is paid both to procedures that afford the desired compounds in racemic form and to asymmetric strategies. The diverse approaches are arranged according to the size of the carbocycle that is fused to the $[c]$ face of proline and are grouped by synthetic methodologies. Because of the abundant literature in the field, synthetic strategies leading to proline analogues that bear heterocyclic rings fused to the $[c]$ face of the pyrrolidine moiety are not included.

\section{Synthesis of six-membered ring $[c]$-fused proline analogues}

\subsection{Synthesis of isoindoline-1-carboxylic acid derivatives}

Various synthetic procedures for the preparation of isoindoline-1-carboxylic acid have been described in the literature, most of them dealing with the preparation of its racemic form. Some methods involve the $\alpha$-carboxylation of a nitrogenated bicyclic precursor (Figure 4, type A substrates), either through an electrophilic alkylation or through nucleophilic acylation. Alternatively, a number of strategies involve the construction of the pyrrolidine ring through intramolecular $\mathrm{C}-\mathrm{N}$ or $\mathrm{C}-\mathrm{C}$ bond-forming reactions (Figure 4, type B substrates). In addition to those routes, cycloaddition reactions have provided access to polyfunctionalized isoindoline-1-carboxylic acid analogues with high degrees of stereocontrol.

A<smiles>[R]NCc1ccccc1</smiles><smiles>[R]Cc1ccccc1C(N[R])C([R])[R]</smiles><smiles>[R]N1Cc2ccccc2C1=O</smiles><smiles>[R]OC(=O)CN([R])Cc1ccccc1Br</smiles>

Figure 4. Precursors used for the synthesis of isoindoline-1-carboxylic acid derivatives.

2.1.1. $\alpha$-Functionalization of isoindoline derivatives 
In 1990, Beeley and Rockell reported the preparation of isoindoline-1-carboxylic acid by $\alpha$-metallation of suitably protected isoindoline 4 (Scheme 1). ${ }^{[19]}$ In turn, the starting precursor 3 can be synthesized by treating $p$-tolylsulfonamide ${ }^{[20]}$ or hexamethylene tetramine ${ }^{[21]}$ with a dihalogenated $o$-xylylene, by reduction of phthalimide with borane tetrahydrofuran complex, ${ }^{[20]}$ or through cycloaddition reactions. ${ }^{[22]}$ Treatment of formamidine 4 with sec-butyllithium, followed by addition of ethyl chloroformate as the electrophile, afforded $\mathbf{5}$ in moderate yield. The acylation reaction was reported to require a large excess of the electrophile to minimize the generation of the 1,1-di(ethoxycarbonyl) derivative through deprotonation of the monoalkylated product. In addition, the asymmetric $\alpha$-deprotonation of isoindoline 3 has been accomplished with chiral oxazoline $^{[20]}$ or formamide ${ }^{[21]}$ auxiliaries as precursors. However, only alkyl and benzyl halides have been tested as the electrophiles.

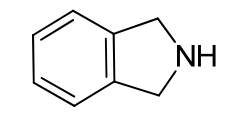

3

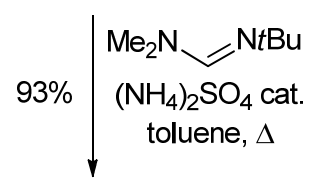

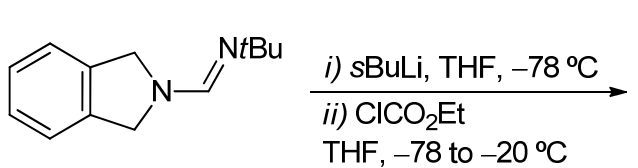

$42 \%$

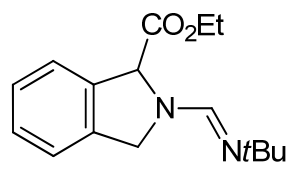

5

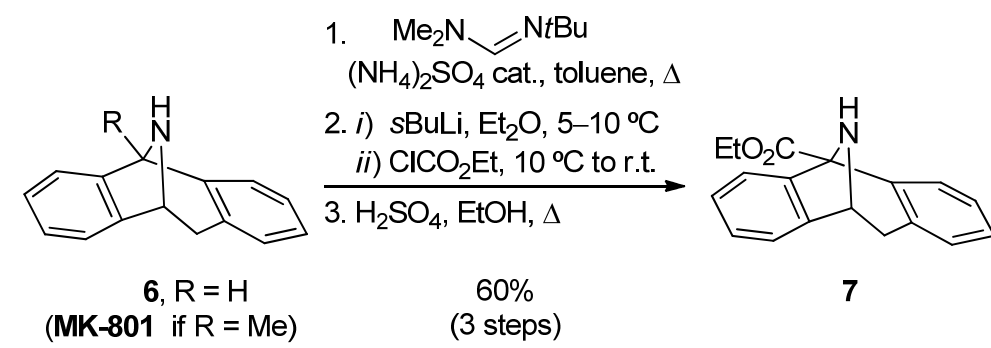

Scheme 1.

Interestingly, lithiation of the doubly benzylic position of the tert-butylformamidine generated from racemic 6 (Scheme 1) provided an $\alpha$-amino carbanion at the bridgehead position that was remarkably stable even at room temperature. ${ }^{[23]}$ Addition of ethyl chloroformate to this anionic species proceeded smoothly, and subsequent acidic hydrolysis provided amino ester 7, which can be seen as a bicyclic analogue of isoindoline-1-carboxylic acid. The interest in this type of compounds stems from the fact 
that MK-801 (Scheme 1) is a potent and selective ligand for brain phencyclidine (PCP) receptors that possesses both anticonvulsant and neuroprotective properties in vivo. ${ }^{[23 \mathrm{~b}]}$

More recently, Sato et al. reported the preparation of 9 (Scheme 2) through carboxylation of stannane 8, which was in turn generated from $\mathrm{N}$-Boc-protected isoindoline $(N$-Boc-3) by $\alpha$-lithiation and subsequent electrophilic substitution with tributyltin chloride. The carboxylation of $\mathbf{8}$ occurred under carbon dioxide in the presence of caesium fluoride as a mild tin activator. ${ }^{[24]}$

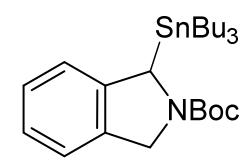

8

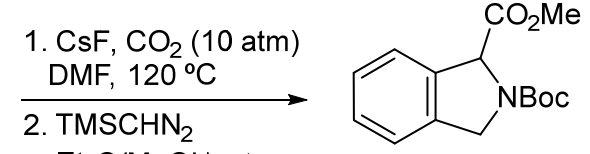

$\mathrm{Et}_{2} \mathrm{O} / \mathrm{MeOH}$, r.t.

$84 \%$

(2 steps)

Scheme 2.

\subsection{2. $\alpha$-Functionalization of isoindolinone derivatives}

The utility of isoindolinone $\mathbf{1 0}$ as a precursor for the preparation of racemic isoindoline1-carboxylic acid 13 has recently been demonstrated (Scheme 3). ${ }^{[25]}$ The procedure involved the reduction of the lactam carbonyl group in $\mathbf{1 0}$ with diisobutylaluminum hydride to obtain an intermediate hemiaminal, which was immediately transformed into the corresponding methoxyaminal. Subsequent treatment of 11 with trimethylsilyl cyanide in the presence of boron trifluoride etherate yielded compound 12, which was hydrolyzed to furnish isoindoline-1-carboxylic acid as the hydrochloride salt. The high yield of each individual step and the easy accessibility to the starting isoindolinone makes this synthetic methodology quite effective. In fact, a substantial number of strategies for the preparation of isoindolinones have been developed; ${ }^{[26,27]}$ they include reductive amination and intramolecular amidation of 2-carboxybenzaldehyde and amines, ${ }^{[26 \mathrm{~b}]}$ Curtius rearrangement of an acyl azide derived from homophthalic acid, ${ }^{[26 \mathrm{c}]}$ palladium catalysed carbonylative cyclization of 2-bromobenzaldehyde with a primary amine, ${ }^{[26 \mathrm{~d}]}$ reduction of phthalimide, ${ }^{[26 e, f]}$ and dephosphonylation of 3-oxoisoindolin-1ylphosphonates obtained by one-pot reaction of 2-formylbenzoic acid with amines and dimethylphosphite. ${ }^{\text {[26a] }}$ 
<smiles>CC(C)(C)O[N+]1(C)Cc2ccccc2C1=O</smiles>

10

1. DIBAL, THF, $-78^{\circ} \mathrm{C}$

2. PPTS, $\mathrm{MeOH}$, r.t.

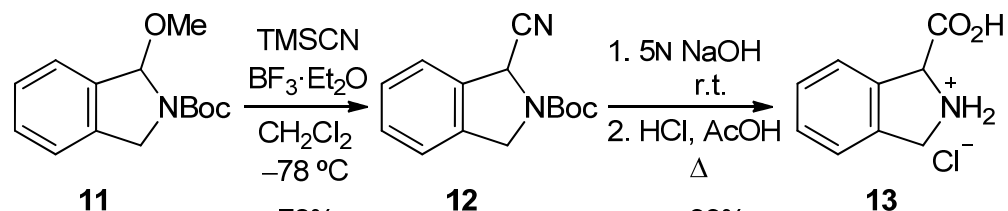

$78 \%$

12

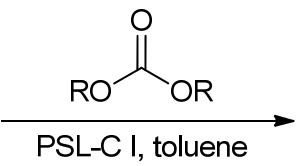

$60^{\circ} \mathrm{C}, 250 \mathrm{rpm}$

$\mathrm{R}=$ allyl or benzyl 63-72\%
$99 \%$<smiles>[R]O[N+]1([O-])Cc2ccccc2[C@H]1C(C)=O</smiles>

15

94-98\% ee

Scheme 3.

In addition, the asymmetric synthesis of isoindoline carbamates (Scheme 3, 15) was successfully achieved through an enzyme-mediated dynamic kinetic resolution process of 14. ${ }^{[25]}$ This strategy employed Pseudomonas cepacia lipase (PSL-C I) as biocatalyst and avoided the use of metal or acid-base catalysis for the racemization of the substrate. Specifically, optically active carbamates $\mathbf{1 5}$ were obtained in good yield and excellent degree of enantioselectivity in alkoxycarbonylation reactions with diallyl or dibenzyl carbonates.

\subsubsection{Intramolecular cyclization through $\mathrm{C}-\mathrm{N}$ bond formation}

Some of the methodologies developed for the synthesis of dihydroisoindole-1carboxylic acid derivatives are based on the construction of the pyrrolidine ring by intramolecular $\mathrm{C}-\mathrm{N}$ bond formation. Reactions between $\alpha$-bromophenyl acetates, such as 16 (Scheme 4), and primary amines or hydrazines furnished dihydroisoindole-1carboxylates. ${ }^{[7,28]}$ These proved to be highly sensitive to air, thus requiring isolation as their hydrochloride salts. In particular, isoindoline 14 was obtained by catalytic hydrogenolysis of the $N$-benzyl derivative $\mathbf{1 7 b}$, but it was also sensitive to air. The use of phenylhydrazine as the nucleophile furnished $\mathbf{1 7 d}$ in only $24 \%$ yield due to concomitant formation of the corresponding isoindole. ${ }^{[29]}$ Conversely, condensation between 16 and 
tert-butyl carbazate afforded $\mathbf{1 7 e}$, which was then converted into the corresponding aminoisoindoline upon acidic treatment. ${ }^{[6]}$

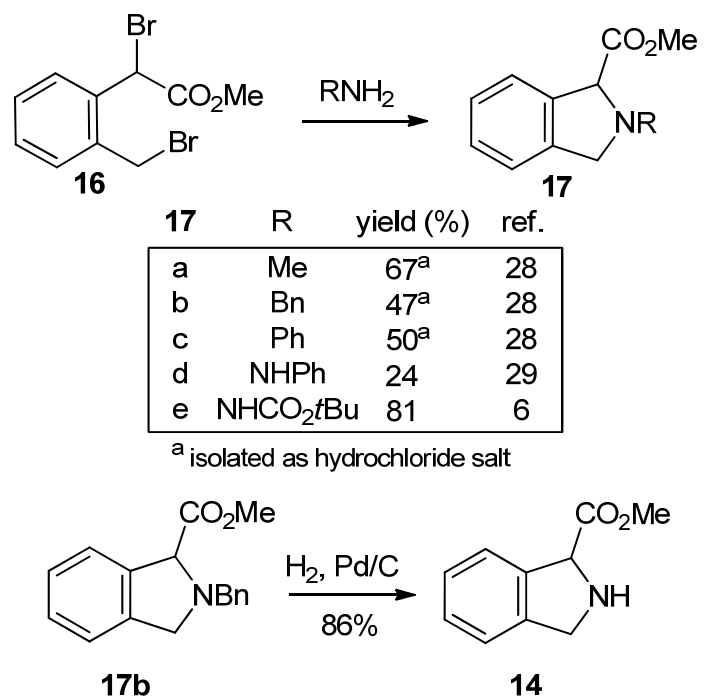

Scheme 4.

More recently, Scherkenbeck et al. reported the preparation of 20 (Scheme 5) as a simplified analogue of the alkaloid cyclopiazonic acid, which is an attractive lead for the development of antimalarial drugs and plant protection. ${ }^{[30]}$ The cyclization of isopropenylated phenylglycine $\mathbf{1 9}$ was achieved by treatment with triflic acid. The protonation of the double bond generated a benzylic cation that was then attacked by the amino function. Therefore, a strongly electron-withdrawing protecting group was required for the nitrogen atom in order to prevent its protonation during the generation of the cationic species. A subsequent two-step deprotection/reprotection sequence provided access to racemic $\mathbf{2 0}$ in gram quantities.

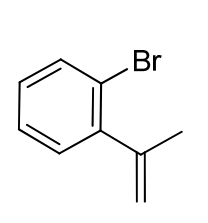

18

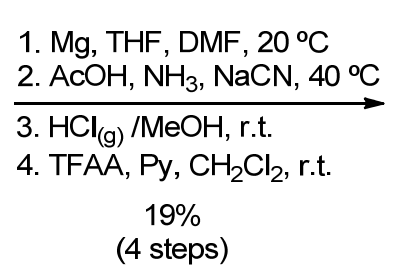

(4 steps)

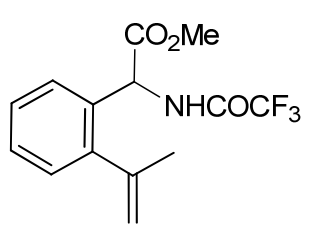

19

1. $\mathrm{TfOH}, \mathrm{CH}_{2} \mathrm{Cl}_{2}$, r.t.

2. i) $5 \mathrm{~N} \mathrm{NaOH}, \mathrm{EtOH}, \Delta \quad \begin{gathered}71 \% \\ \text { (2 steps) }\end{gathered}$ ii) $\mathrm{SOCl}_{2}, \mathrm{MeOH}$, r.t.<smiles>CC(=O)C1NC(C)(C)c2ccccc21</smiles>

Scheme 5. 


\subsubsection{Intramolecular cyclization through $\mathrm{C}-\mathrm{C}$ bond formation}

A different cyclization strategy for the synthesis of dihydroisoindole-1-carboxylic acid derivatives was described by Buchwald and Gaertzen (Scheme 6). ${ }^{[31]}$ The pyrrolidine ring formation was achieved through palladium-catalysed intramolecular $\alpha$-arylation of $\alpha$ amino acid esters $\mathbf{2 1}$. The reaction conditions were optimized in terms of base, solvent, metal source and ligand. It was found that catalysts based on biphenyl aminophosphines provided better results than those based on trialkyl- or triarylphosphine ligands with regard to yield and reaction rate. According to the authors, this could be related to the fact that the biphenyl backbone provides a weak coordination site to the metal, either through the amino group or through the arene itself.

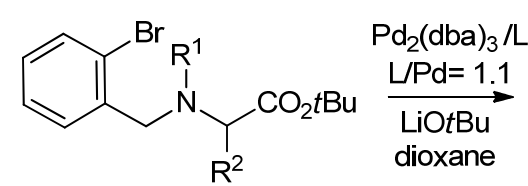

21

\begin{tabular}{|lllccc|}
$\mathrm{R}^{1}$ & $\mathrm{R}^{2}$ & $\mathrm{~L}$ & $\mathrm{~T}\left({ }^{\circ} \mathrm{C}\right)$ & $\mathrm{t}(\mathrm{h})$ & yield $(\%)$ \\
\hline $\mathrm{Ph}$ & $\mathrm{H}$ & $\mathrm{a}$ & 85 & 1 & 79 \\
$\mathrm{Ph}$ & $\mathrm{Me}$ & $\mathrm{a}$ & 85 & 24 & 91 \\
$\mathrm{Ph}$ & $i \mathrm{Pr}$ & $\mathrm{b}$ & 110 & 48 & 51 \\
$\mathrm{Ph}$ & $\mathrm{Ph}$ & $\mathrm{b}$ & 90 & 2 & 99 \\
$\mathrm{Cbz}$ & $\mathrm{Me}$ & $\mathrm{b}$ & 90 & 24 & 67 \\
$\mathrm{Cbz}$ & $\mathrm{Ph}$ & $\mathrm{b}$ & 90 & 2 & 86 \\
\hline
\end{tabular}<smiles>[R1]N1Cc2ccccc2C1([R17])[R]</smiles>

22

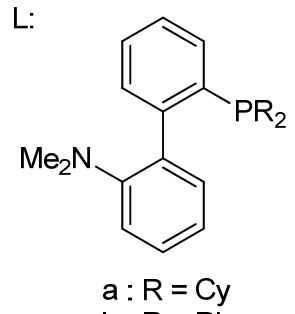

Scheme 6.

In a related approach, Solé and Serrano reported palladium-catalysed intramolecular $\alpha-$ arylation reactions of (2-iodobenzyl)amino acid esters $\mathbf{2 3}$ that allowed the selective synthesis of either isoindolines $\mathbf{2 5}$ or of the corresponding isoindole-1-carboxylates 24 in a very efficient manner (Scheme 7) ${ }^{[32]}$ In particular, isoindoles 24 were the result of a palladium-catalysed cascade that involved enolate arylation and dehydrogenation of the initially formed isoindoline. Interestingly, analogous aryl bromides or aryl triflates were less efficient than aryl iodides in the $\alpha$-arylation reaction, being either completely unreactive or unstable, respectively. 
<smiles>[R]OC(=O)C1c2ccccc2CN1Cc1ccccc1</smiles>

25

$\mathrm{R}=\mathrm{Me}, \mathrm{Et}, t \mathrm{Bu}$

88-91\%

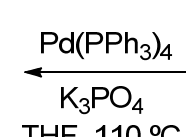
THF, $110^{\circ} \mathrm{C}$

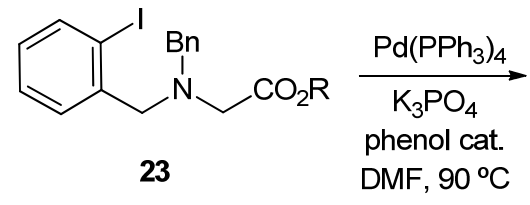

23<smiles>[R]OC(=O)c1c2ccccc2cn1Cc1ccccc1</smiles>

24

$\mathrm{R}=\mathrm{Me}, \mathrm{Et}, t \mathrm{Bu}$ $78-85 \%$

Scheme 7.

\subsubsection{Cycloaddition reactions}

As previously mentioned, cycloaddition reactions have provided access to polyfunctionalized isoindoline-1-carboxylic acid analogues with high degrees of stereocontrol. Durst et al. described that azaallyllithium species 27 (Scheme 8) reacted with benzyne to furnish a 1,3-dihydroisoindole through a [3+2] cycloaddition when the reaction was quenched after a short reaction time at low temperature $\left(3 \mathrm{~h},-78^{\circ} \mathrm{C}\right) .{ }^{[33]} \mathrm{It}$ was suggested by the authors that the formation of a single stereoisomer of $\mathbf{2 8}$ with a cis relationship between the ethoxycarbonyl group and the 3-alkyl substituent is consistent with a concerted cycloaddition involving an azaallyllithium species that exhibits lithium complexation to both oxygen and nitrogen atoms. It was also observed that dihydroisoindole 28 rearranged to $(2 H)$-isoquinolin-3-one 29 on prolonged exposure of 26 to base at temperatures above $0{ }^{\circ} \mathrm{C}$. ${ }^{[33]}$

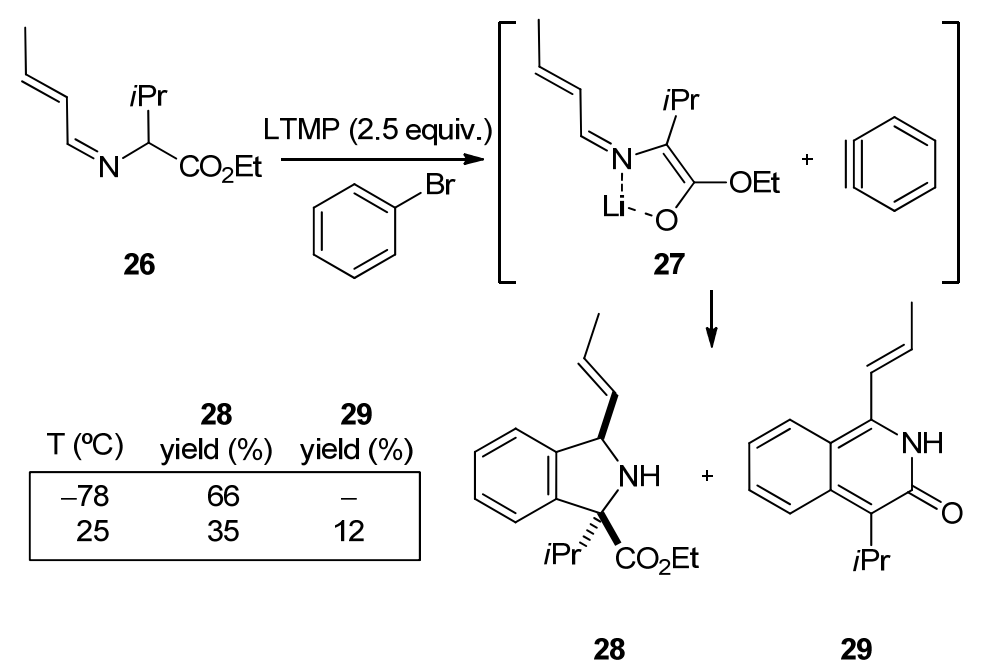

Scheme 8.

More recently, [4+2] cycloaddition reactions between 1,3-disubstituted isoindoles and alkynes or benzynes (Scheme 9) have provided access to complex dihydroisoindole-1carboxylic acid derivatives, such as $\mathbf{3 1}$ and $\mathbf{3 2}$, in good yields. ${ }^{[34]}$ These adducts have 
proved to be ideal precursors for the preparation of aromatic hydrocarbons through an oxidative deamination process.<smiles>[R]OC(=O)c1[nH]c(C(C)C)c2ccccc12</smiles>

30

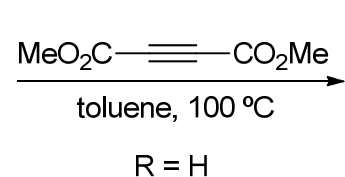

$98 \%$

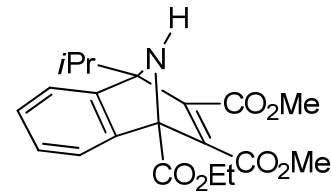

31<smiles></smiles>

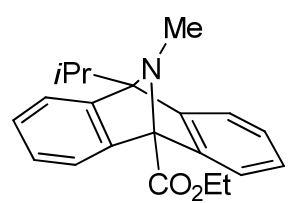

32

Scheme 9.

In this context, several authors have demonstrated the utility of azomethine ylide dipoles for the synthesis of isoindoline-1-carboxylic acid derivatives. ${ }^{[35]}$ Gong et al. reported the use of ylides generated by activation of azomethines with chiral phosphoric acids (Scheme 10). ${ }^{[35 \mathrm{c}]}$ For example, the reaction between quinone and the azomethine ylide generated from $p$-nitrobenzaldehyde and $p$-chlorophenylglycine methyl ester, followed by a base-promoted isomerization, was reported to furnish isoindoline $\mathbf{3 5}$ in good yield and with good enantioselectivity. Similarly, Wang et al. described a one-pot approach to enantioenriched isoindolines 38 (Scheme 10), each also containing a quaternary stereogenic centre, through highly efficient $\mathrm{Cu}(\mathrm{I})$-catalysed 1,3-dipolar cycloaddition of azomethine ylides and quinone derivatives, followed by silica-gel-promoted aromatization. The absolute configuration of one adduct was determined by X-ray crystallographic analysis of a single crystal, and those of other adducts were tentatively proposed on the basis of that result. ${ }^{[35 \mathrm{~d}]}$ 
Published in Eur. J. Org. Chem. 2015, 1633-1658 (doi: 10.1002/ejoc.201403121)<smiles>NC(C(=O)O[Na])C(=O)c1ccccc1</smiles>

34<smiles>O=C1C=CC(=O)c2ccccc21</smiles><smiles>[R]C=NC([R7])C(C)OC</smiles>

37

$\mathrm{R}^{1}=$ aryl, heteroaryl, alkyl $\mathrm{R}^{2}=\mathrm{Me}, \mathrm{Et}, \mathrm{Pr}, \mathrm{BBu}, \mathrm{Bn}, \mathrm{Ph}$

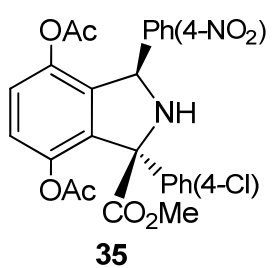

$76 \%, 86 \%$ ee

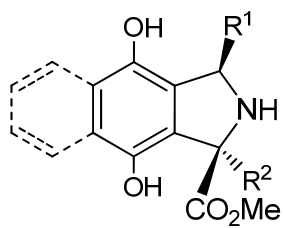

38

$70-93 \%$

$d r>20: 1,86-97 \%$ ee<smiles></smiles>

$\mathrm{Ar}=$ anthracenyl

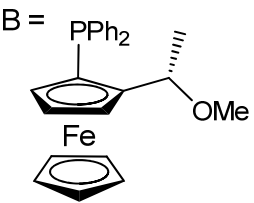

Scheme 10.

Dixneuf and Osipov employed cycloaddition reactions of unsaturated $\alpha$-trifluoromethyl amino acid esters to assemble the aromatic ring of the isoindoline scaffold (Scheme 11). On one hand, $\alpha$-alkynyl amino acid ester 39 allowed access to a five-membered ring by enyne metathesis performed with a ruthenium-allenylidene complex. ${ }^{[36]}$ The resulting $\alpha$ trifluoromethylated proline derivative containing a diene moiety underwent a Diels-Alder reaction followed by aromatization upon treatment with DDQ. On the other hand, ruthenium-catalysed cyclotrimerizations were achieved with suitable 1,6-diynes, such as 42, and acetylene. ${ }^{[37]}$ 


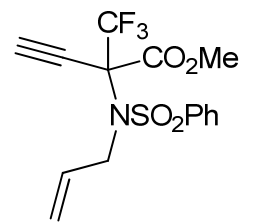

39

$70 \%{ }_{\downarrow} \begin{aligned} & {\left[\mathrm{Ru}=\mathrm{C}=\mathrm{C}=\mathrm{CPh}_{2}(\mathrm{Cl})\left(\mathrm{PCy}_{3}\right)(p-\text { cymene })\right]^{+} \mathrm{PF}_{6}{ }^{-} \text {cat. }} \\ & \text { toluene, } 80^{\circ} \mathrm{C}\end{aligned}$
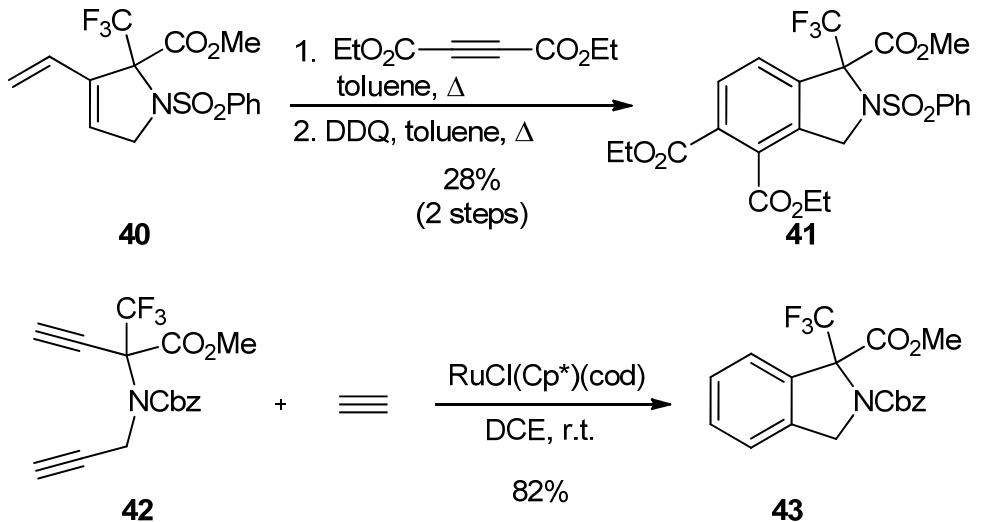

Scheme 11.

\subsection{Synthesis of octahydroisoindole-1-carboxylic acid derivatives}

A number of strategies have been devised for the preparation of octahydroisoindole-1carboxylic acid derivatives with either cis or trans relative dispositions of the hydrogen atoms at the ring junction. Strategies that give access to $c i s$-fused octahydroisoindole-1carboxylic acid derivatives involve the hydrogenation of isoindole or isoindolinone precursors, as well as the activation of the $\mathrm{C}-\mathrm{H}$ bond $\alpha$ to the nitrogen atom in $c i s[c]-$ fused bicyclic pyrrolidines (Figure 5, type A substrates). In addition, intramolecular radical cyclizations of $\alpha$-(phenylthio)glycine derivatives or cycloaddition reactions of pyroglutamate derivatives (type B substrates) also preferably furnish cis-fused bicyclic systems. On the other hand, the trans relative disposition of the hydrogen atoms at the ring junction has been accomplished through reductive cyclization of cyclohexane derivatives exhibiting trans relative disposition of appropriate carboxylic acid and amine substituents (substrates C). 
A<smiles>[R17]C(=O)C1NCc2ccccc21</smiles>

B<smiles>[R]OC(=O)C([Sn])N([R])CC1C=CCCC1</smiles><smiles>[R17]C(=O)C1NC(=O)c2ccccc21</smiles><smiles>C1CCC2CNCCC2C1</smiles>

C<smiles>CCOC(=O)C1CCCC[C@H]1C[N+](=O)[O-]</smiles>

Figure 5. Precursors used for the synthesis of octahydroisoindole-1-carboxylic acid derivatives

\subsubsection{Synthesis from isoindoline-1-carboxylic acid derivatives}

Racemic octahydroisoindole-1-carboxylate $45 \mathbf{a}$ has been synthesized by hydrogenation of the isoindole precursor (Scheme 12). ${ }^{[13]}$ The use of rhodium on charcoal as a catalyst provided a single stereoisomer in good yield after recrystallization. It was tentatively presumed by the authors that the hydrogen atoms at the chiral centres have a cis relationship as a result of the hydrogenation taking place on the less hindered face of the molecule. Similar hydrogenations provided access to ethyl, and tert-butyl ester derivatives. Later, the chemical resolution of the ethyl ester derivative by using $(1 S)-(+)-$ 10-camphorsulfonic acid was indicated in a patent, ${ }^{[12]}$ but no details regarding the efficacy of the process were provided. In the same way, catalytic hydrogenations of $\mathbf{4 4} \mathbf{b}^{[30]}$ and $\mathbf{4 4} c^{[38]}$ led to the exclusive formation of $\mathbf{4 5 b}$ and $\mathbf{4 5 c}$ as single stereoisomers.<smiles>[R17]C([R])([R])NC1([R])NC([R])([R])c2ccccc21</smiles>

44

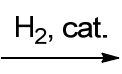<smiles>[R]OC1([R2])NC([R])([R])C2([R])CCCCC12[R]</smiles>

45

\begin{tabular}{|c|c|c|c|c|c|c|c|c|}
\hline 44 & $\mathrm{R}^{1}$ & $\mathrm{R}^{2}$ & $\mathrm{R}^{3}$ & cat. & solvent & $\mathrm{T}\left({ }^{\circ} \mathrm{C}\right)$ & $\mathrm{P}$ (bar) & 45 yield (\%) \\
\hline$a^{a}$ & $\mathrm{Me}$ & $\mathrm{H}$ & $\mathrm{H}$ & $\mathrm{Rh} / \mathrm{C}$ & $\mathrm{MeOH} / \mathrm{AcOH}$ & -1 r.t. & $-^{\mathrm{b}}$ & $-\mathrm{a}, \mathrm{c}$ \\
\hline b & $\mathrm{Me}$ & $\mathrm{H}$ & $\mathrm{Me}$ & $\mathrm{PtO}_{2}$ & $\mathrm{EtOH}$ & r.t. & 8 & 45 \\
\hline c & $t \mathrm{Bu}$ & $\mathrm{Me}$ & $\mathrm{H}$ & $\mathrm{Rh} / \mathrm{C}$ & $\mathrm{MeOH}$ & 60 & 4 & 56 \\
\hline
\end{tabular}

Scheme 12.

2.2.2. Synthesis from 3-oxo-1H-isoindolin-1-carboxylic acid derivatives

The $c i s$-fused octahydroisoindole- $1 H$-carboxylic acid system has also been constructed in a straightforward manner from methyl 3-oxo-1H-isoindolin-1-carboxylate 46 (Scheme 

13). ${ }^{[39]}$ The four-step procedure for the stereoselective synthesis of 49 started with the hydrogenation of $\mathbf{4 6}$ under hydrogen (atmospheric pressure) in the presence of platinum oxide as a catalyst. This treatment provided a 96:4 ratio of stereoisomers, $\mathbf{4 7}$ and $\mathbf{4 8}$. The major stereoisomer was isolated by column chromatography and the relative cis orientation of the two bridgehead hydrogen atoms with respect to that at the carbon $\alpha$ position was established by NMR experiments. Subsequent protection of the amino function in isolated $\mathbf{4 7}$ improved the electrophilic nature of the lactam carbonyl group and allowed its reduction to a methylene group by sequential treatment with diisobutylaluminum hydride and triethylsilane.

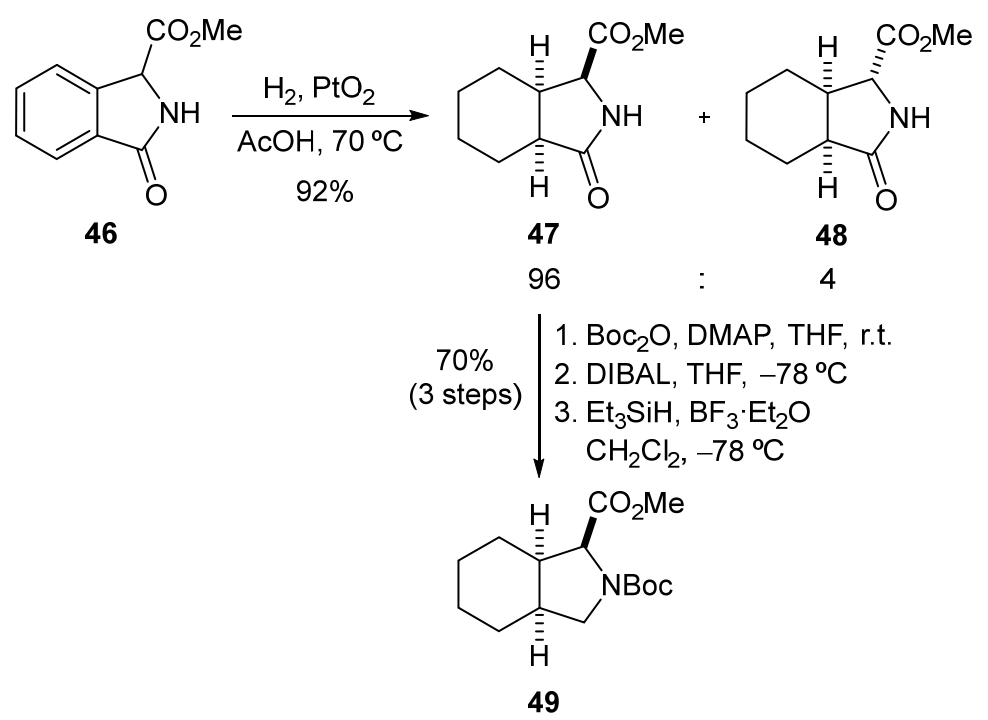

Scheme 13.

This methodology is quite convenient because many approaches to the preparation of isoindolinone precursors have been described in the literature. ${ }^{[40,41,42]}$ The preparative pathways for such isoindolinones (Scheme 14) include the nucleophilic attack of 3metalated isoindolines onto carbon dioxide (path a), ${ }^{[40 \mathrm{a}]}$ and the addition of nitrogen equivalents to phthalonic acid (path c) ${ }^{[40 \mathrm{~b}]}$ phthalaldehydic acid (path d) ${ }^{[40 \mathrm{c}]}$ or diethyl $\alpha$ bromohomophthalate (path e). ${ }^{[40 \mathrm{~d}]}$ Specifically, compound 46 (Scheme 13) was obtained by carbonylation of an orthopalladated complex generated from a phenylglycine derivative (Scheme 14, path b). ${ }^{[40 e, f]}$ 


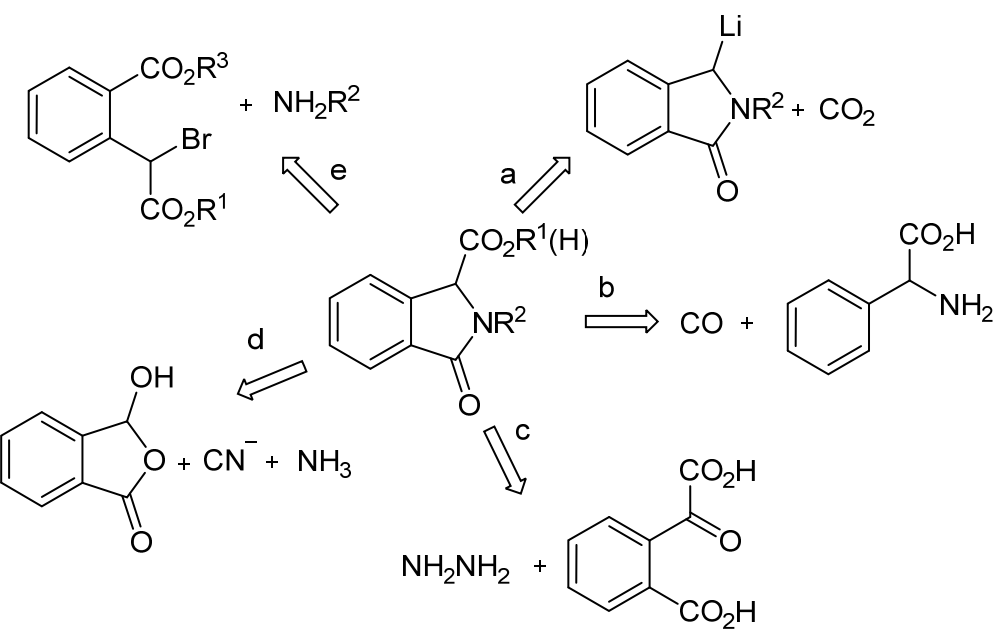

Scheme 14.

In addition, octahydroisoindolinone 48 (Scheme 13) was synthesized through a 5-endotrig dearomatizing anionic intramolecular cyclization of a lithiated benzamide precursor. ${ }^{[43]}$ Interestingly, stereospecific lithiations of more complex benzamides have provided access to octahydroisoindolinone derivatives that have proven valuable intermediates for the synthesis of analogues of kainic and domoic acids. ${ }^{[44]}$

\subsection{3. $\alpha$-Functionalization of octahydro- $(1 H)$-isoindole derivatives}

Turner et al. described the enantioselective synthesis of $\mathbf{5 1}$ (Scheme 15), a useful precursor of octahydroisoindole-1-carboxylic acid, through direct activation of the $\mathrm{C}-\mathrm{H}$ bond $\alpha$ to the nitrogen atom in pyrrolidine 50. ${ }^{[45]}$ The process involved the use of the biocatalyst MAO-N D5 (monoamine oxidase from Aspergillus niger) and molecular oxygen for the generation of an intermediate enantiopure $\Delta^{1}$-pyrroline. This compound underwent nucleophilic addition in the presence of cyanide and provided a diastereomeric mixture of $\alpha$-amino nitriles, which were converted to trifluoroacetamides. The diastereoselectivity achieved during the nucleophilic addition was reported to be strongly dependent on the reaction conditions. In buffered aqueous medium the addition of cyanide to the $\Delta^{1}$-pyrroline occurred with high diastereoselectivity $(d r 82: 18)$ and preferentially furnished 51, with a trans relative disposition between the nitrile group and the sixmembered cycle. In addition, the authors reported that MAO-N D5 displayed good activity towards a range of substituted pyrrolidines. In general, increasing the pyrrolidine bulk and lipophilicity correlated with higher rates of oxidation. 


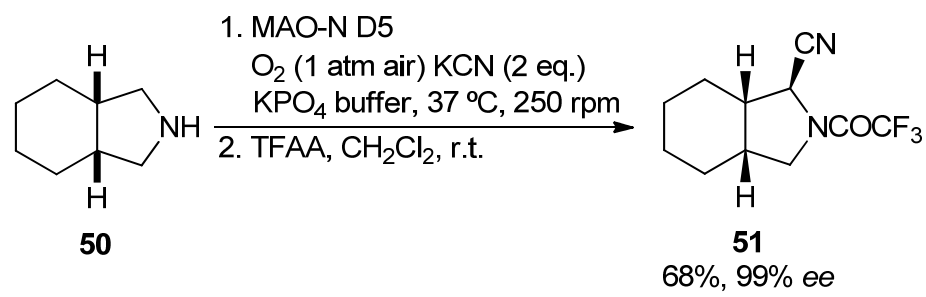

Scheme 15.

The introduction of the carboxylic acid moiety $\alpha$ to the amine function by means of a chemical oxidative process followed by nitrile addition had previously been reported. ${ }^{[38,46]}$ In particular, oxidation and $\alpha$-cyanation of pyrrolidine 52 (Scheme 16) afforded nitrile 53, which after hydrolysis gave amino acid $\mathbf{5 4}$ as the only stereoisomer. ${ }^{[38]}$ Similarly, pyrrolidine 55 furnished 56 accompanied by trace amounts of the other stereoisomer, which was removed by chromatography following a $N$-methylation. ${ }^{[38]}$ The structural assignment, based on NMR experiments, determined that in both cases the rigid structure forced the nitrile anion to attack the nitrone intermediate from the si face of the double bond.
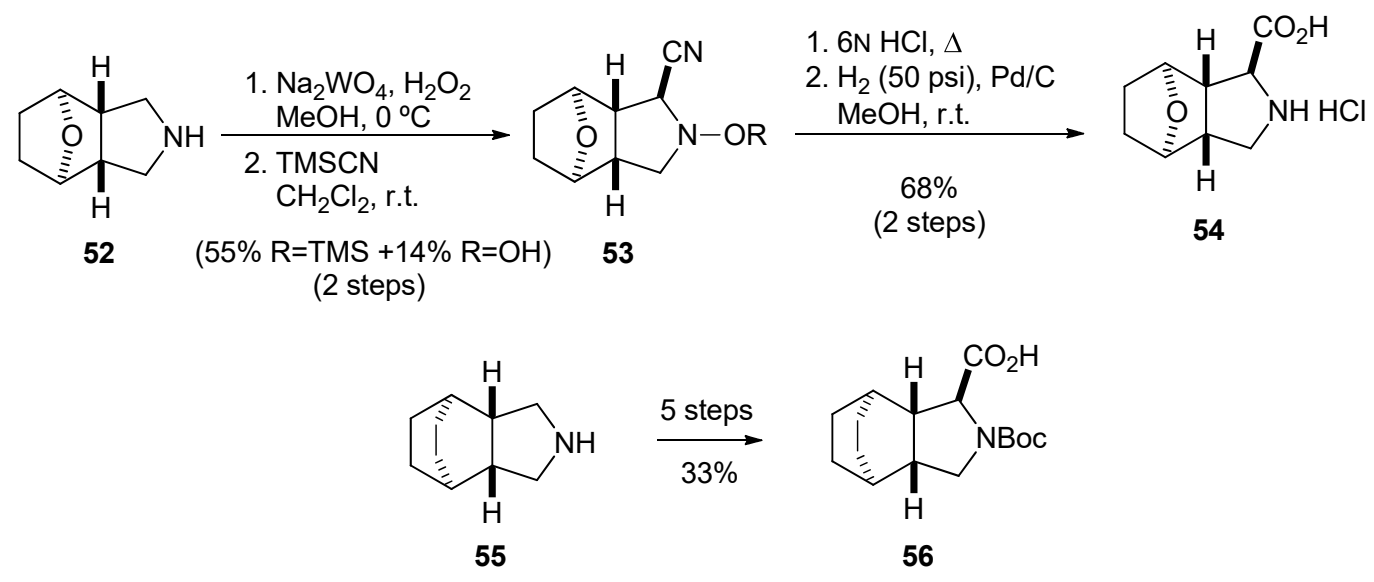

Scheme 16.

Alternatively, the octahydroisoindole-1-carboxylic acid system has been assembled through $\mathrm{N}$-Boc-directed lithiation of a pyrrolidine followed by carboxylation. In particular, Kotsuki et al. described the preparation of enantiomerically pure anthracenefused proline analogues, 59 and $\mathbf{6 0}$ (Scheme 17). ${ }^{[4]}$ The lithiation of $N$-Boc protected pyrrolidine $\mathbf{5 7}$ gave amino acid $\mathbf{5 8}$ as a mixture of endo- and exo-isomers. Their treatment with (-)-menthol gave a diastereomeric mixture of menthyl esters that underwent isomerization quite smoothly to furnish the more stable exo isomers. Removal of the $N$ Boc protecting group gave nearly equal amounts of free amino menthyl esters that were 
isolated by column chromatography. Alkaline hydrolysis of the menthyl esters provided enantiopure 59 and 60, which were used as organocatalysts. ${ }^{[47]}$ Their stereochemistry was unambiguously established by X-ray crystallographic analysis of the menthyl ester derivative of 60 .

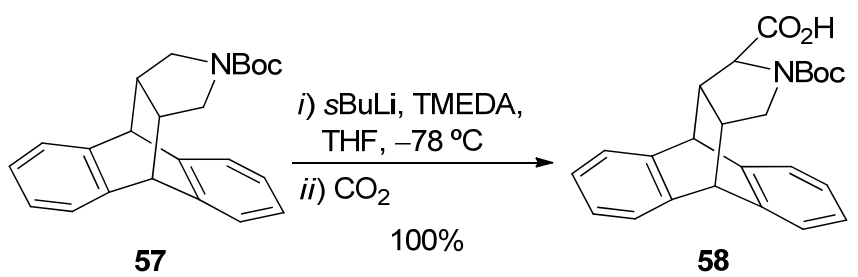

$100 \%$

58

1. (-)-Menthol, DCC, DMAP, $\mathrm{CH}_{2} \mathrm{Cl}_{2}$, r.t.

2. i) TFA, $\mathrm{CH}_{2} \mathrm{Cl}_{2}$, r.t., ii) aq. $\mathrm{NaOH}$, then column chromatography

3. $1 \mathrm{M} \mathrm{NaOH}, \mathrm{MeOH}, 45^{\circ} \mathrm{C}$

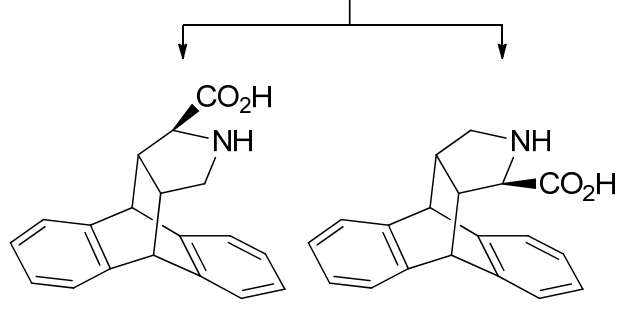

59

60

Scheme 17.

\subsubsection{Intramolecular cyclization through $\mathrm{C}-\mathrm{N}$ bond formation}

Reductive intramolecular cyclization of 61 and 64 has been employed for the preparation of racemic octahydroisoindole-1-carboxylic acid derivatives $\mathbf{6 3}$ and 66, which are cis- and trans-fused bicyclic prolines, respectively (Scheme 18). ${ }^{[38]}$ In the synthesis of 63 , compound 62 was obtained as a mixture of stereoisomers. The ring junction was set in the disposition depicted in $\mathbf{6 3}$ during the alkylation of $\mathbf{6 2}$. Subsequent reduction of the lactam carbonyl group, and treatment of the aminoacetal with a Lewis acid, afforded an acyl iminium species that underwent attack by the nitrile anion exclusively from the si face. Similar elaboration of gem-dimethyl-substituted $\mathbf{6 5}$, with a trans ring junction, provided $\mathbf{6 6}$ as the only isomer. In this case, the nitrile anion attacks from the re face of the intermediate acyl iminium species. Presumably, the attack from the $s i$ face is not favoured due to axial interactions with a methyl group and the hydrogen atom at the ring junction. 


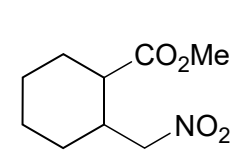

61
1. $\mathrm{H}_{2}$, Raney $\mathrm{Ni}, \mathrm{MeOH}$, r.t.

2. $\mathrm{NaOMe}, \mathrm{MeOH}, \Delta$

3. $\mathrm{Boc}_{2} \mathrm{O}, \mathrm{DMAP}, \mathrm{Et}_{3} \mathrm{~N}, \mathrm{THF}$, r.t.

$70 \%$

(3 steps)

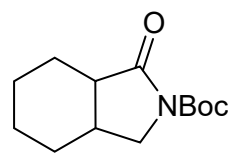

62

1. $\mathrm{LDA}, \mathrm{BnBr}, \mathrm{THF},-78^{\circ} \mathrm{C}$

2. $\mathrm{LiBHEt}_{3}, \mathrm{THF},-78^{\circ} \mathrm{C}$

3. $\mathrm{TMSCN} \mathrm{BF}_{3} \cdot \mathrm{Et}_{2} \mathrm{O}$ $\mathrm{CH}_{2} \mathrm{Cl}_{2},-78^{\circ} \mathrm{C}$

4. conc. $\mathrm{HCl}, \triangle$
$20 \%$ (4 steps)<smiles>O=C(O)[C@@H]1NC[C@@H]2CCCC[C@@]21Cc1ccccc1</smiles>

63<smiles>CC(=O)[C@H]1CCCC[C@H]1C(C)(C)[N+](=O)[O-]</smiles>

64

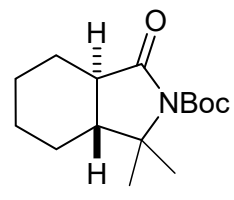

65

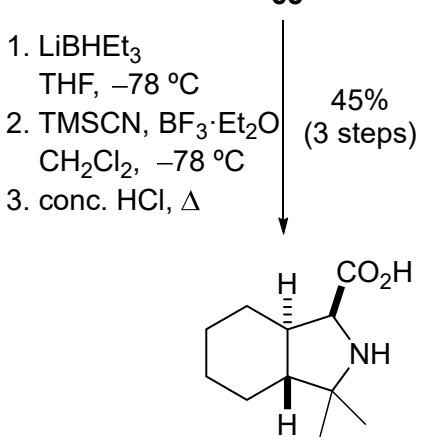

66

Scheme 18.

Gais et al. described the asymmetric synthesis of bicyclic proline 74, with a cis relative disposition between the carboxylic acid ester group and the six-membered ring, by making use of a migratory cyclization procedure (Scheme 19). ${ }^{[48 a]}$ Treatment of enantiomerically pure allylic sulfoximine 67 with $n \mathrm{BuLi}$ and $\mathrm{ClTi}(\mathrm{O} i \mathrm{Pr})_{3}$ afforded bis(allylsulfoximine)titanium complex $\mathbf{6 8}$, which underwent addition to a sulfonyl imino ester to furnish a mixture of $\mathbf{6 9}$ and $\mathbf{7 0}$ with high regio- and diastereoselectivity. Activation of the $N$-methyl sulfoximine group of $\mathbf{7 0}$ afforded sulfoxonium salt $\mathbf{7 1}$. The migratory cyclization took place through isomerization of the double bond in $\mathbf{7 1}$. The allylic sulfoxonium salt $\mathbf{7 2}$ underwent an intramolecular substitution of the sulfoxonium group that provided bicyclic proline 73. Finally, cleavage of the tert-butylsulfonyl protecting group under acidic conditions furnished $\mathbf{7 4}$ in enantio- and diastereomerically 
Published in Eur. J. Org. Chem. 2015, 1633-1658 (doi: 10.1002/ejoc.201403121)

pure form. Alternatively, allylic chloride $\mathbf{7 5}$ was obtained from $\mathbf{7 0}$ when a chloroformate was used for the activation and migratory substitution. ${ }^{[48 b]}$ Subsequent treatment of $\mathbf{7 5}$ with DBU gave proline derivative $\mathbf{7 6}$ in practically quantitative yield.
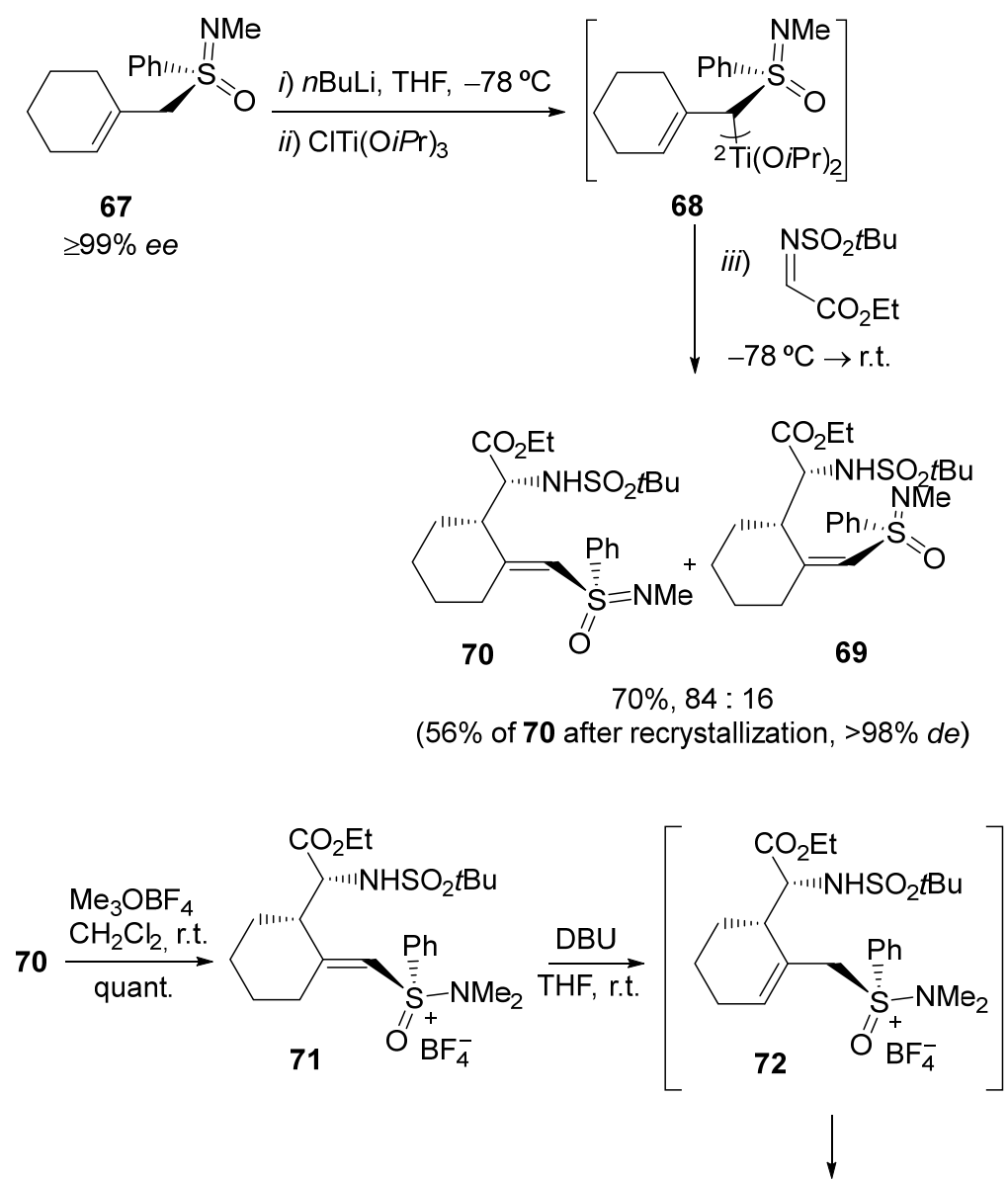<smiles>O=C(O)C1NCC2=CCCC[C@H]21</smiles>

74

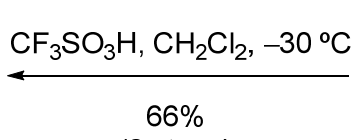

(2 steps)

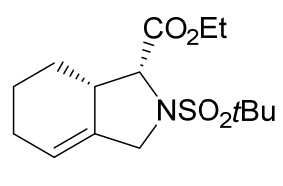

73

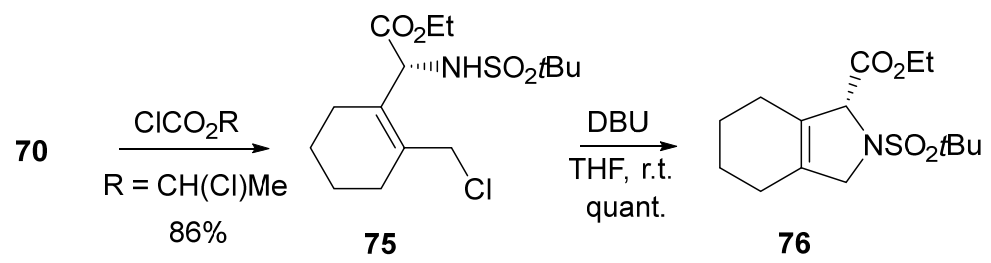

Scheme 19.

\subsubsection{Intramolecular cyclization through $\mathrm{C}-\mathrm{C}$ bond formation}

The preparation of racemic cis-fused octahydroisoindole-1-carboxylic acid derivatives 78 and 79 has been accomplished through the reductive intramolecular cyclization of $\alpha$ - 
(phenylthio)glycines 77, each bearing a 3-alkenyl substituent at the nitrogen atom (Scheme 20). ${ }^{[49]}$ The treatment of $\mathbf{7 7 a}$ with tributyltin hydride and a catalytic amount of AIBN in toluene solution at $80-90^{\circ} \mathrm{C}$ produced a captodative radical that preferentially underwent a 5-exo intramolecular cyclization. Similar results were observed in the copper(I)-catalysed chlorine transfer radical cyclization of $\alpha$-chloroglycine $\mathbf{7 7 b}{ }^{[50]}$ In this case, the authors suggested the cyclization of an incipient free radical. The copper complex acts as a carrier of the chlorine atom by way of a redox reaction.

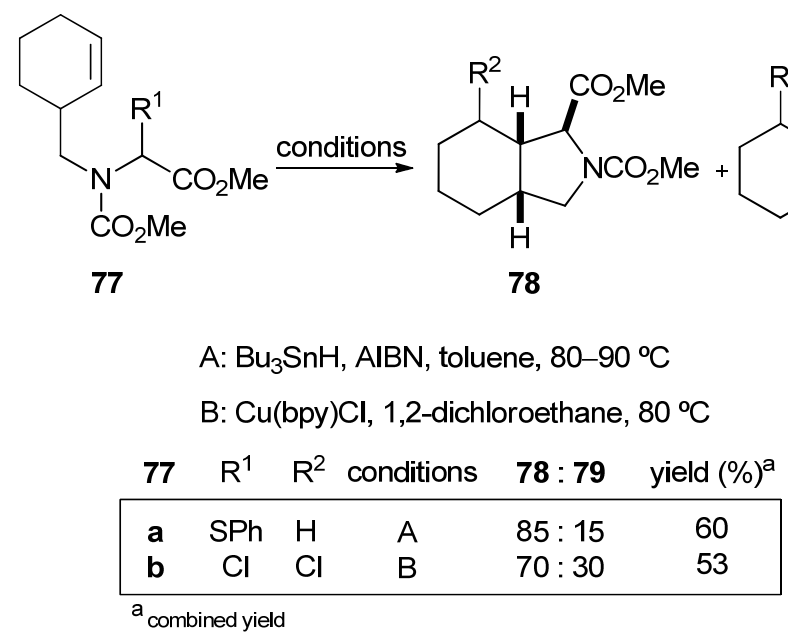

Scheme 20.

\subsubsection{Cycloaddition reactions}

A variety of procedures for the preparation of the bicyclic octahydroisoindole-1carboxylic acid skeleton make use of cycloaddition reactions. Diels-Alder reactions of pyroglutaminol or proline derivatives provided access to the bicyclic skeleton with cis relative disposition of the hydrogen atoms at the ring junction. ${ }^{[14 a, 51]}$ For example, treatment of $\mathbf{8 0}$ with cyclopentadiene was reported to furnish 81 in $67 \%$ yield (Scheme 21). Unfortunately, details relating to the stereochemical outcome of the cycloaddition step, as well as the effectiveness of the subsequent transformations to obtain $\mathbf{8 2}$, were not provided by the authors. ${ }^{[14 a]}$

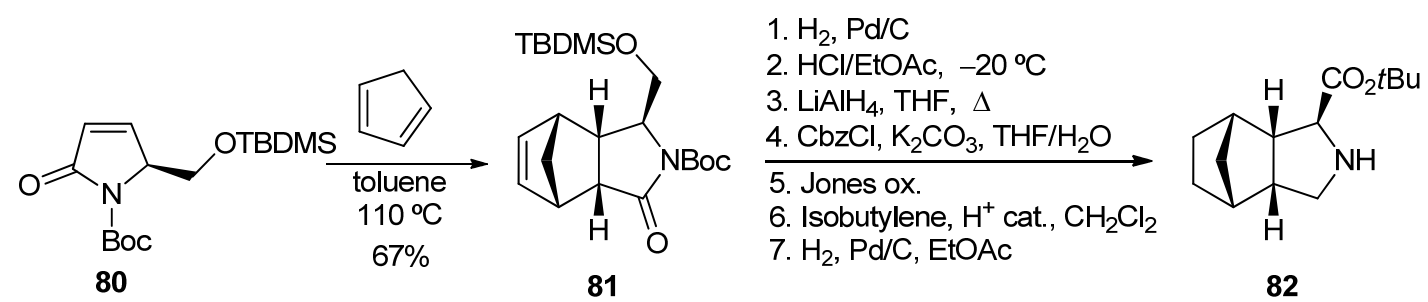

Scheme 21. 
More recently, Poisson et al. described the high-pressure-promoted Diels-Alder cycloaddition of dehydroproline derivative 83 and Danishesfsky's diene (Scheme 22). ${ }^{[51]}$ According to the authors, an enormous effect of pressure on the rate of racemization of 83 was observed. As a consequence, it was essential to remove traces of triethylamine contained in the diene in order to preserve the enantiomeric excess of the product. The cycloaddition was face-selective, with the stereochemical outcome governed by the ester group in the $\alpha$ position, and furnished $\mathbf{8 4}$ with a 3:1 endo/exo ratio of the methoxy group in the cycloadducts. This mixture was converted into $\mathbf{8 5}$, which was isolated with an ee better than $99 \%$ upon recrystallization. Next, base-induced monodecarboxylation of $\mathbf{8 5}$ and exposure of the product to diazomethane produced a nonconjugated ketone that was subsequently converted into conjugated enone $\mathbf{8 6}$ by treatment with DBU. The assumption of the cis ring fusion in $\mathbf{8 6}$, from the DBU-induced transformation, was shown to be correct through its successful conversion into (-)-kainic acid.

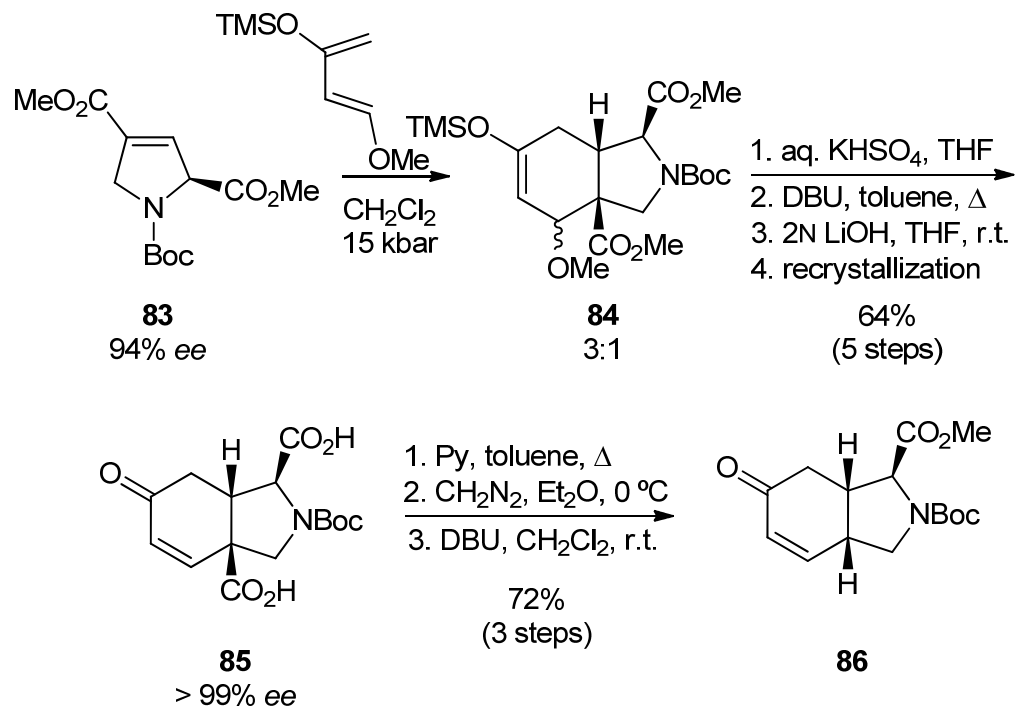

Scheme 22.

In addition, the construction of the octahydroisoindole-1-carboxylate scaffold embedded in a fused tricyclic system by means of an intramolecular Diels-Alder reaction has also been reported. ${ }^{[52]}$

Alternatively, [3+2]-cycloadditions between azomethine ylides and dipolarophiles such as cyclic $\alpha, \beta$-unsaturated ketones, quinones or alkenes have provided access to $c i s$-fused polyfunctional octahydroisoindole-1-carboxylic acid derivatives. ${ }^{[53]}$ For example, silvercatalysed cycloadditions of $\mathbf{8 7}$ to cyclohexadione lactone $\mathbf{8 8}$ in the presence of a chiral 
catalyst provided compounds $\mathbf{8 9}$ in high yields and with excellent levels of diastereo- and enantioselectivity (Scheme 23). ${ }^{[53 \mathrm{~g}]}$

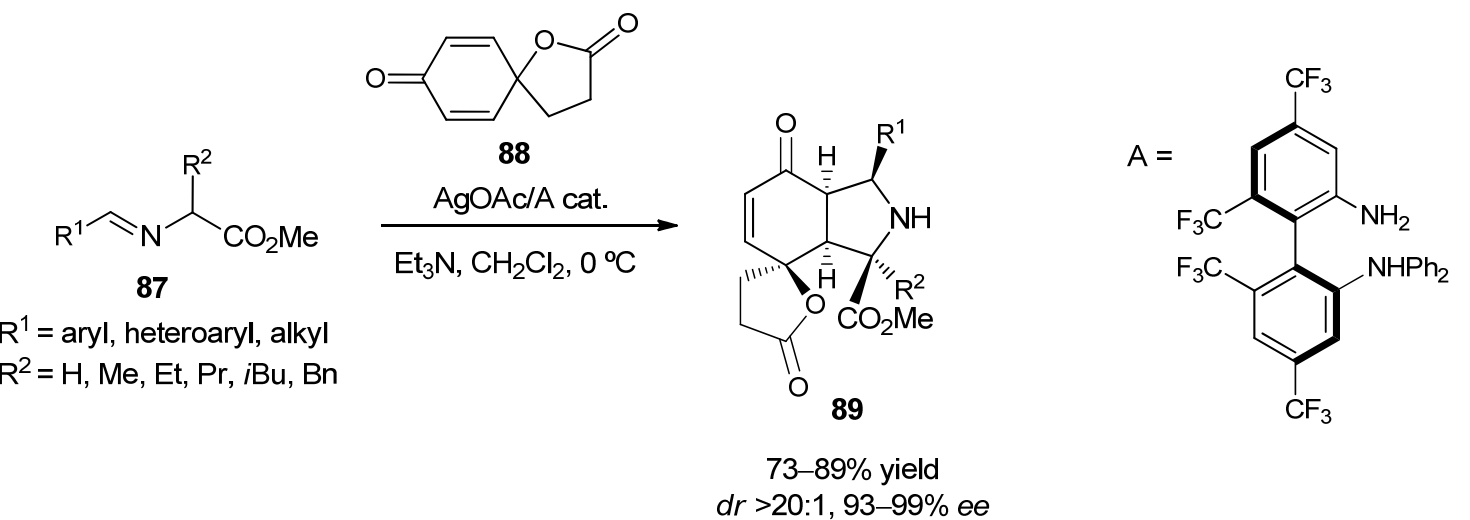

Scheme 23.

On the other hand, aziridine-allylsilane 92 (Scheme 24) underwent an intramolecular formal [3+2] cycloaddition reaction that preferentially gave access to the bicyclic skeleton with trans relative disposition of the hydrogen atoms at the ring junction. ${ }^{[54]}$ This aziridine-allylsilane was synthesized by treatment of 91 with the cuprate derived from iodide 90. The intramolecular cyclization occurred upon treatment of 92 with a catalytic amount of $\mathrm{BF}_{3} \cdot \mathrm{Et}_{2} \mathrm{O}$ in dichloromethane, and provided an isomeric mixture of 93 and 94 contaminated with olefin 95. According to the authors, the stereochemical integrity during the SN2-type intramolecular displacement of the optically pure aziridine with the allylsilane was very high. Column chromatography of the mixture allowed for the ready separation of the cis- and trans-fused bicycles and their stereochemistry was assigned by NMR experiments. The preparation of trans-fused octahydroisoindole-1-carboxylic acid 96 was accomplished by oxidation of silane 93 to carboxylic acid in two steps, followed by removal of the amino protecting group. 
Published in Eur. J. Org. Chem. 2015, 1633-1658 (doi: 10.1002/ejoc.201403121)

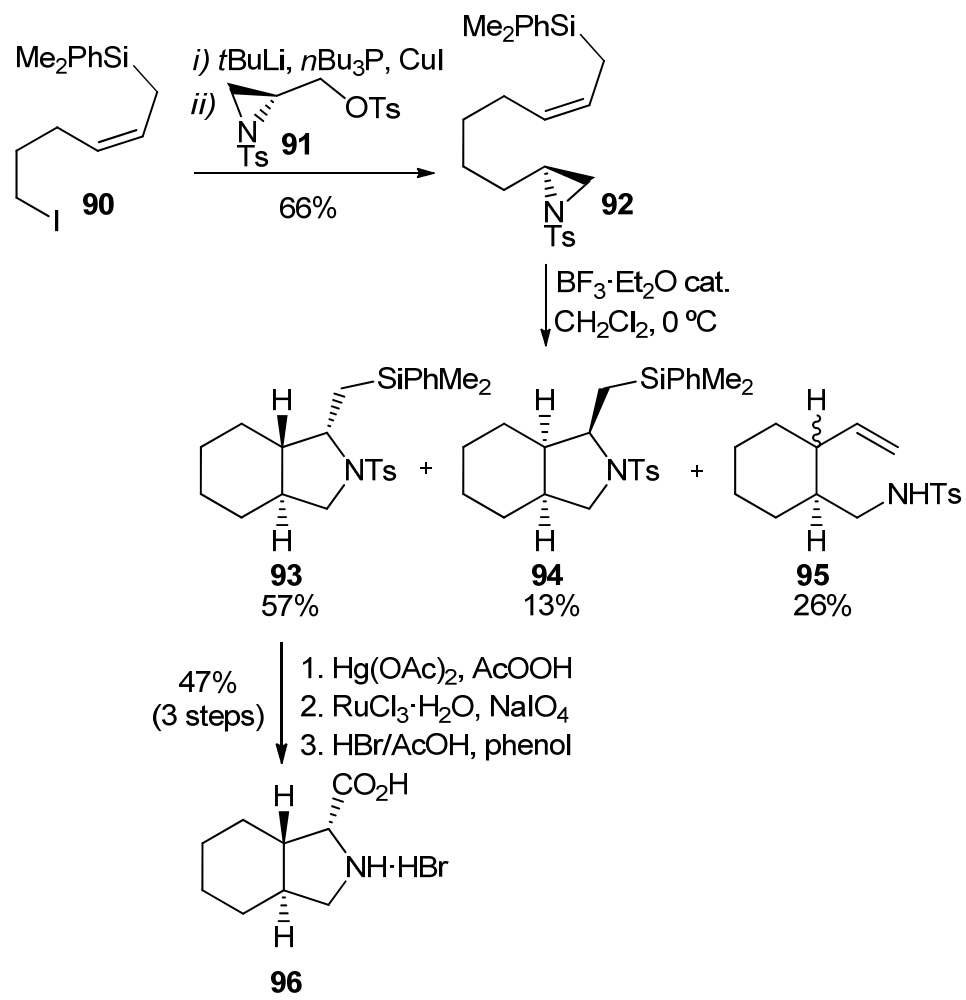

Scheme 24.

\subsubsection{Miscellaneous}

An approach to trans-octahydroisoindole derivative $\mathbf{9 8}$ through Favorskii-type ring contraction of $\alpha$-chlorinated lactam 97 was described by Henning and Urbach (Scheme $25) .{ }^{[55]}$ The rearrangement of 97 on treatment with barium hydroxide in aqueous solution afforded 98 in isomerically pure form. According to the authors, the stereoselectivity achieved reflects the thermodynamic equilibrium between the two isomers that can be established under the strongly basic reaction conditions. The trans disposition between the carboxylic acid group and the six-membered ring in $\mathbf{9 8}$ makes this isomer more stable than the one exhibiting a cis relative disposition.<smiles>O=C1CC(Cl)[C@@H]2CCCC[C@@H]2CN1</smiles>

97

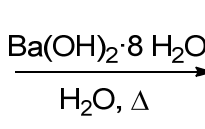

$96 \%$<smiles>O=C(O)[C@@H]1NC[C@@H]2CCCC[C@@H]21</smiles>

98

Scheme 25. 


\section{Synthesis of five-membered ring $[c]$-fused proline analogues}

Nearly all the strategies previously described for the synthesis of cis-fused octahydroisoindole-1-carboxylic acid derivatives (Figure 5) have also been applied to the preparation of 3-azabicyclo[3.3.0]octane-2-carboxylic acid homologues. In addition, abundant contributions have been made in the field of intramolecular and intermolecular cycloaddition reactions for the stereoselective and asymmetric preparation of polysubstituted cis-fused 3-azabicyclo[3.3.0]octane-2-carboxylic acid derivatives.

\subsection{Synthesis from 3-azabicyclo[3.3.0]octane derivatives}

The strategy based on the enantioselective biocatalytic oxidative desymmetrization of a bicyclic pyrrolidine (see Scheme 15), followed by nucleophilic addition of cyanide, has also been applied to the synthesis of five-membered ring [c]-fused proline derivatives (Scheme 26). ${ }^{[45,56]}$ Thus, the use of the biocatalyst MAO-N D5 and molecular oxygen for the oxidation of 99 provided the imine 100 in $94 \%$ ee. Treatment of the organic extracts of the biotransformation with TMSCN/MeOH in dichloromethane afforded a 96:4 diastereomeric mixture of $\alpha$-amino nitriles with isomer $\mathbf{1 0 1}$ as the major product. Their hydrolysis led, after ion exchange chromatography and recrystallization, to $\mathbf{1}$ in a $d r$ of 150:1 and 98\% ee. The combination of the biocatalytic desymmetrization of $c i s[c]$-fused pyrrolines with a three-component Ugi reaction has been recently applied to the highly stereoselective synthesis of substituted prolyl peptides. ${ }^{[57]}$

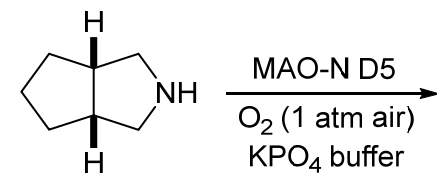

99

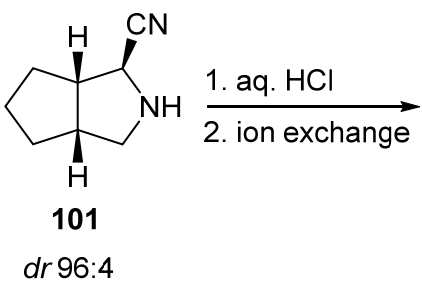

dr 96:4

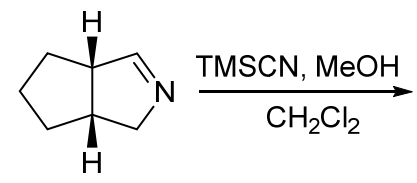

100

$94 \%$ ee

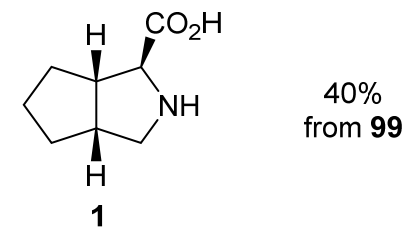

dr $95: 5,94 \%$ ee dr 150:1, 98\% ee after recrystallization

Scheme 26. 
Previously, a patent by Tanoury et al. had described ${ }^{[58]}$ the preparation of $\mathbf{1 0 5}$ through lithiation and carboxylation of 102, followed by chemical resolution with $(S)$-1,2,3,4tetrahydro-1-naphthylamine (Scheme 27). Subsequent processing of 104 gave oxalate salt 105 with an enantiomeric excess of $99 \%$.
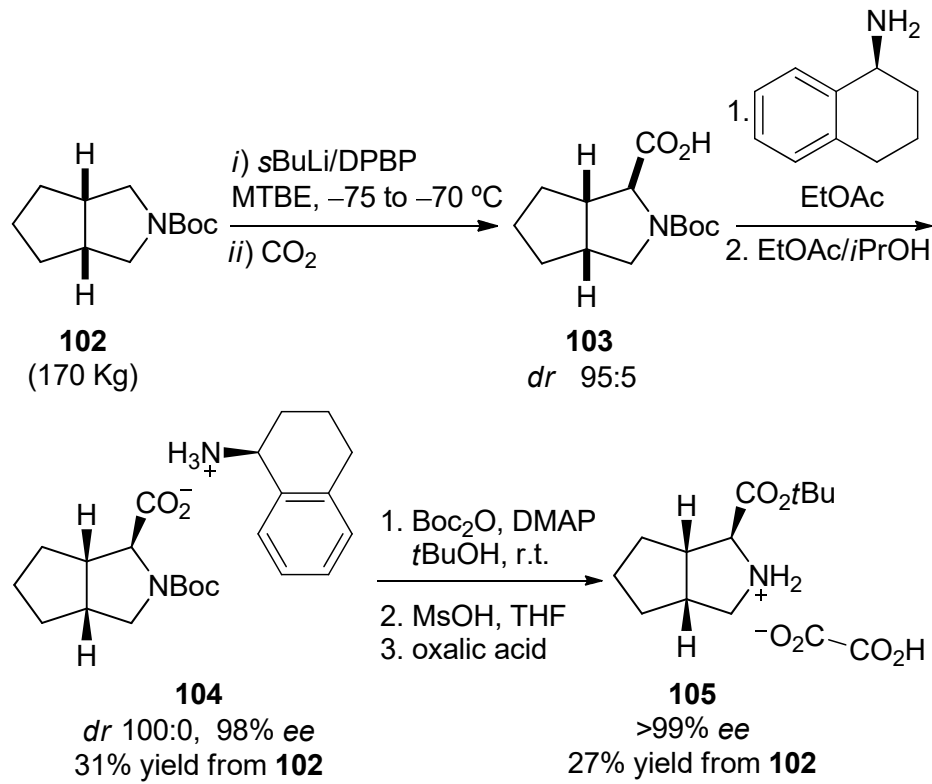

Scheme 27.

\subsection{Intramolecular cyclization through $\mathrm{C}-\mathrm{N}$ bond formation}

The chiral phase-transfer-catalysed asymmetric conjugate addition of glycine derivative 106 to $\alpha, \beta$-unsaturated aldehyde 107 gave an optically enriched $\alpha$-amino acid ester that underwent intramolecular imine formation after hydrolysis of the amine protecting group (Scheme 28). ${ }^{[59]}$ Catalytic hydrogenation of the resulting imine 108 provided 3azabicyclo[3.3.0] octane-2-carboxylate $\mathbf{1 0 9}$ as a single diastereoisomer. 


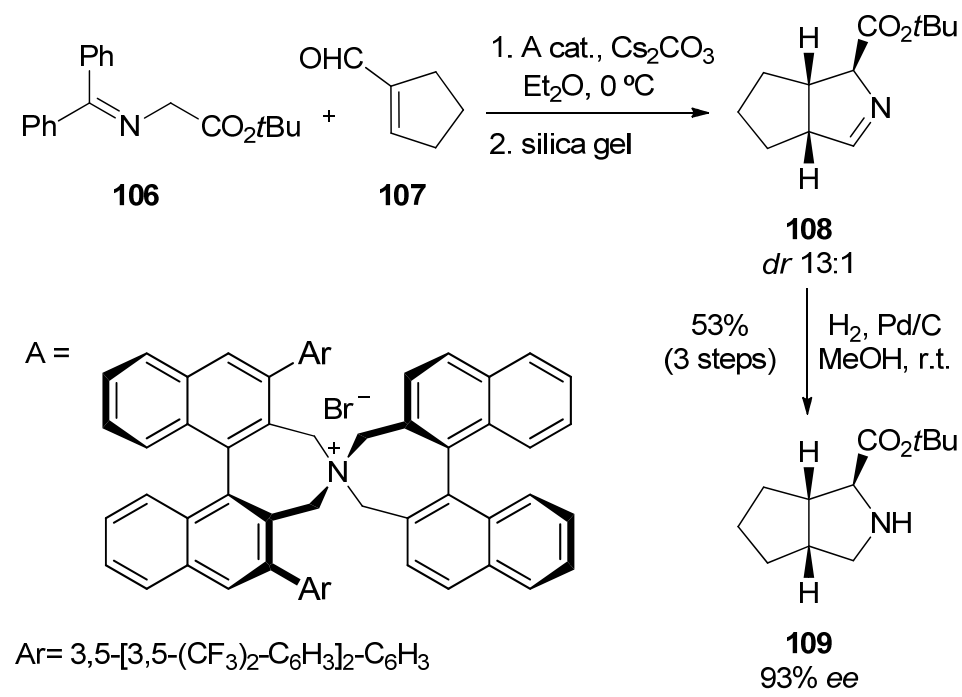

Scheme 28.

\subsection{Intramolecular cyclization through $\mathrm{C}-\mathrm{C}$ bond formation}

The preparation of racemic cis-fused 3-azabicyclo[3.3.0]octane-2-carboxylic acid derivatives 111a and 112a has been accomplished through the reductive intramolecular cyclization of $\alpha$-(phenylthio)glycine 110a (Scheme 29). ${ }^{[49]}$ In the same way as described previously for the homologous six-membered bicyclic proline analogue (see Scheme 20), treatment of 110a with tributyltin hydride and a catalytic amount of AIBN in toluene solution at $80-90{ }^{\circ} \mathrm{C}$ generated a captodative radical that underwent cyclization to produce the exo stereoisomer preferentially. Similar results were also observed in the copper(I)-catalysed chlorine transfer radical cyclization of $\alpha$-chloroglycine $\mathbf{1 1 0 b} .^{[50]}$

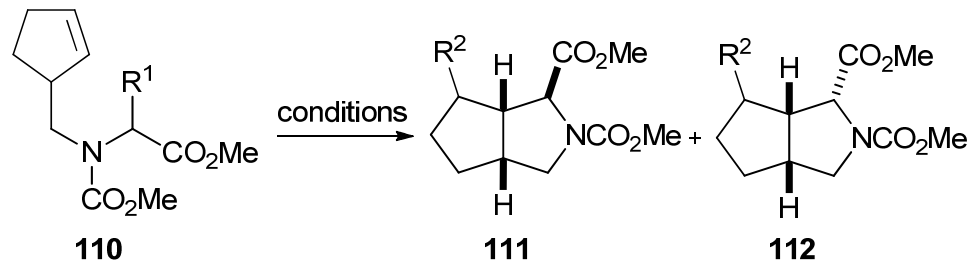

\begin{tabular}{|c|c|c|c|c|c|}
\hline \multicolumn{6}{|c|}{$\mathrm{A}: \mathrm{Bu}_{3} \mathrm{SnH}, \mathrm{AlBN}$, toluene, $80-90^{\circ} \mathrm{C}$} \\
\hline 110 & $\mathrm{R}^{1}$ & $\mathrm{R}^{2}$ & conditions & $111: 112$ & yield $(\%)^{a}$ \\
\hline a & $\mathrm{SPh}$ & $\mathrm{H}$ & A & $87: 13$ & 89 \\
\hline$b$ & $\mathrm{Cl}$ & $\mathrm{Cl}$ & $B$ & $88: 12$ & 75 \\
\hline
\end{tabular}

Scheme 29. 
Alternatively, Bunch et al. demonstrated the utility of $(S)$-pyroglutaminol as precursor for the enantioselective synthesis of cis-fused bicyclic proline 116, which can also be seen as a conformational restricted $(S)$-glutamic acid analogue (Scheme 30). ${ }^{[60]}$ The reaction between 80 and the cuprate generated from vinyl bromide 113 set the desired absolute stereochemistry in 114. Subsequent removal of the $p$-methoxybenzyl group, followed by conversion of the free alcohol to a phenylsulfonic ester, allowed for cyclization into $\mathbf{1 1 5}$. Hydroboration of the methylidene group in $\mathbf{1 1 5}$ gave a high degree of facial selectivity with use of Wilkinson's catalyst/catecholborane ( $d r$ 90:10). Further reduction of the lactam carbonyl group, alcohol oxidation and nitrogen deprotection provided the target compound in $99 \%$ ee after recrystallization of the diastereomeric mixture.

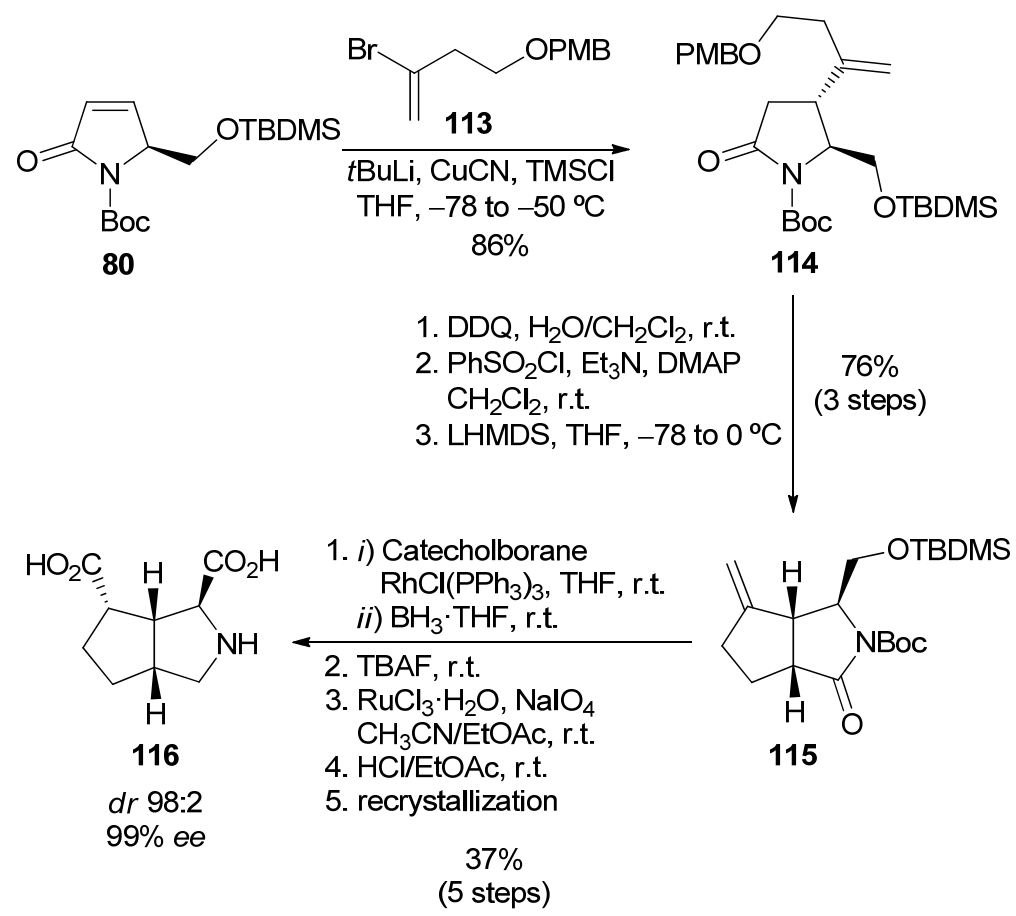

Scheme 30.

\subsection{Cycloadditions}

Unsaturated lactam 117, which is derived from $(S)$-pyroglutaminol, proved to be an excellent substrate for a palladium-assisted trimethylenemethane [3+2] cycloaddition reaction (Scheme 31). ${ }^{[61]}$ The treatment of the silylated allylic acetate 118 with $\mathrm{Pd}\left[\mathrm{P}(\mathrm{O} i \mathrm{Pr})_{3}\right]_{4}$, generated in situ with palladium(II) acetate and tri(isopropyl)phosphite, produced trimethylenemethane that underwent a totally regioselective and stereoselective cycloaddition with 117. The resulting tricyclic lactam 119 was subjected to cyclopropanation of the double bond, $\mathrm{N}, \mathrm{O}$-benzylidene acetal deprotection, lactam 
reduction, and protective and oxidative treatment of the nitrogen and alcohol, respectively, thus affording proline analogue $\mathbf{1 2 0 .}$

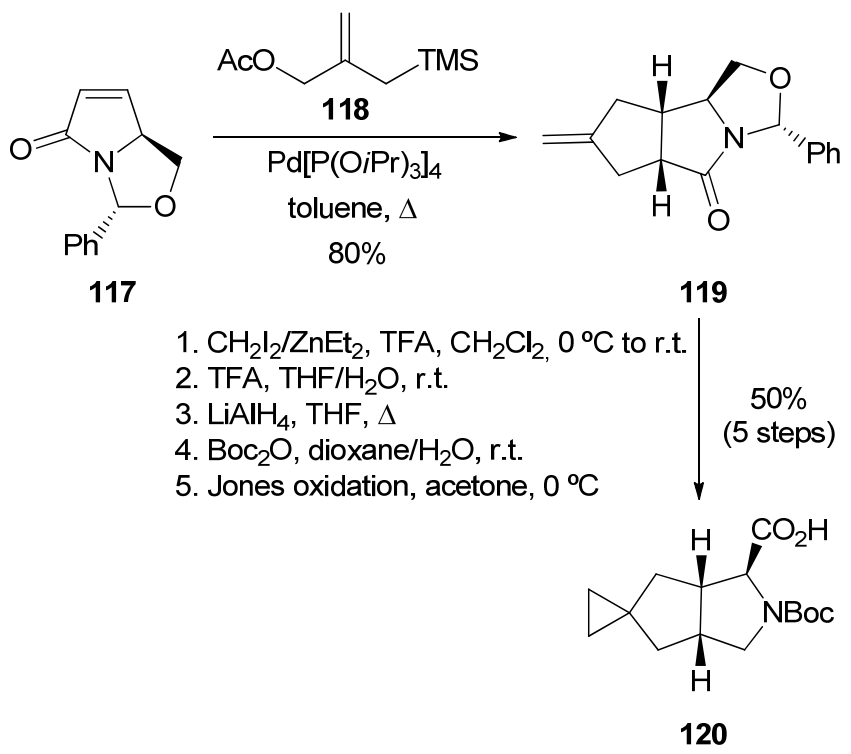

Scheme 31.

An intramolecular version of this type of cycloaddition was employed by Shirama et al. for the preparation of related 3-azabicyclo[3.3.0]octane-2-carboxylic acid derivatives featuring an exocyclic double bond attached to the carbocyclic ring. ${ }^{[62]}$

In 2003, Arawaka et al. described the synthesis of $\mathbf{1 2 3}$ starting from enantiopure dehydroproline 121 (Scheme 32). ${ }^{[63]}$ A Diels-Alder reaction of 121 with cyclopentadiene afforded $\mathbf{1 2 2}$ as a single stereoisomer. This cycloadduct was smoothly converted to $\mathbf{1 2 3}$ by ruthenium tetroxide oxidation. Although some racemization of the starting material was observed during the synthetic process, the amino acid $\mathbf{1 2 3}$ isolated after recrystallization proved to be optically pure.

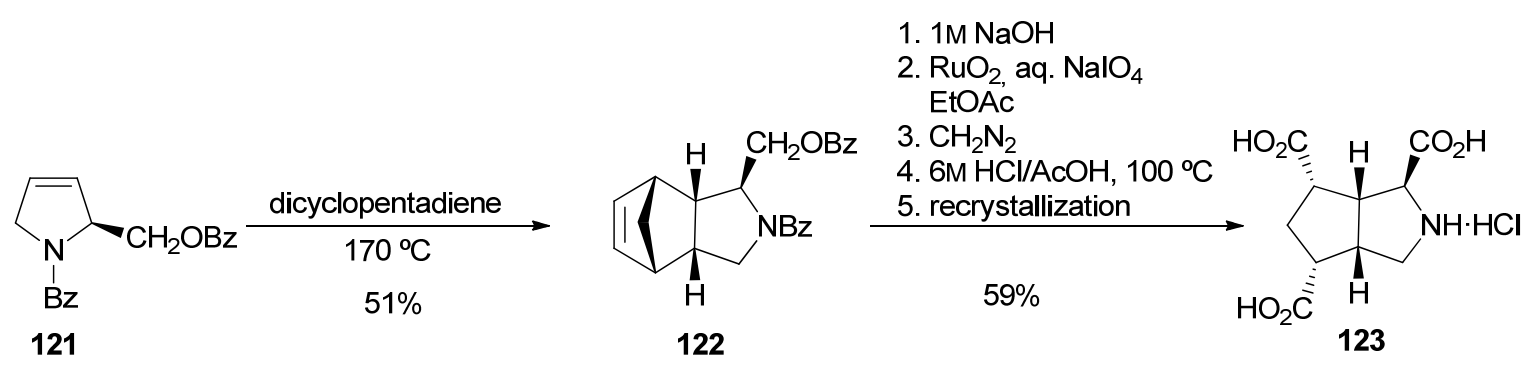

Scheme 32.

The bicyclic skeleton of 3-azabicyclo[3.3.0]octane-2-carboxylic acid has also been assembled through intramolecular cycloaddition reactions. ${ }^{[54,64]}$ Contrary to what had 
previously been observed for the synthesis of octahydroisoindole-1-carboxylic acid (see Scheme 24), the intramolecular formal [3+2] cycloaddition reaction of aziridineallylsilane 124 (Scheme 33), by treatment with $\mathrm{BF}_{3} \cdot \mathrm{Et}_{2} \mathrm{O}$, gave the bicyclic skeleton with the cis relative disposition of the hydrogen atoms at the ring junction as the major compound. ${ }^{[54]}$ Column chromatography gave diastereomerically pure $\mathbf{1 2 5}$. Its treatment with mercury (II) acetate gave an alcohol derivative that was further oxidized to provide 127.

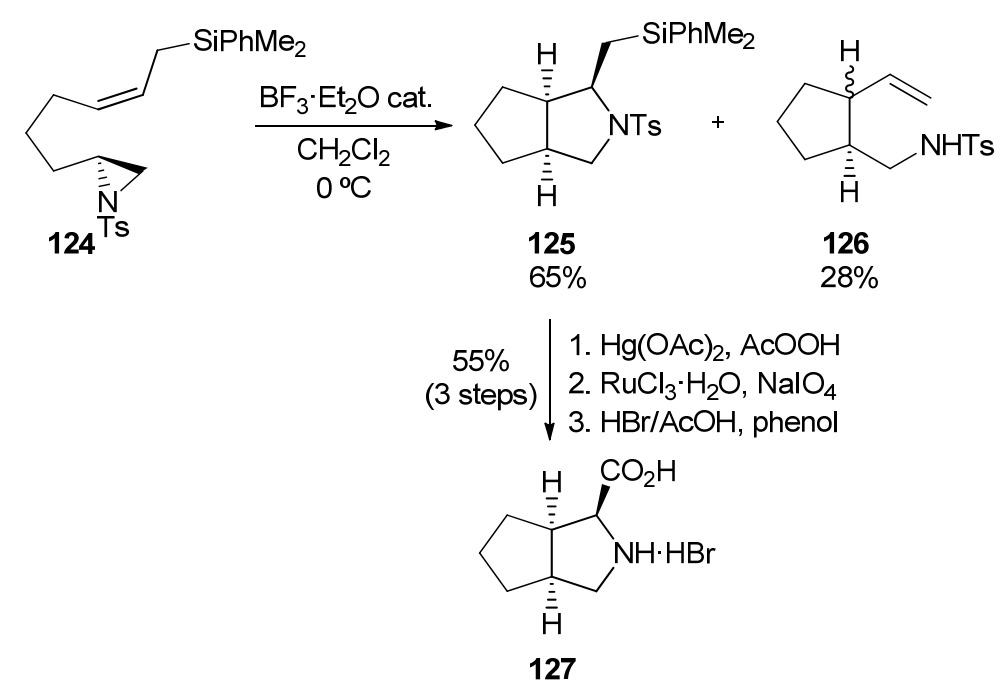

Scheme 33.

In addition, azabicyclooctanones $\mathbf{1 3 0}$ have been synthesized through iron-mediated intramolecular cycloadditions (Scheme 34). ${ }^{[64]}$ The addition of protected amino acids to $\left(\eta 5\right.$-pentadienyl) $\mathrm{Fe}(\mathrm{CO})_{3}$ cations gave ( $\eta$ 4-dienylamine $) \mathrm{Fe}(\mathrm{CO})_{3}$ complexes 128 . These in turn provided azabicyclooctanones 130 upon treatment with LDA at $-78{ }^{\circ} \mathrm{C}$ under carbon monoxide. The authors suggested that the formation of compounds $\mathbf{1 3 0}$ as single diastereoisomers arise from anti addition of the $\alpha$-face of enolate $\mathbf{1 2 9}$ at the internal position of the diene. 


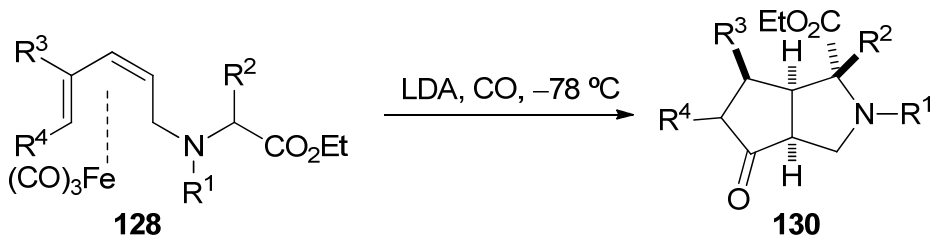

$\left.\begin{array}{|llllll|}128 & \mathrm{R}^{1} & \mathrm{R}^{2} & \mathrm{R}^{3} & \mathrm{R}^{4} \text { yield (\%) } \\ \hline \mathrm{a} & \mathrm{Me} & \mathrm{H} & \mathrm{H} & \mathrm{H} & 50 \\ \mathrm{~b} & \mathrm{Et} & \mathrm{Bn} & \mathrm{H} & \mathrm{H} & 33 \\ \mathrm{c} & \mathrm{Et} & \mathrm{Me} & \mathrm{H} & \mathrm{H} & 44 \\ \mathrm{~d} & \mathrm{CH}_{2} \mathrm{CH}=\mathrm{CHCH}_{3} & \mathrm{Me} & \mathrm{H} & \mathrm{H} & 69 \\ \mathrm{e} & \mathrm{Me} & \mathrm{H} & \mathrm{H} & \mathrm{Me} & 36^{\mathrm{a}} \\ \mathrm{f} & \mathrm{Me} & \mathrm{H} & \mathrm{Me} & \mathrm{H} & 46^{\mathrm{b}}\end{array}\right]$

Scheme 34.

Intramolecular Pauson-Khand cycloaddition of optically pure enyne amino acid derivatives has provided access to enantiopure 3-azabicyclo[3.3.0]octane-2-carboxylic acid derivatives such as 133 and 135 (Scheme 35). ${ }^{[65 a]}$ It was observed that enynes 131 and 132 both gave 133 as a single isomer; that is, the vinyl part of the starting enyne amino acid ester does not control the configuration of the resulting cycloadduct. The starting amino acid esters were synthesized by Mannich-type reaction of phenylethenylboronic acid, chiral $N$-propargylamines and glyoxylic acid. Interestingly, optically pure lactone 134, which is easily obtained from $(S)-N$-2-propargyl-2phenylglycinol, underwent the Pauson-Khand cycloaddition in high yield.
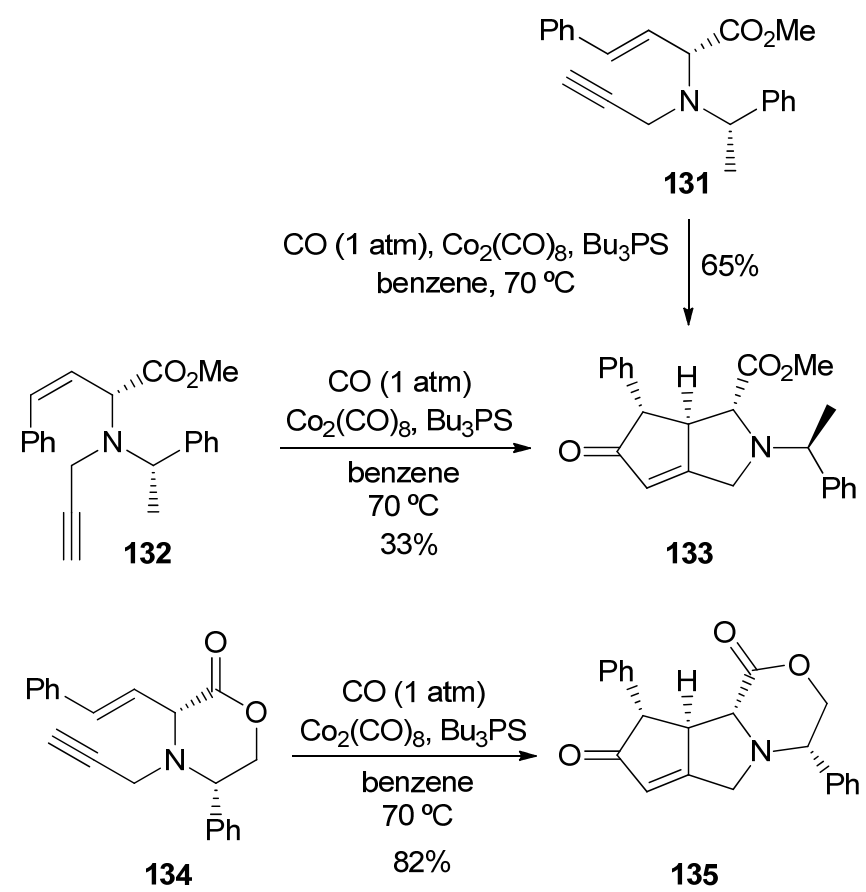

Scheme 35. 
Subsequently, Brummond et al. studied the Pauson-Khand cycloaddition of allenynes 136 in the presence of molybdenum hexacarbonyl (Scheme 36). ${ }^{[65 \mathrm{~b}-\mathrm{d}]}$ It was found that amino acids with aromatic side chains (Entries a and b) afforded azabicycles with opposite diastereoselectivity in comparison with amino acids with aliphatic side chains (Entries $\mathrm{c}$ and e). The reversal in diastereoselectivity was attributed to different complexation models of the substrate with the transition metal (complexation models A and B). In the case of the aromatic side chains, the complexation of the aryl ring with the metal places the ester group in a pseudoequatorial position, whereas aliphatic substituents reside preferentially in such a pseudoequatorial orientation. In all cases the bicyclic compounds 139 were obtained as byproducts. Substrates 137 (entries a-b) and 138 (entries c-e) have found utility for the preparation of tricyclic pyrrole libraries for biological tests. ${ }^{[65 \mathrm{c}, \mathrm{d}]}$

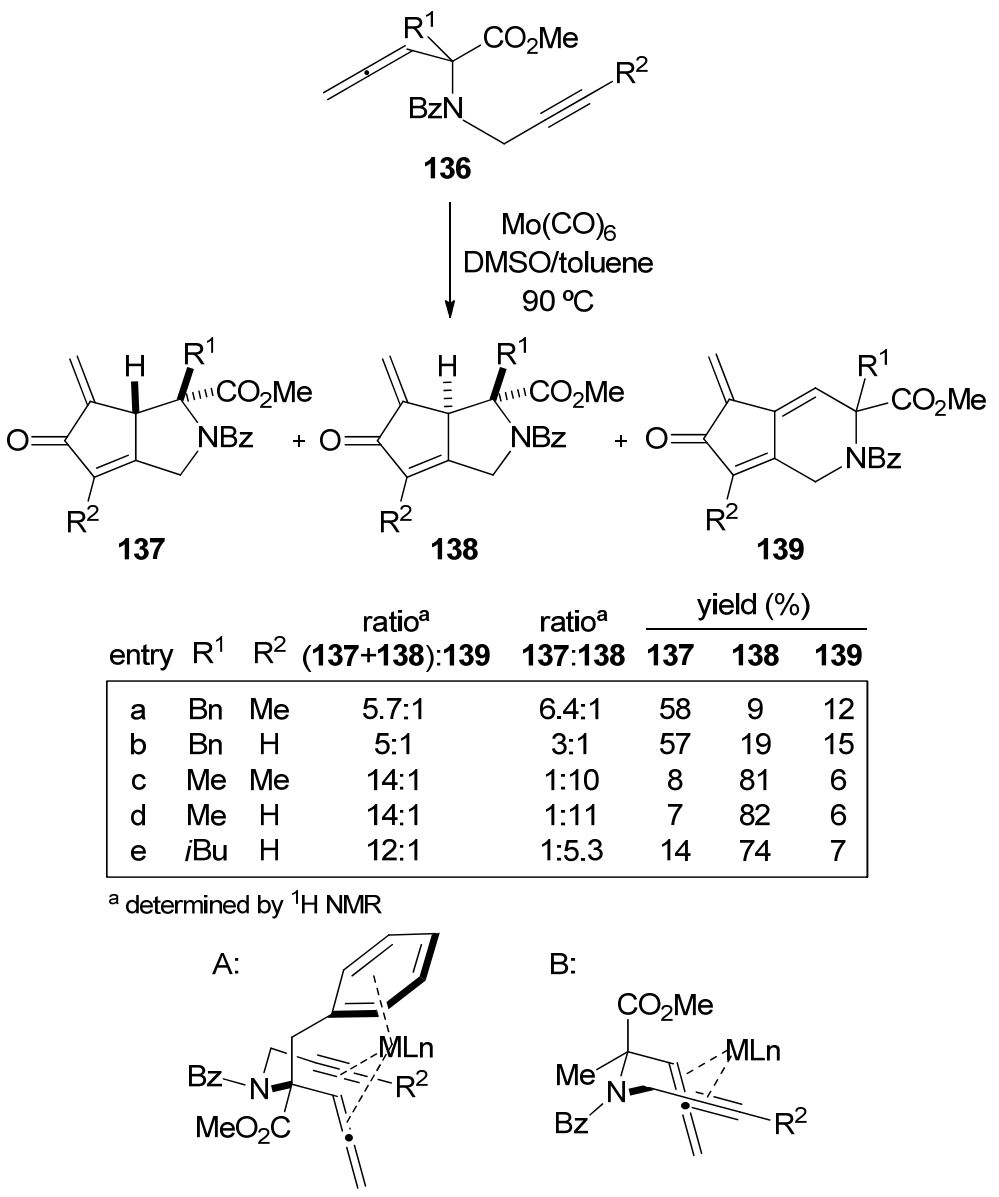

Scheme 36.

In 1994, Monn and Valli reported the stereocontrolled preparation of azabicyclooctanone 144 through cycloaddition between an azomethine ylide and 2cyclopentenone (Scheme 37). ${ }^{[66]}$ The required ylide was generated in situ from thiazolium 
bromide 140 and triethylamine. The cycloaddition reaction provided a diastereomeric mixture of tetracycles that were not separated because the thiotetrahydrofuranyl portion was excised in a later step. The stereochemical outcome of the cycloaddition was attributed to thiazolium ylide $\mathbf{1 4 1}$ reacting in the conformation depicted. The alternative conformation, in which the ester is placed in proximity to the adjacent methyl substituent, is less favourable due to $\mathrm{A}^{1,3}$-strain. The relative stereochemistry of substituents was established by single-crystal X-ray analysis of azabicyclooctanone 144, obtained by reductive cleavage of the thiazolidine $\mathrm{C}-\mathrm{S}$ bond in 142 and 143 , followed by hydrolysis of the resulting hemiaminal and protection of the nitrogen atom. A number of selective transformations of the oxo moiety in 144 have afforded access to $145,{ }^{[66]} \mathbf{1 4 7},{ }^{[14 b, 15]}$ and fluorinated 148. ${ }^{[14 \mathrm{~b}, 15,38]}$
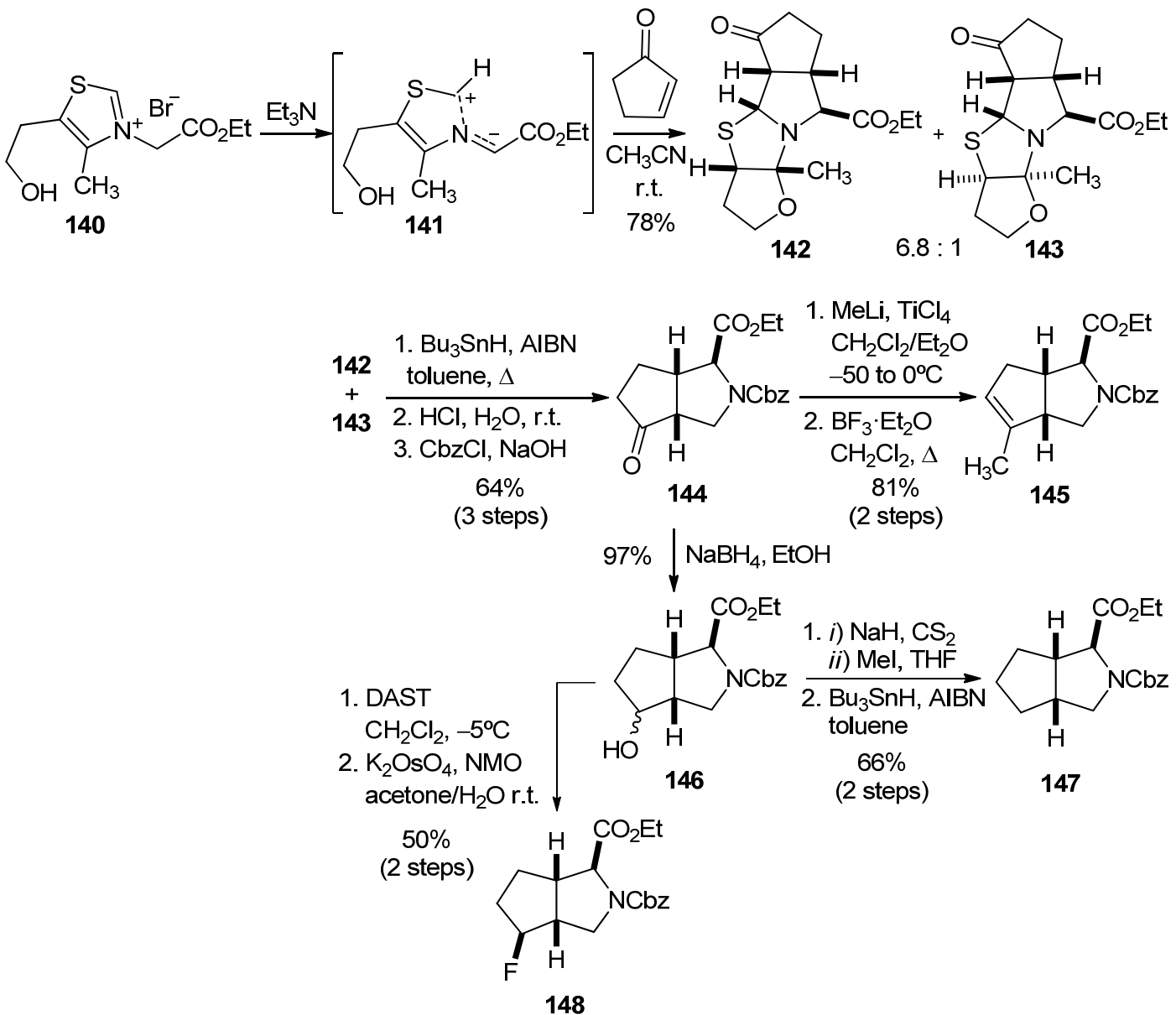

Scheme 37.

More recently, the application of asymmetric 1,3-dipolar cycloadditions of azomethine ylides derived from iminoesters for the preparation of the 3-azabicyclo[3.3.0]octane-2carboxylic acid skeleton has been reported. The protocols are based on the use either of 
chiral dipholarophiles ${ }^{[67]}$ (Scheme 38) or of chiral catalysts ${ }^{[68]}$ (Scheme 39) and give access to $c i s$-fused bicyclic proline analogues with high enantiocontrol. In particular, $\alpha$ sulfinylcyclopentenone 149 reacted with the ylide generated by treatment of $150 a$ with DBU in the presence of a silver salt in a completely regio and endo-selective manner but with low facial selectivity (Scheme 38 , entry a). ${ }^{[67]}$ In contrast, the use of LHMDS as a base afforded $\mathbf{1 5 1}$ in high yield. The authors assumed that this reaction takes place by a nucleophilic/ring closure process in which the lithium acts as a tether between the reagent and the substrate in a way that is essential for achieving complete stereoselectivity. Adducts 151 (entries b-e) were transformed into 6-oxo-3-azabicyclo[3.3.0]octane-2carboxylic acid derivatives through hydrogenolysis of the $\mathrm{C}-\mathrm{S}$ bond with Raney nickel.
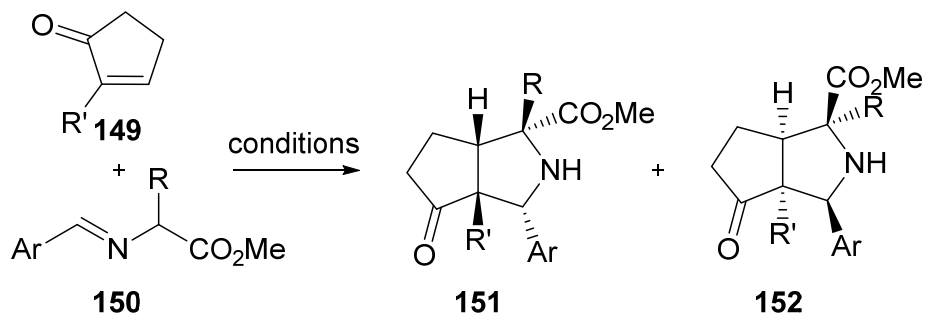

A: $\mathrm{AgOAc/DBU}, \mathrm{CH}_{3} \mathrm{CN}$, r.t. B: LHMDS, THF, $-78^{\circ} \mathrm{C}$

$$
\mathrm{R}^{\prime}=\xi_{\xi^{\prime}}^{\mathrm{O}} \stackrel{\mathrm{V}}{\mathrm{Tol}}
$$

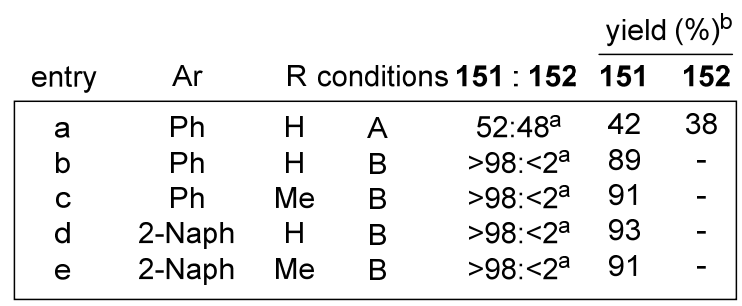

$$
\begin{aligned}
& \text { a determined by }{ }^{1} \mathrm{H} \text { NMR from the crude reaction mixture } \\
& { }^{b} \text { homochiral integrity was supported by comparison of }[\alpha]_{D} \text { values of } \\
& \text { enantiomers resulting from desulfinylation of } 151 \mathrm{a} \text { and } 152 \mathrm{a}
\end{aligned}
$$

Scheme 38.

Alternatively, Carretero et al. reported cycloadditions between azomethine ylides derived from iminoesters 153 (Scheme 39, entries a-d) and cyclopentenone in the presence of $\mathrm{Cu}^{\mathrm{I}}$-Fesulphos complex as a catalyst. ${ }^{[68 \mathrm{a}]}$ The reactions between $N$-aryl imines of glycine methyl ester (entries a-d) and 2-cyclopentenone catalysed by the cationic $\mathrm{Cu}^{\mathrm{I}}$ complex of $\mathbf{1 5 6}$ afforded the bicyclic adducts with high endo selectivity, enantioselectivity and chemical yield. Only the electron rich imine derived from $p$ methoxybenzaldehyde (entry d) showed a lower reactivity and stereochemical control. 
Published in Eur. J. Org. Chem. 2015, 1633-1658 (doi: 10.1002/ejoc.201403121)

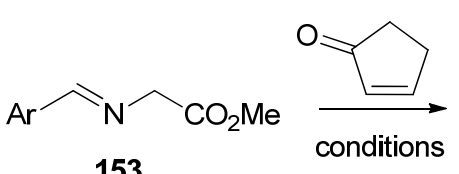

153

156

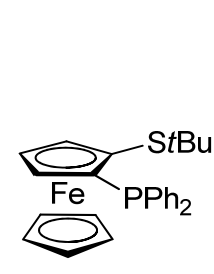

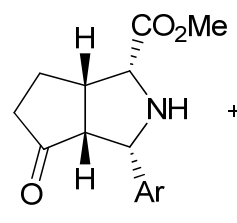

154<smiles>CC(=O)C1NC([Al])[C@H]2C(=O)CC[C@@H]12</smiles>

155
A: $156 / \mathrm{CuClO}_{4}$ cat., $\mathrm{Et}_{3} \mathrm{~N}, \mathrm{CH}_{2} \mathrm{Cl}_{2}$ r.t.

B: $157 /\left[\mathrm{Cu}\left(\mathrm{CH}_{3} \mathrm{CN}\right)_{4}\right] \mathrm{ClO}_{4}$ cat., Et $\mathrm{Et}_{3} \mathrm{~N}, \mathrm{CH}_{2} \mathrm{Cl}_{2}$, r.t.

C: $158 / \mathrm{AgOAc}$ cat., $\mathrm{Et}_{3} \mathrm{~N}, \mathrm{CH}_{2} \mathrm{Cl}_{2}$ r.t.

D: $159 / \mathrm{AgClO}_{4}$ cat., $\mathrm{Et}_{3} \mathrm{~N}$, toluene, $-20^{\circ} \mathrm{C}$

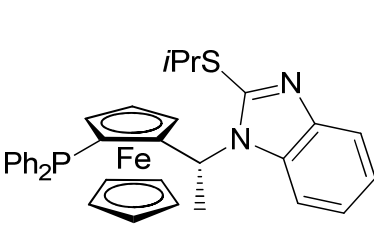

157

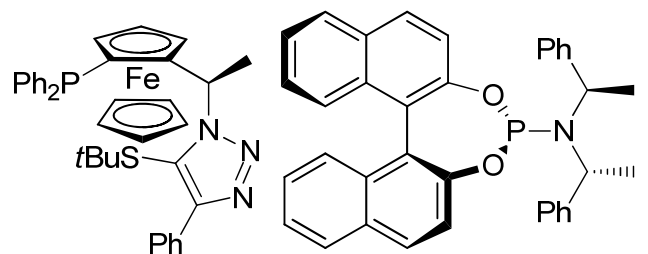

158
159

\begin{tabular}{|c|c|c|c|c|c|c|}
\hline \multirow[b]{2}{*}{ entry } & \multirow[b]{2}{*}{$\mathrm{Ar}$} & \multirow[b]{2}{*}{ conditions } & \multirow[b]{2}{*}{ exo:endo } & \multicolumn{2}{|c|}{155} & \multirow[b]{2}{*}{ ref. } \\
\hline & & & & yield (\%) & ee $(\%)^{\mathrm{d}}$ & \\
\hline a & $\mathrm{Ph}$ & $A$ & $10: 90^{a, b}$ & 70 & 94 & $68 a$ \\
\hline$b$ & 2-Naph & $A$ & $2: 98^{a, b}$ & 61 & 91 & $68 a$ \\
\hline $\mathrm{C}$ & 4- $\mathrm{BrC}_{6} \mathrm{H}_{4}$ & $A$ & $2: 98^{a, b}$ & 68 & 95 & $68 a$ \\
\hline d & $4-\mathrm{MeOC}_{6} \mathrm{H}_{4}$ & $A$ & $25: 75^{a}$ & 52 & 85 & $68 a$ \\
\hline e & $2-\mathrm{ClC}_{6} \mathrm{H}_{4}$ & $B$ & $-c$ & 93 & $>99$ & $68 b$ \\
\hline$f$ & $4-\mathrm{FC}_{6} \mathrm{H}_{4}$ & $B$ & $-c$ & 82 & $>99$ & $68 b$ \\
\hline $\mathrm{g}$ & $4-\mathrm{NO}_{2} \mathrm{C}_{6} \mathrm{H}_{4}$ & $B$ & $-c$ & 82 & $>99$ & $68 b$ \\
\hline $\mathrm{h}$ & 4- $\mathrm{MeOC}_{6} \mathrm{H}_{4}$ & $B$ & $-\mathrm{C}$ & 86 & 99 & $68 b$ \\
\hline i & 2-Thienyl & $B$ & $-c$ & 82 & $>99$ & $68 b$ \\
\hline j & 2-Naph & $B$ & $-c$ & 89 & $>99$ & $68 b$ \\
\hline $\mathrm{k}$ & $4-\mathrm{ClC}_{6} \mathrm{H}_{4}$ & C & $-c$ & 73 & 98 & $68 c$ \\
\hline I & 2-Naph & $\mathrm{D}$ & $2: 98^{a}$ & 72 & 94 & $68 d$ \\
\hline
\end{tabular}

Scheme 39.

More recently, chiral ferrocenyl $P, S$ ligands 157 and 158 have been successfully applied in asymmetric 1,3-dipolar cycloadditions between azomethine ylides 153 (Scheme 39, entries e-k) and cyclopentenone. ${ }^{[68 b, c]}$ Both ligands provided copper-complexes that effectively catalysed the cycloaddition to give the endo cycloadducts with complete enantiocontrol. In particular, when $P, S$ ligand 157 was used, a substrate with an electronwithdrawing substituent (entry g) showed higher reactivity than one with an electrondonating group (entry h). Azomethine ylides derived from 2-thiophenecarbaldehyde (entry i) or 2-naphthalenecarbaldehyde (entry j) also proved to be suitable substrates and gave the endo cycloadducts in $>99 \%$ ee.

\subsection{Miscellaneous}

Sançon and Sweeney reported the stereocontrolled formation of azabicyclooctene $\mathbf{1 6 1}$ through the sigmatropic rearrangement of an ammonium ylide generated from amine $\mathbf{1 6 0}$ 
(Scheme 40). ${ }^{[69]}$ The authors suggested that the remarkably low temperature required for the rearrangement to proceed might be due to the rigidity of $\mathbf{1 6 0}$ that provides a preorganization of the endo transition state required for the key [2,3]-rearrangement.

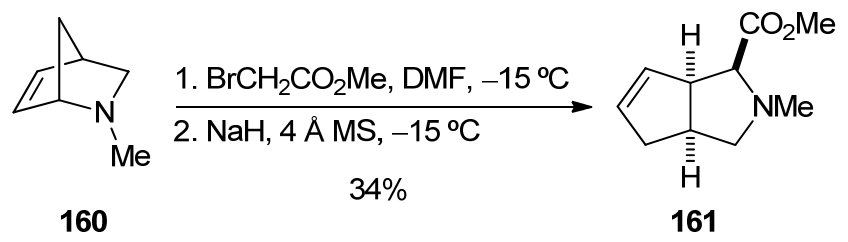

Scheme 40.

\section{Synthesis of four-membered ring $[c]$-fused proline analogues}

The stereoselective synthesis of 2-substituted 3-azabicyclo[3.2.0]heptanes has been accomplished by the intramolecular [2+2]-photocycloaddition of vinylglycine derivative 162 (Scheme 41). ${ }^{[70]}$ The cycloaddition, which makes use of acetophenone as triplet sensitizer, gave a 2:1 mixture of compounds 163 and 164, each exhibiting a cis-relative configuration of the hydrogen atoms at the ring junction. The relative configuration of the major diastereoisomer 163 was explained based on a preferred conformation of 162 that minimizes the 1,3-allyl strains and places the methoxycarbonyl group in a pseudoequatorial position.

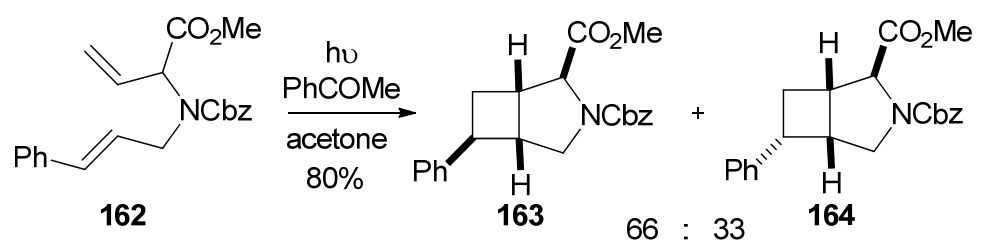

Scheme 41.

In addition, the [2+2]-photochemical cycloaddition of ethylene to unsaturated $\gamma$-lactams is a straightforward methodology for the preparation of azabicycles that can be useful precursors towards the synthesis of four-membered ring $[c]$-fused proline derivatives. For example, the cycloaddition between enantiopure $\mathbf{8 0}$ and ethylene was reported to afford 165 in a stereoselective manner (Scheme 42). ${ }^{[71 \mathrm{a}]}$ Moreover, Aitken et al. described the synthesis of lactams 167 and 168 from enantiopure $\gamma$-lactam 166. ${ }^{[71 b]}$ A subsequent twostep deprotection-reprotection sequence provided access to $N$-Boc protected derivatives 169 and 170. 

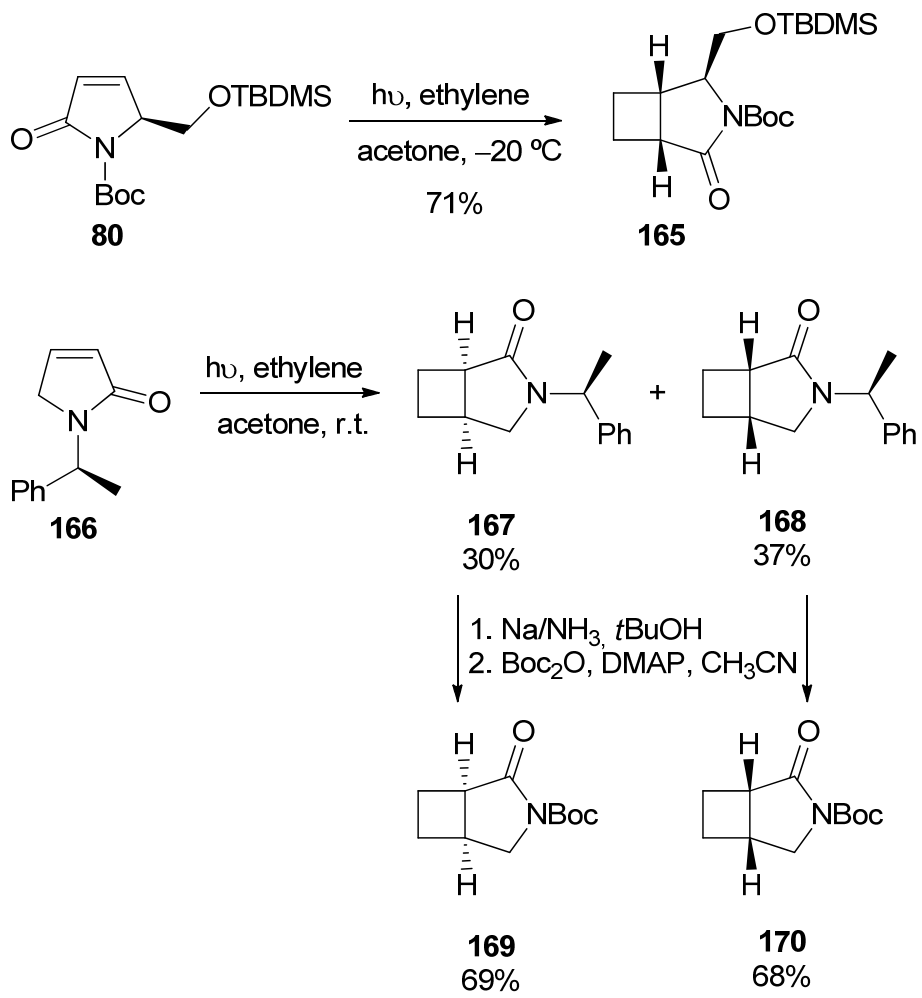

Scheme 42.

Alternatively, polysubstituted 3-azabicyclo[3.2.0]heptane 2-carboxylic acids 173 and 176 (Scheme 43) have been synthesized through 1,3-dipolar cycloaddition between münchnone 172 and 1,2-dicyanocyclobutene, ${ }^{[72]}$ and by metal-promoted alkylation of lactone 174, respectively. ${ }^{[73]}$ In the latter case, azalactones 175 were employed as nucleophiles for the ring opening of $\mathbf{1 7 4}$. According to the authors, this process probably furnishes a carboxylic acid, which appears to undergo rupture of the azalactone moiety followed by cyclization to a lactam. The resulting cycloadducts were obtained with high diastereoselectivity (typically $\leq 10 \%$ of the lactam epimeric at the quaternary centre was observed in crude reactions mixtures), thus making feasible the isolation of diastereomerically pure 176 in yields ranging $26-68 \%$. 

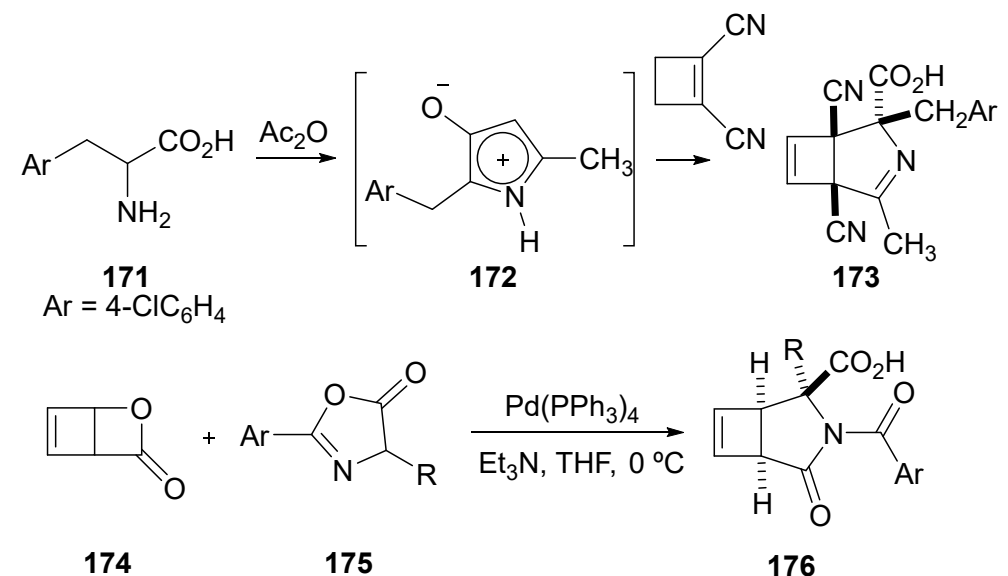

$$
\mathrm{R}=\mathrm{Me}, \mathrm{Et}, \mathrm{Bu},\left(\mathrm{CH}_{2}\right)_{2} \mathrm{Ph}, \mathrm{Allyl}, \mathrm{Bn} \quad 26-68 \%
$$

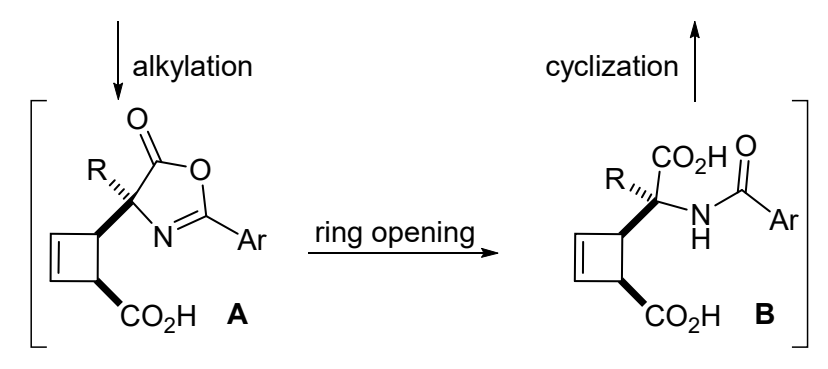

Scheme 43.

\section{Synthesis of three-membered ring $[c]$-fused proline analogues}

\subsection{From 3-azabicyclo[3.1.0]hexane derivatives}

Several methods for the synthesis of racemic and enantiomerically pure 3,4methanoproline derivatives have been reported (Figure 6). The most general strategies, which involve the cyclopropanation of pyrrolidine derivatives (type B substrates) and the conversion of cyclopropane derivatives (type $\mathrm{C}$ substrates), have been reviewed previously. ${ }^{[74]}$ In recent years, very efficient procedures that make use of 3azabicyclo[3.1.0]hexane derivatives (A) or natural products as starting materials have been developed, especially for the manufacture of trans-6,6-dimethyl-3,4-methano-Lproline, the key component of medicinally relevant drugs Boceprevir and Narlaprevir. ${ }^{[3]}$ 

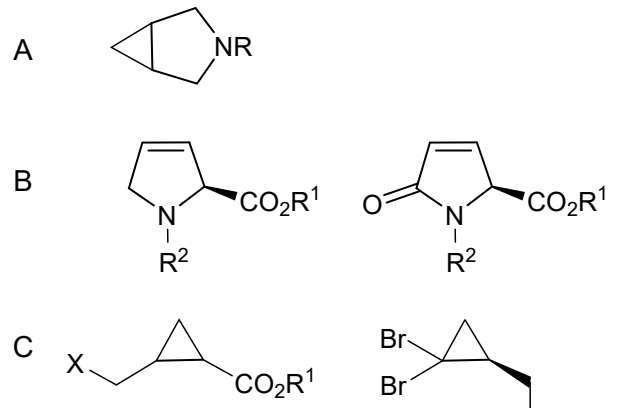

Figure 6. Precursors used for the synthesis of 3,4-methanoproline derivatives

The multigram preparation of enantiomerically pure $N$-Boc protected $c i s$ - and trans-3,4methanoproline analogues has been accomplished by resolution of the racemates synthesized by lithiation of $N$-Boc protected 3-azabicylo[3.1.0]hexane (Scheme 44). ${ }^{[75]}$ Lithiation of 177 in the presence of diamine 178 preferentially afforded 179 (cis stereoisomer). On the basis of ab initio calculations, the authors suggested that the unexpected cis selectivity was due to a more energetically favoured staggered conformation for the cis Li-177-diamine-178 complex that was maintained through the $\mathrm{CO}_{2}$-insertion mechanism. The trans stereoisomer was obtained by means of an epimerization process, that is, a double deprotonation of 177 with LDA, which afforded a 1:9 cis/trans ratio of stereoisomers. The enantioselective deprotonation of $\mathbf{1 7 7}$ with secBuLi and (-)-sparteine was tested but it resulted in only a 32\% yield of $\mathbf{1 7 9}$ and $73 \%$ ee. Optical resolution of 179 and 180 was accomplished through diastereomeric salt formation (Scheme 44) or, alternatively, by chromatography of the benzyl ester derivative of the cis stereoisomer on a chiral stationary phase. In this case, epimerization of enantiomerically pure 181 gave access to enantiopure $\mathbf{1 8 0 b}$ after hydrogenolysis. In order to avoid transformations of large batches of $\mathbf{1 8 1}$, and to achieve good productivity of 180b, a flow set-up reactor was employed for the epimerization step. 


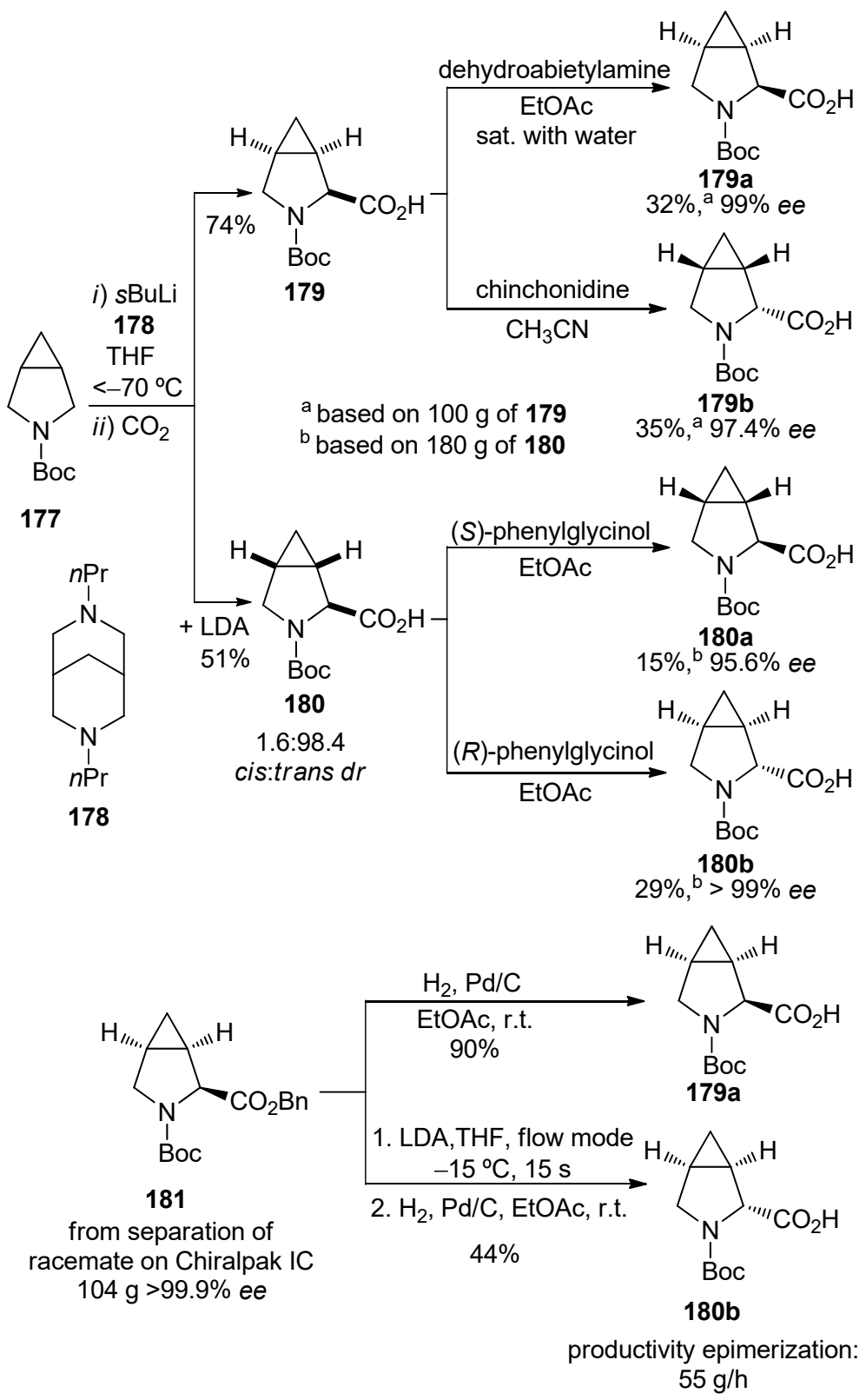

Scheme 44.

Previously, the synthesis of racemic cis- and trans-3,4-methanoproline derivatives by a procedure including a Strecker reaction, together with their chemical resolution, had been disclosed in patents. ${ }^{[76 a-c]}$ More recently, an oxidative Strecker reaction that involves a chemoenzymatic process ${ }^{[76 \mathrm{~d}, \mathrm{e}]}$ has been developed for the manufacture of enantiomerically pure 186 (Scheme 45), the key structural feature of Boceprevir and Narlaprevir. The prochiral amine 182 was subjected to an enzymatic oxidative desymmetrization after had been improved the activity and thermal stability of MAON (from Aspergillus niger) over four rounds of evolution. An amino sulfonate was generated in the enzymatic reaction stream by sodium bisulfite treatment of the imine generated in 
situ. In addition, the enzymatic reaction stream was subjected to cyanation and gave only the trans stereoisomer 185, in $>99 \%$ ee. This compound was treated under Pinner conditions for the generation of the methyl ester derivative, and the free amine was crystallized as the hydrochloride salt $\mathbf{1 8 6}$.
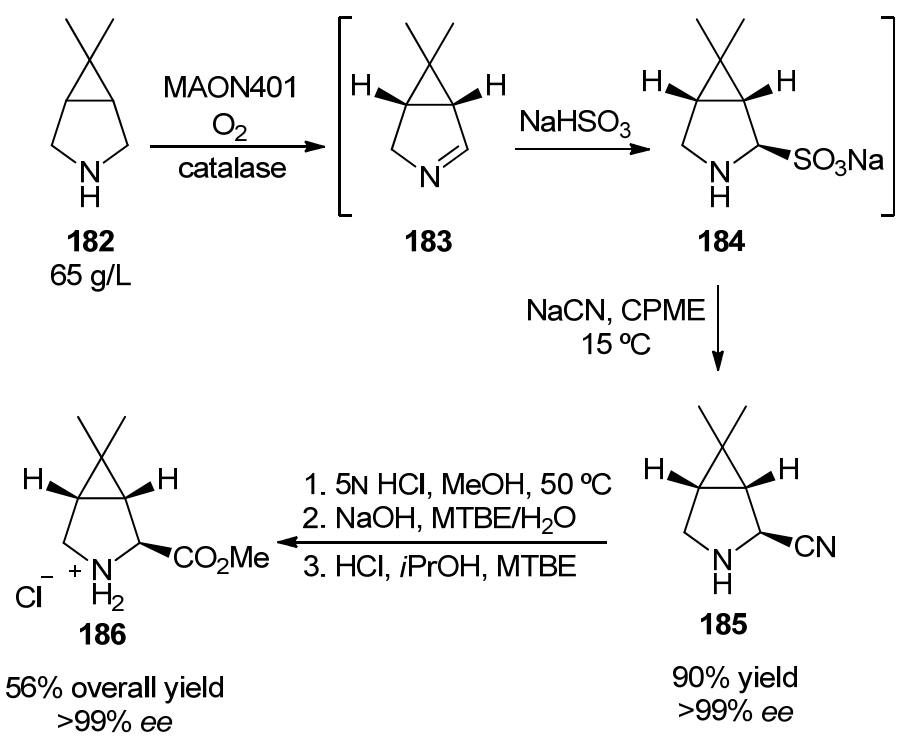

$$
90 \% \text { yield }
$$

Scheme 45 .

\subsection{From proline derivatives}

The addition of carbenes $^{[77]}$ and titanacyclopropane reagents ${ }^{[78]}$ to $3,4-$ dehydroprolinates proceeds diastereoselectively to afford mainly trans-3,4methyleneproline derivatives 188 and 189 in enantioenriched or enantiomerically pure form (Scheme 46). In particular, the aminocyclopropanation of 187 (entry d) involved the generation of a titanacyclopropane intermediate from a Grignard reagent and methyltitanium triisopropoxide. After ligand exchange with 187, the titanacyclopropane intermediate underwent insertion of the carbonyl group of the formamide into the titanium-carbon bond. The resulting oxatitanacyclopentane underwent ring opening to an iminium-titanium oxide inner salt that cyclized to the cyclopropylamine. The overall transformation gave only one diastereoisomer, in which the tert-butoxycarbonyl group, the dibenzylamino group and the two cyclopropane bridgehead protons are cis-oriented with respect to each other. According to the authors, the high diastereoselectivity in the transformation was due to the considerable steric bulk of the tert-butyl ester group. 


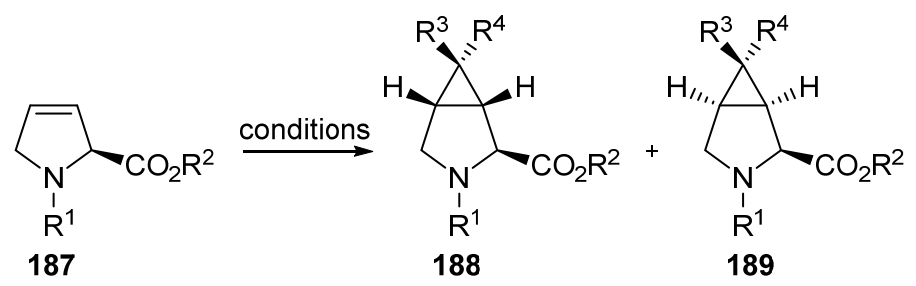
A: $\mathrm{CH}_{2} \mathrm{~N}_{2}$, $\mathrm{CuCl}$, r.t.
C: $\mathrm{CHCl}_{3}, 50 \%$ aq. $\mathrm{NaOH}$, r.t.
B: $\mathrm{CF}_{3} \mathrm{CHN}_{2}$, CuOTf
D: $\mathrm{MeTi}(\mathrm{O} / \mathrm{Pr})_{3}, \mathrm{Bn}_{2} \mathrm{NCHO}, \mathrm{cHexMgBr}$, THF, r.t.

\begin{tabular}{|c|c|c|c|c|c|c|c|c|c|c|}
\hline \multirow[b]{2}{*}{ entry } & \multirow[b]{2}{*}{$R^{1}$} & \multirow[b]{2}{*}{$\mathrm{R}^{2}$} & \multirow[b]{2}{*}{$\mathrm{R}^{3}$} & \multirow[b]{2}{*}{$\mathrm{R}^{4} \mathrm{c}$} & \multirow[b]{2}{*}{ conditions } & \multicolumn{3}{|c|}{ yield (\%) } & \multirow[b]{2}{*}{ ee (\%) } & \multirow[b]{2}{*}{ ref. } \\
\hline & & & & & & 188:189 & 188 & $\overline{189}$ & & \\
\hline$a$ & $\mathrm{COCF}_{3}$ & $\mathrm{Me}$ & $\mathrm{H}$ & $\mathrm{H}$ & $A$ & $78: 22$ & $44^{a}$ & $12^{a}$ & $\mathrm{~b}$ & $77 a$ \\
\hline b & Boc & $\mathrm{Me}$ & $\mathrm{CF}_{3}$ & $\mathrm{H}$ & B & -- & $15^{\mathrm{c}}$ & & -- & $77 b$ \\
\hline c & Boc & $t \mathrm{Bu}$ & $\mathrm{Cl}$ & $\mathrm{Cl}$ & C & -- & 40 & -- & -- & $77 c$ \\
\hline$d$ & Boc & $t \mathrm{Bu}$ & $\mathrm{NBn}_{2}$ & $\mathrm{H}$ & D & -- & 50 & -- & $95^{d}$ & 78 \\
\hline
\end{tabular}

a yields of desalted amino acids

${ }^{b}[\alpha]_{D}$ of 189 coincident with cis amino acid extracted from seeds of Aesculus parviflora

${ }^{c}$ combined modest yield of isomers having $\mathrm{R}^{1}=\mathrm{CO}_{2} \mathrm{CH}_{2} \mathrm{CF}_{3}$

$d_{\text {from }} 95 \%$ ee 187

Scheme 46.

The same stereoselectivity was observed for the titanium-mediated aminocyclopropanation of 3,4-dehydroprolinol derivative 190 (Scheme 47). ${ }^{[79]}$ Removal of the silyl-protecting group furnished 191, which proved to be a suitable starting material for the introduction of different protecting groups. In particular, the $N \gamma$-Fmoc/Na-Boc protected derivative (193) was shown to be compatible with solid-phase peptide chemistry.

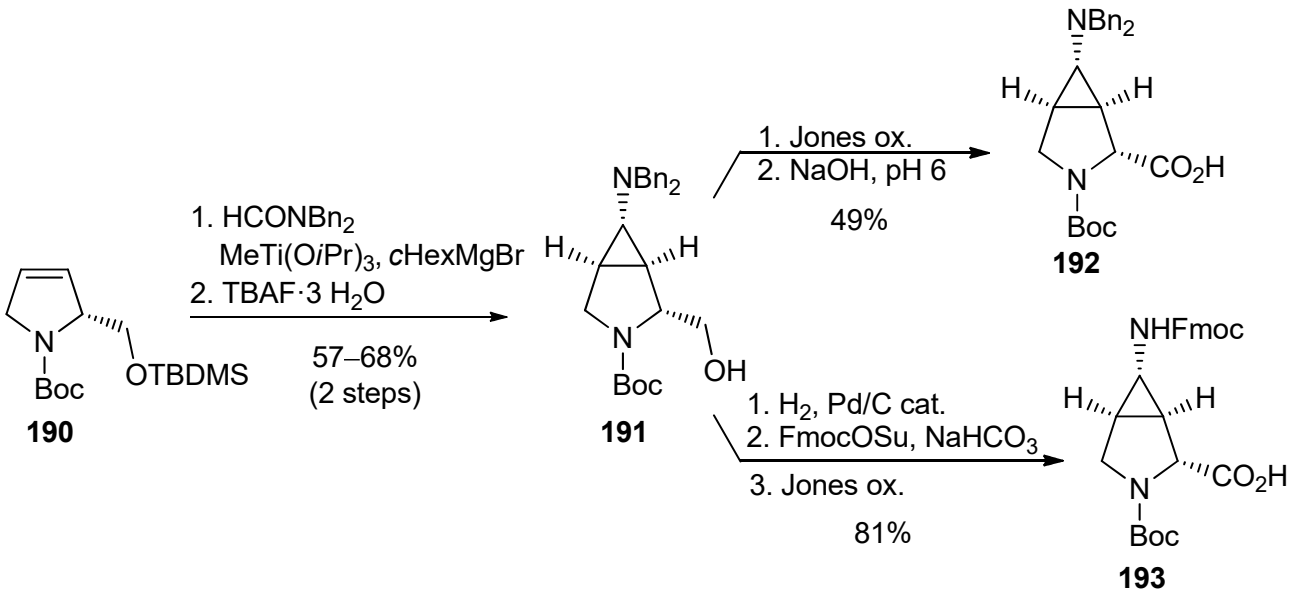

Scheme 47.

Access to the 3-azabicyclo[3.1.0]hexane system by cyclopropanation of unsaturated lactams 117, 80 (Scheme 48) ${ }^{[14 a, 80,81]}$ and 197 (Scheme 49) ${ }^{[82]}$ with alkylidene transfer reagents has also been explored. In particular, Madalengoitia et al. reported the stereoselective cyclopropanation of $\mathbf{1 1 7}$ and $\mathbf{8 0}$ with different sulfur ylides (Scheme 
$48)^{[80 \mathrm{a}]}$ and explored the applicability of the resulting azabicycles in the design of poly-Lproline type II peptide mimics. ${ }^{[80 \mathrm{~b}-\mathrm{f}]}$ Furthermore, a procedure of this type was also employed by Masse et al. for the preparation of deuterated derivatives. ${ }^{[83]}$ The cyclopropanation of $\mathbf{1 1 7}$ and $\mathbf{8 0}$ with sulfur ylides afforded the products of addition from the less hindered faces of the bicyclic lactams. The syn/anti cyclopropane stereochemistry (Scheme 48, entries d-g) was found to be dependent both on the synthon and on the sulfur ylide. The stereochemical outcome of these reactions was interpreted by the authors on the basis of the synclinal-like transition state geometry A which is favoured by steric and electrostatic factors only for small $\mathrm{R}^{2}$ substituents (i.e. $\mathrm{R}^{2}=\mathrm{Me}$ ). Therefore, for such substituents the anti isomer is favoured.
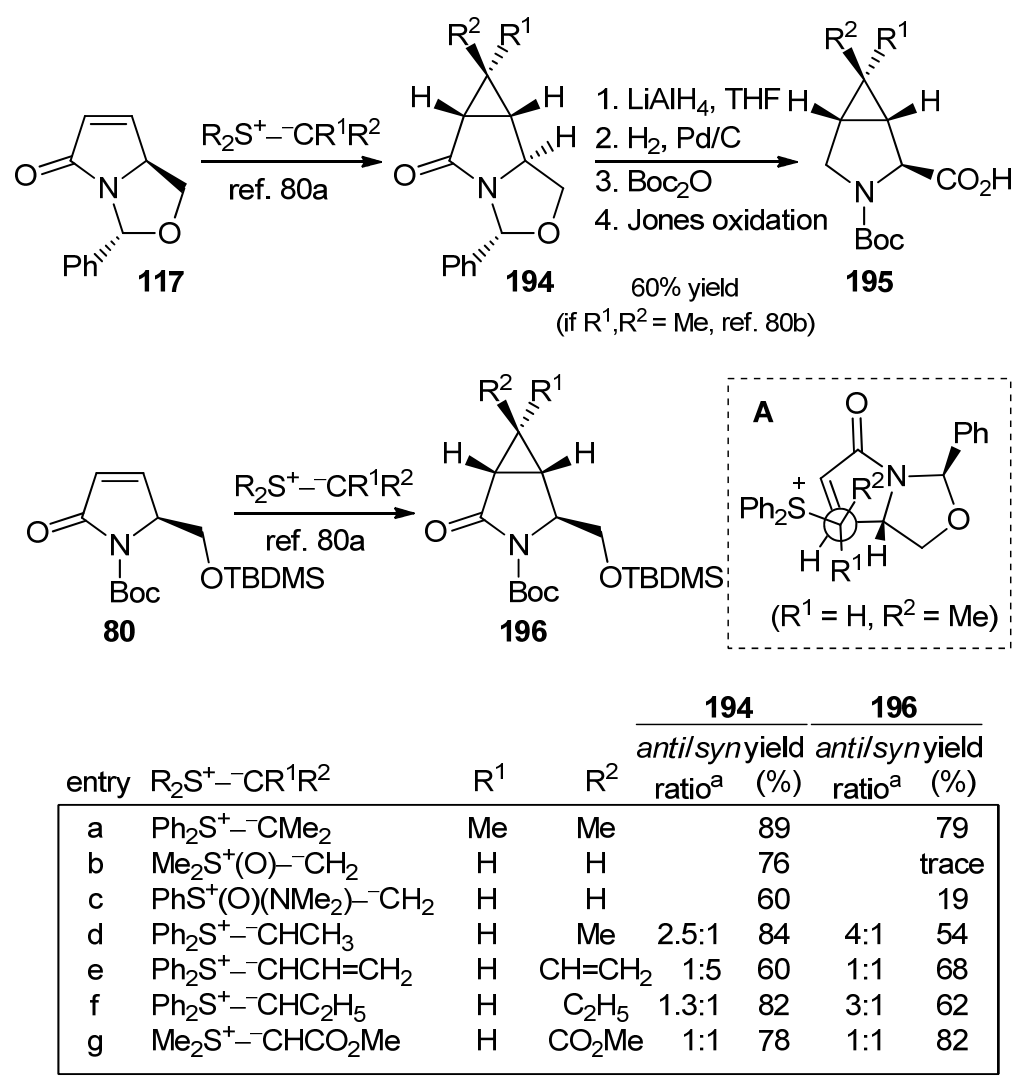

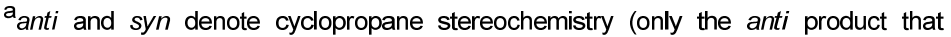
exhibits $\mathrm{R}^{1}=\mathrm{H}$ in trans disposition with respect to the hydrogens at the ring junction is represented for entries $\mathrm{d}-\mathrm{g}$ )

Scheme 48.

Alternatively, Venkatraman et al. reported the stereoselective cyclopropanation of $\mathbf{1 1 7}$ (Scheme 48) with isopropylidenetriphenylphosphorane. ${ }^{[81]}$ The resulting adduct $194\left(\mathrm{R}^{1}\right.$, $\left.\mathrm{R}^{2}=\mathrm{Me}\right)$ was subsequently transformed into $195\left(\mathrm{R}^{1}, \mathrm{R}^{2}=\mathrm{Me}\right)$ by Madalengoitia's procedure $^{[80 b]}$ with some modifications. 
Oba and Nishiyama ${ }^{[82]}$ reported the use of unsaturated pyroglutamate derivatives in which the carboxy functionality is protected as an orthoester for the stereocontrolled synthesis of cis- and trans-3,4-methano-L-proline derivatives in enantiomerically pure form (Scheme 49). The cyclopropanation of 197 by 1,3-dipolar cycloaddition of diazomethane followed by photolysis of the resultant pirazoline afforded adduct 199 . The authors suggest that the orthoester group limits the approach of diazomethane from the $\beta$ face of the olefin, thus resulting in the stereospecific cyclopropanation. In addition, the ABO group prevents racemization at the $\alpha$ carbon atom. Acidic hydrolysis of 199 followed by methanolysis of the orthoester and reprotection of the amino function was needed to accomplish the chemoselective reduction of the lactam. Enantiomerically pure $\mathbf{2 0 0}$ was isolated after hydrolysis and deprotection under acidic conditions followed by treatment with an ion-exchange resin.

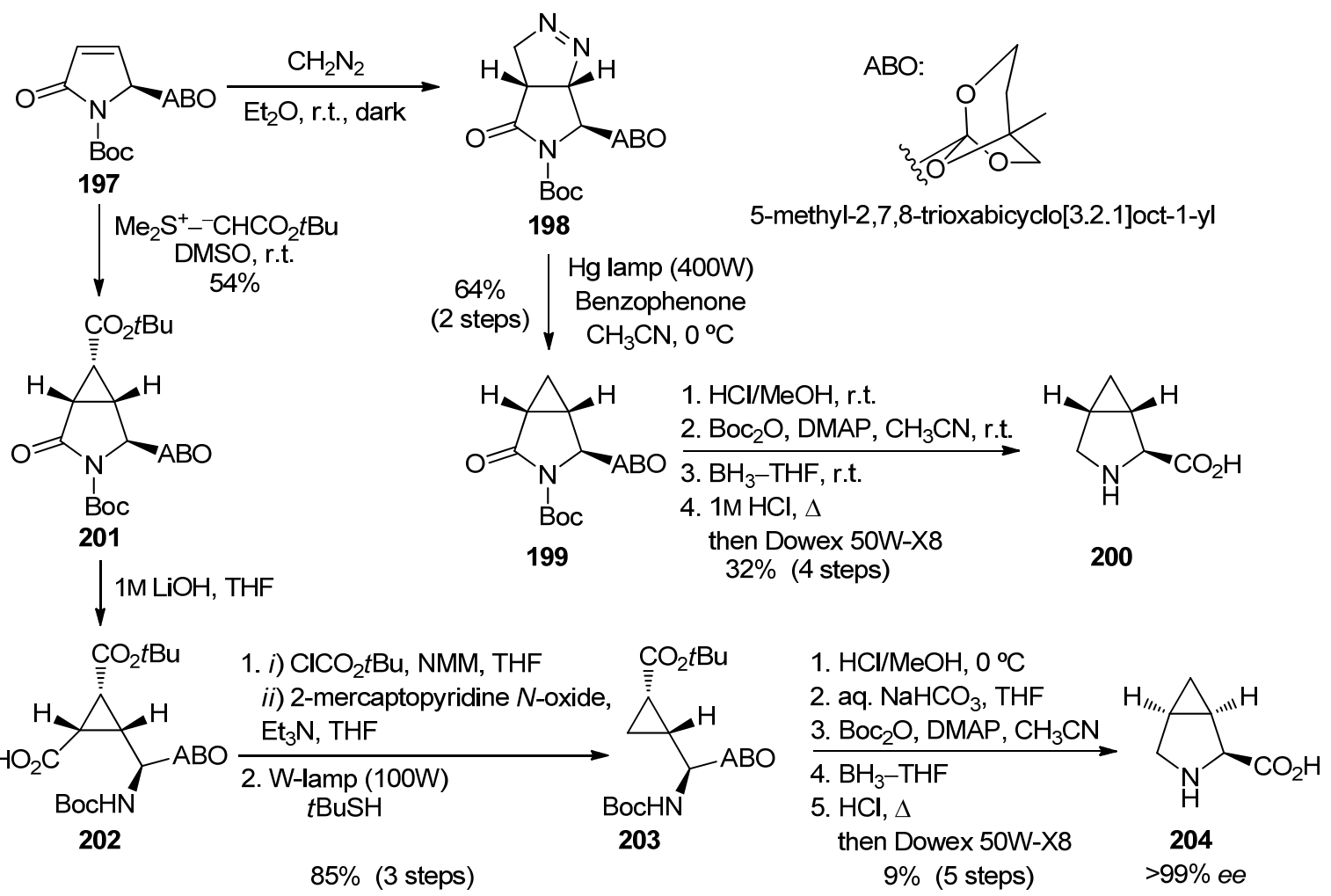

Scheme 49.

In turn, the cis-fused 3,4-methano-L-proline framework was assembled through a fourstep sequence that involved carboxycyclopropanation of 197, ring opening of the lactam, decarboxylation of the resulting acid, and intramolecular cyclization. The carboxycyclopropanation of $\mathbf{1 9 7}$ with tert-butyl dimethylsulfuranylideneacetate gave a 67:33 mixture of adducts with opposite configuration of the substituent at the 
cyclopropane ring, and these were chromatographically separable. The chemoselective ring-opening of the major isomer 201 afforded 202, which was subjected to Barton decarboxylation reaction. Subsequent treatment of $\mathbf{2 0 3}$ with dry hydrogen chloride in methanol afforded an intermediate dimethyl ester derivative that was neutralized to effect the intramolecular cyclization reaction. The resulting pyroglutamate derivative was subjected to standard deprotection, reduction and reprotection protocols that provided enantiopure 204.

Additional procedures for the synthesis of analogous pyroglutamates are disclosed in the literature, ${ }^{[84]}$ although their suitability for the preparation of 3,4-methanoproline derivatives has not been explored. For example, the preparation of 209 and $\mathbf{2 1 0}$ involved rhodium-catalysed cyclopropanation of 205 with ethyl diazoacetate (Scheme 50). ${ }^{\text {84a,b] }}$ The cleavage of the acetal group provided a diol that was oxidized to hemiketal 206. This compound was subjected to Strecker reaction and the resulting amino acids, obtained with poor stereoselectivity, were protected, separated by chromatography and oxidized. The relative configurations of $\mathbf{2 0 9}$ and $\mathbf{2 1 0}$ were assigned on the basis of nOe measurements and coupling constant analysis.

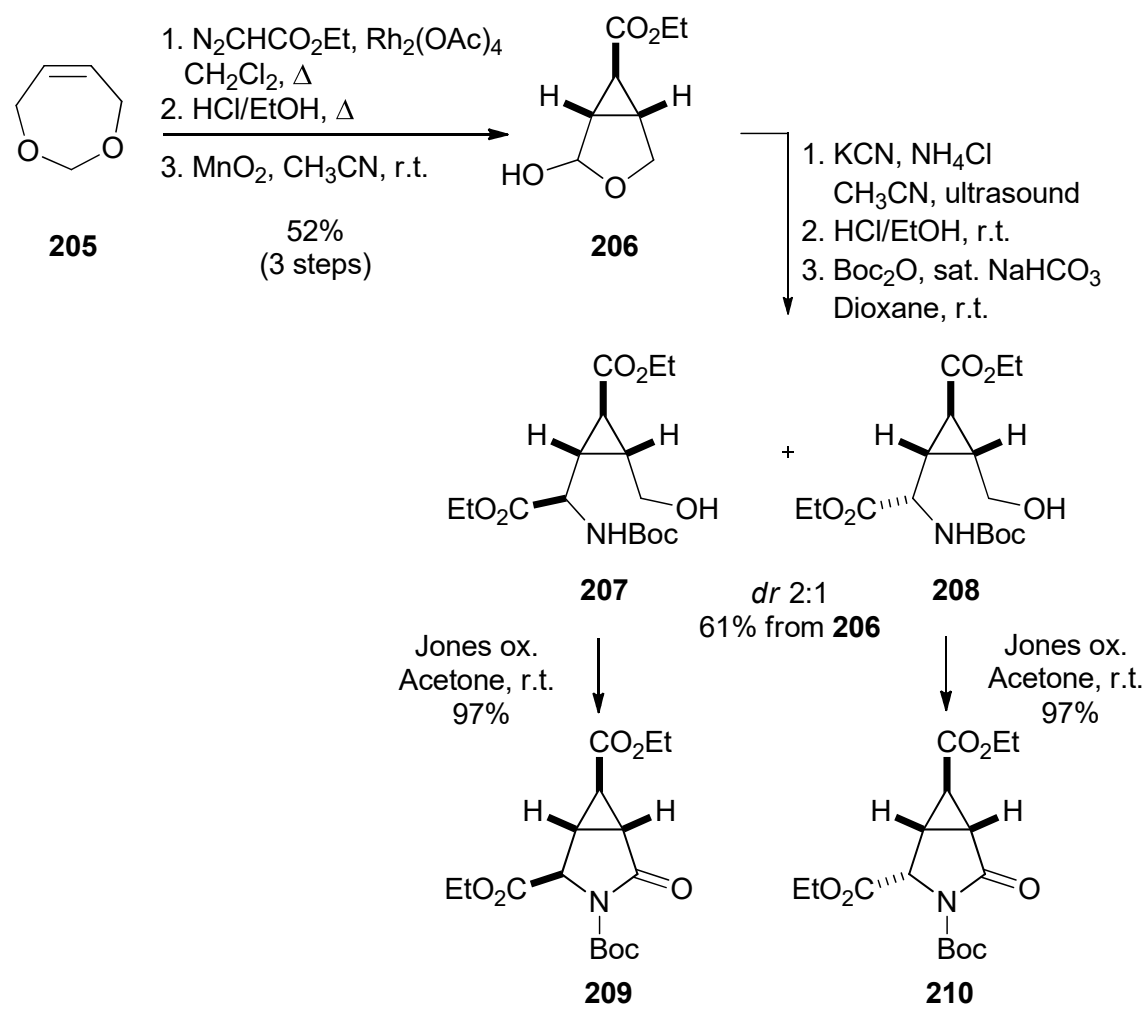

Scheme 50. 


\subsection{Intramolecular cyclization through $\mathrm{C}-\mathrm{N}$ bond formation}

The synthesis of $\mathrm{N}$-Boc protected cis-3,4-methano-L-proline in enantiomerically form has been accomplished in an efficient manner through the coupling of two easily accessible enantiopure starting materials, 211 and 212, followed by the construction of the pyrrolidine ring by intramolecular $\mathrm{C}-\mathrm{N}$ bond formation (Scheme 51$).{ }^{[85]}$ The method involved the generation of the dianion of 211, which reacted with glycidyl triflate 212 to furnish $\beta$-epoxy sulfone 213. The addition of one more equivalent of $n \mathrm{BuLi}$ generated a carbanion $\alpha$ to the sulfone group that underwent epoxide ring-opening to furnish 214 . Cyclization of the mesylates derived from 214 afforded a mixture of 215 and 216 that were separable by chromatography. cis- $N$-Boc-3,4-methanoproline 179a was finally obtained after removal of the tetrahydropyranyl group from 216, reductive desulfonylation and Jones oxidation.

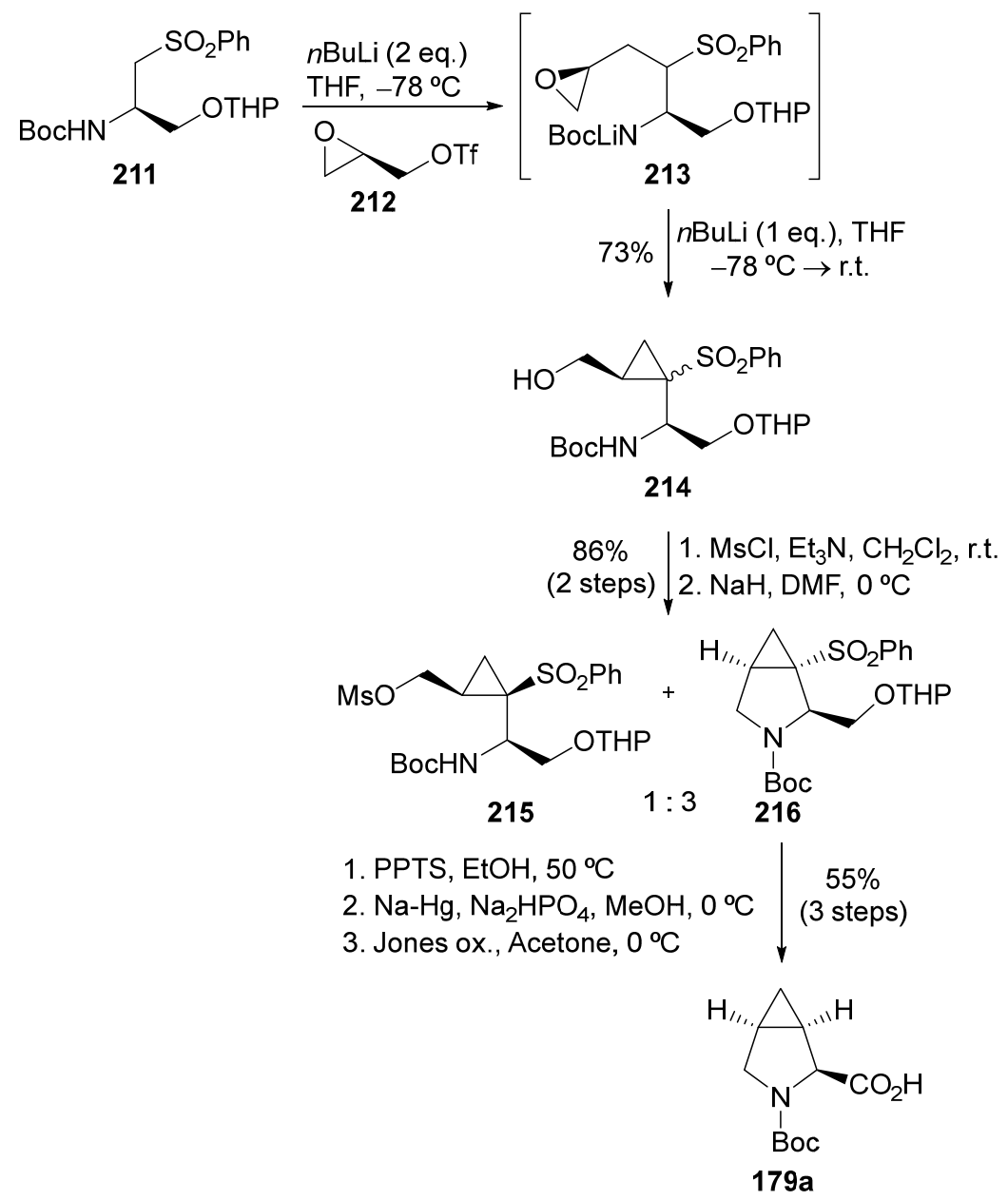

Scheme 51. 
Nair et al. made an interesting contribution that takes advantage of the inherent chirality of the natural product $(+)$-3-carene (217) for the preparation of enantiomerically pure 222 on a multigram scale (Scheme 52). ${ }^{[86]}$ The sequence started with the oxidative cleavage of the olefin in (+)-3-carene, esterification of the resulting ketoacid, and Baeyer-Villiger oxidation to produce acetate $\mathbf{2 1 8}$. Deacetylation of $\mathbf{2 1 8}$ gave a hydroxy ester that cyclized under reflux in the presence of catalytic amounts of base. Introduction of the amine moiety on the carbon $\alpha$ to the carbonyl of $\mathbf{2 1 9}$ was achieved through an oximation/reduction sequence. Reduction of oxime $\mathbf{2 2 0}$ from the less hindered side afforded the amino group with a trans relative disposition with respect to the bridgehead hydrogen atoms. Methanolysis of this lactone gave amino ester 221 along with a $20 \%$ of its C-2 epimer. This mixture underwent cyclization upon treatment under Mitsunobu conditions. When the epimeric bicyclic methyl ester was hydrolysed with $\mathrm{LiOH}$, thermodynamically favoured $\mathbf{2 2 2}$ was formed exclusively.

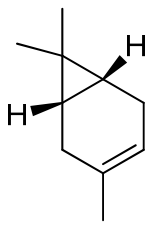

217

(+)-3-carene
1. $\mathrm{RuCl}_{3}, \mathrm{NaIO}_{4}$ $t \mathrm{BuOH} / \mathrm{H}_{2} \mathrm{O}, 35-40^{\circ} \mathrm{C}$ 2. $\mathrm{Cs}_{2} \mathrm{CO}_{3}, \mathrm{Mel}, \mathrm{DMF}, 40^{\circ} \mathrm{C}$ 3. $m \mathrm{CPBA}, 1,1,2-\mathrm{TCE}, 65-75^{\circ} \mathrm{C}$ $76 \%$

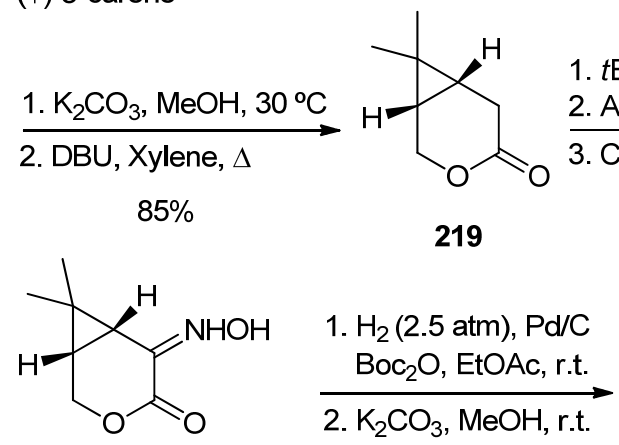

220
$85 \%$<smiles>CC(=O)CC[C@@H]1[C@H](COC(C)=O)C1(C)C</smiles>

218 
Alternative procedures that involve the construction of the pyrrolidine ring of the desired 3,4-methanoproline through intramolecular $\mathrm{C} \alpha-\mathrm{N}$ bond formation, instead of the $\mathrm{C} \delta-\mathrm{N}$ closure described by Nair, and make use of a natural product as the starting material have been reported. ${ }^{[87,88]}$ As one example, Berranger and Demonchaux ${ }^{[87]}$ reported the multigram preparation of enantiomerically pure 229 starting from (-)-biocartol (223), which is also derived from (+)-3-carene (217) (Scheme 53). (-)-Biocartol furnished the bicyclic lactone 224 in good yield through ester hydrolysis, concomitant aldehyde reduction and subsequent condensation reaction. Treatment of $\mathbf{2 2 4}$ with thionyl cloride provided 225, which underwent a substitution reaction with ammonia to afford 226. After protection of the amino function, the procedure involved reduction of the lactam carbonyl group with diisobutylaluminum hydride to obtain an intermediate hemiaminal, which was transformed into methoxyaminal 227. Subsequent treatment of 227 with trimethylsilyl cyanide in the presence of trimethylsilyl triflate stereoselectively yielded compound $\mathbf{2 2 8}$, which was hydrolysed to furnish $\mathbf{2 2 9}$.
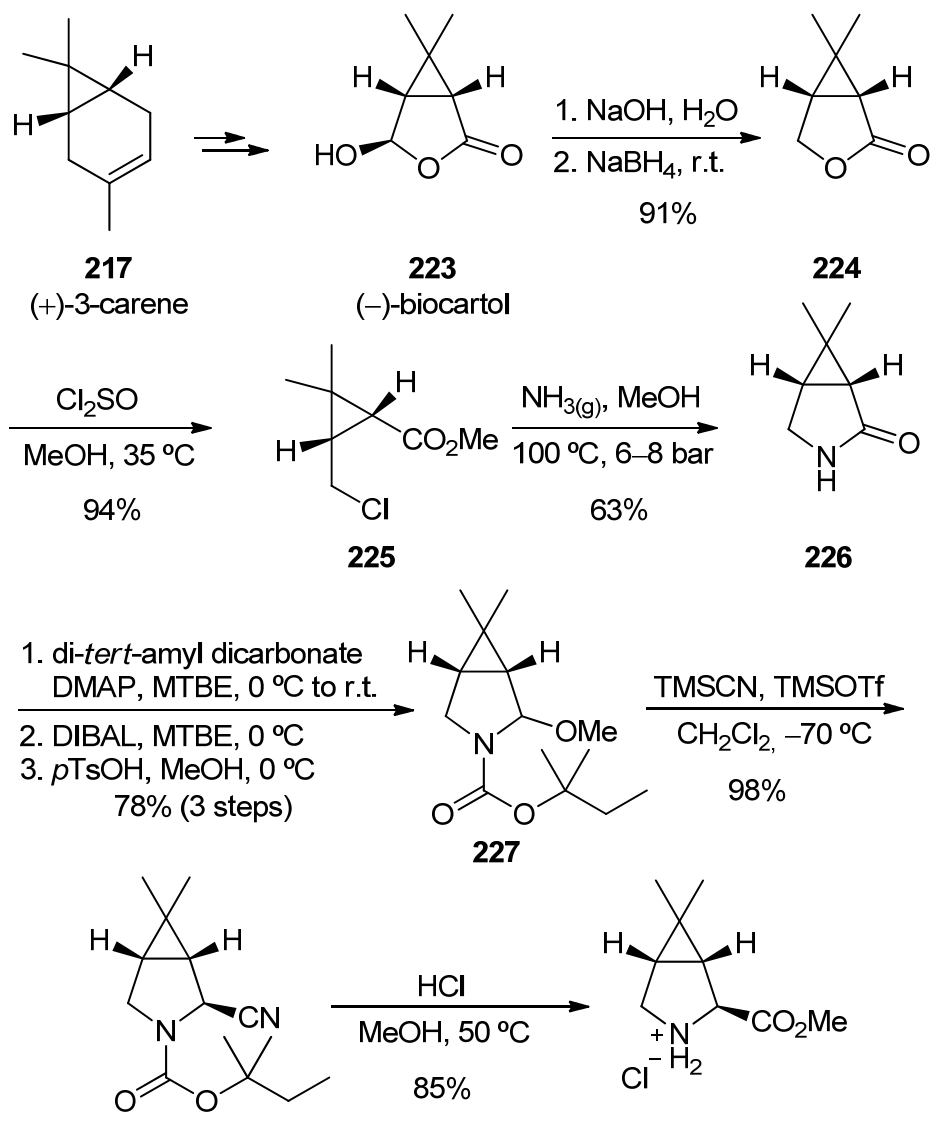

228

229

Scheme 53. 


\subsection{Intramolecular cyclization through $\mathrm{C}-\mathrm{C}$ bond formation}

Baird et al. reported the construction of azabicyclo[3.1.0]hexane derivatives through formal insertion of a cyclopropylidene unit into a $\mathrm{C}-\mathrm{H}$ bond adjacent to a nitrogen atom (Scheme 54). ${ }^{[89]}$ The required precursor 231 was synthesized from enantiomerically pure dibromocyclopropane $\mathbf{2 3 0}$ in several steps. Subsequent treatment of $\mathbf{2 3 1}$ with methyllithium furnished an intermediate cyclopropylidene that cyclized to afford $\mathbf{2 3 2}$ as the major isomer. Selective debenzylation of $\mathbf{2 3 2}$, followed by trifluoroacetylation of the nitrogen atom, oxidation of the phenyl group and nitrogen deprotection afforded cis-3,4methanoproline derivative 233. This methodology was also applied to the synthesis of enantiomerically pure cis-3,4-methano-L-proline that was obtained in $40 \%$ overall yield from the corresponding $R$-configured dibromocyclopropane carboxylic acid.

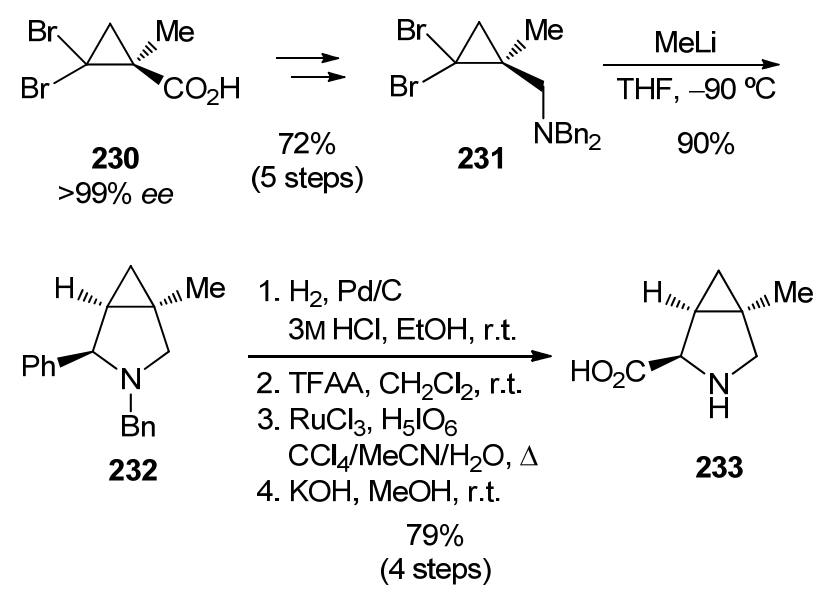

Scheme 54.

Alternatively, cis- and trans-3,4-methano-L-proline derivatives were synthesized by use of a carbene insertion as the key step (Scheme 55). ${ }^{[90]}$ Compound 234 was $N$-nitrosilated and the crude material rearranged in the presence of pyrrolidine to an $\alpha$-diazoketone. The treatment of this with palladium acetate produced a carbene that underwent intramolecular addition to the olefin group. Interestingly, compounds with methyl- or ethyl-disubstituted olefin groups led exclusively to the cycloaddition adducts $\mathbf{2 3 5}$ (entries a,b), possibly due to more favourable steric and electronic interactions in the exo-form of the carbene generated. Conversely, a cyclopropyl-substituted olefin (entry c) lead to a 1:1 separable mixture of pyrrolidones that, in turn, afforded access to proline derivatives such as $\mathbf{2 3 7}$ upon deprotection and reduction of the lactam moiety. The structure of $\mathbf{2 3 6}$ was confirmed by single crystal X-ray analysis of the lactam obtained after removal of the $\mathrm{N}, \mathrm{O}$-dimethyl acetal. 

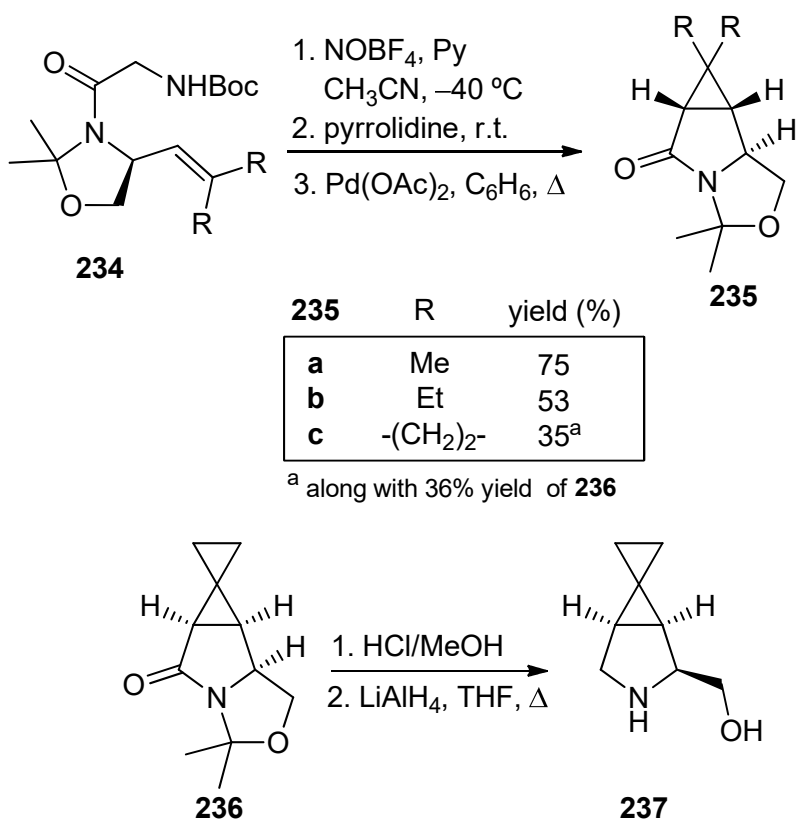

Scheme 55.

\subsection{Miscellaneous}

Dixneuf et al. explored the transformation of fluorinated mixed propargyl allyl amides into azabicyclo[3.1.0] hexane derivatives (Scheme 56, entries a-d). ${ }^{[91]}$ It was shown that the process involves a ruthenium-catalysed tandem addition of a diazoalkane followed by cyclopropanation. The sequential carbene addition and cyclopropanation reactions of enynes took place under very mild conditions and with high stereoselectivity. Enynes 238a and 238b reacted with $\mathrm{N}_{2} \mathrm{CHSiMe}_{3}$ in diethyl ether to give the diastereoisomers with the $\mathrm{Z}$ configuration of the alkenyl group. Conversely, the catalytic transformation of enynes $\mathbf{2 3 8 c}$ and $\mathbf{2 3 8 d}$ with ethyl diazoacetate led preferentially to products with $E$ configured alkenyl side-chain, probably due to thermal factors because the reaction took place at $100{ }^{\circ} \mathrm{C}$. In each case, the major diastereoisomer 240 exhibited a trans relative disposition of the ester and the alkenyl group. In addition, the presence of a substituent on the double bond of the starting enyne (Scheme 56, entries e-g) induced the predominant formation of one diastereoisomer with the $\mathrm{Z}$ configuration of the vinylsilane moiety. The relative stereochemistry of $\mathbf{2 3 9 d - g}$ was established on the basis of NMR experiments. 
Published in Eur. J. Org. Chem. 2015, 1633-1658 (doi: 10.1002/ejoc.201403121)

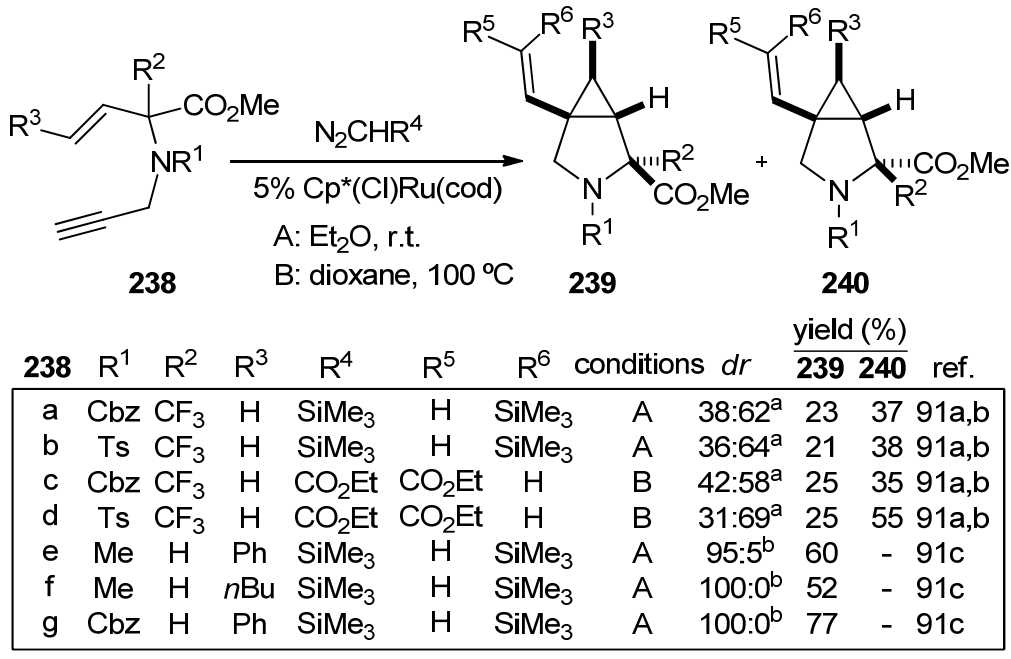

${ }^{a}$ relative configuration established by X-Ray diffraction analysis of $\mathbf{2 3 9 b}$

${ }^{b}$ relative configuration of major isomer established by NMR

Scheme 56.

Recently, the synthesis of azabicyclo[3.1.0]hexane derivatives, such as $\mathbf{2 4 7}$ and $\mathbf{2 4 8}$, has been accomplished by means of a tandem process initiated by the conjugate addition of an allylic amine to a vinylsulfonium salt generated in situ from a bromoethylsulfonium salt (Scheme 57). ${ }^{[92]}$ The resulting sulfur ylide underwent intramolecular addition to the Michael acceptor to give a sulfonium enolate that ring-closed to the cyclopropane. In this manner, enantioenriched 244 and 246 were obtained with high diastereoselectivity. The relative stereochemistry of $\mathbf{2 4 6}$ was determined by X-ray analysis and related compounds were assigned by analogy. Deprotection and oxidation of $\mathbf{2 4 4}$ gave 247, which can be seen as a conformationally locked glutamic acid analogue. On the other hand, oxidative cleavage of the phenyl group in 246 gave pyrrolidine 248, which is both an $\alpha$ - and $\beta$ amino acid derivative.

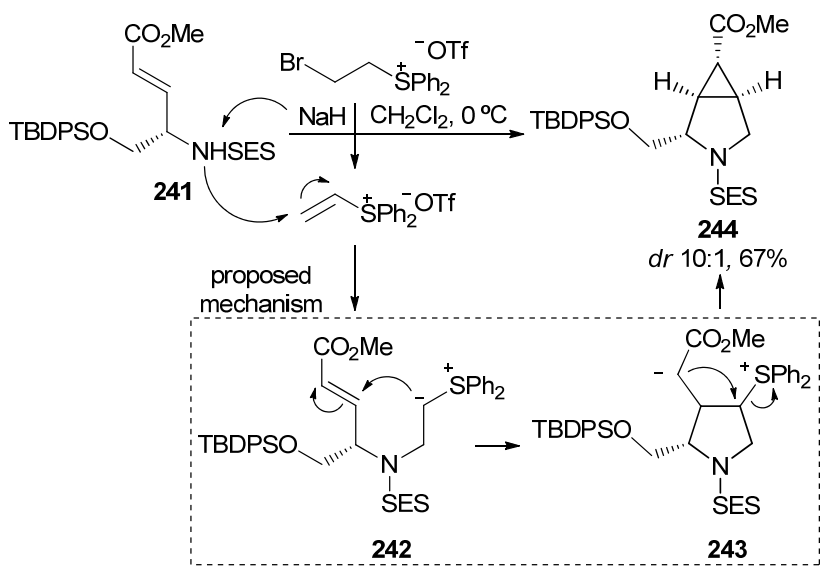



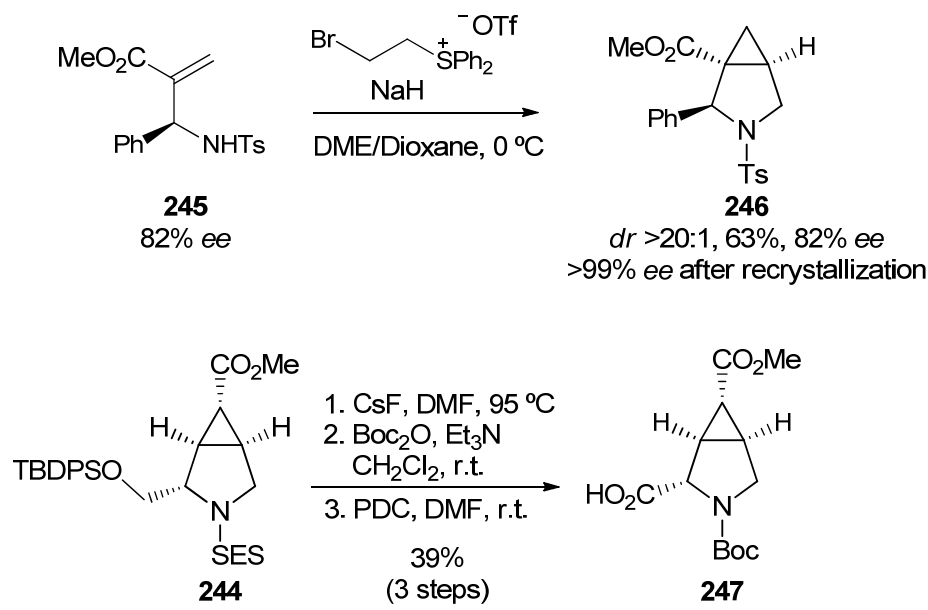

1. $\mathrm{CsF}, \mathrm{DMF}, 95^{\circ} \mathrm{C}$ 2. $\mathrm{Boc}_{2} \mathrm{O}, \mathrm{Et}_{3} \mathrm{~N}$

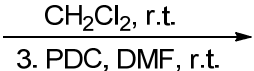
$39 \%$ (3 steps)<smiles>CC(=O)OC1[C@@H]2[C@@H]1N(C(=O)OCc1ccccc1)C[C@@H]2C(=O)O</smiles>

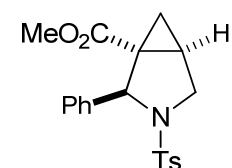

$( \pm)-246$

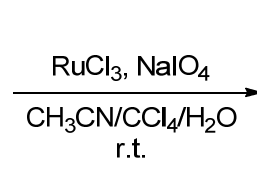

$72 \%$<smiles>CC(=O)OC1[C@H]2C[C@H]2CN([125I])[C@H]1C(=O)O</smiles>

248

Scheme 57.

\section{Concluding remarks}

In this review, we have collected the methods available for the synthesis of bicyclic proline analogues incorporating a carbocyclic ring fused to the $[c]$ face of the pyrrolidine moiety. Procedures that provide the target compounds in racemic form and those that afford enantioenriched products have both been considered. Although a number of strategies have been effectively applied to the large-scale synthesis of enantiopure 3azabicyclo[3.3.0]octane- and 3-azabicyclo[3.1.0]hexane-2-carboxylic acid derivatives, which are component units of important drugs on the market, many other approaches for the stereoselective and asymmetric construction of $[c]$-fused bicyclic proline analogues have also been established. In this context, those methods that make use of cycloaddition reactions proved to be mainly suited for the preparation of polysubstituted $[c]$-fused bicyclic proline analogues. The different methods described should encourage further investigations focusing on the refinement of the procedures and catalytic processes for providing the target molecules in enantiomerically pure form.

\section{Abbreviations and acronyms}

Abbreviations and acronyms used in this article are summarized in Table 1. 
Table 1.

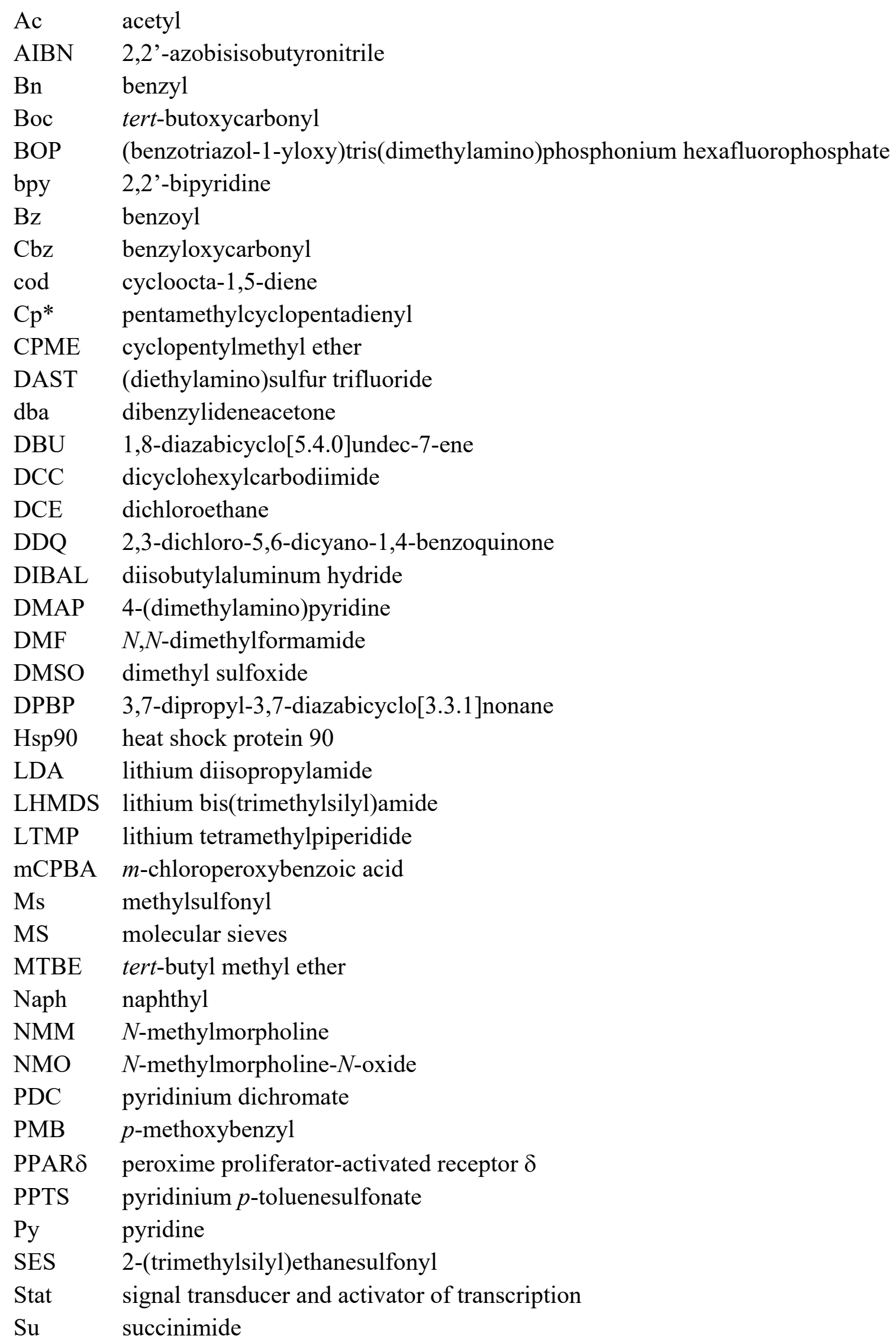




$\begin{array}{ll}\text { TBAF } & \text { tetrabutylammonium fluoride } \\ \text { TBAT } & \text { tetrabutylammonium difluorotriphenylsilicate } \\ \text { TBDMS } & \text { tert-butyldimethylsilyl } \\ \text { TBDPS } & \text { tert-butyldiphenylsilyl } \\ \text { TCE } & \text { trichloroethane } \\ \text { TFA } & \text { trifluoroacetic acid } \\ \text { TFAA } & \text { trifluoroacetic anhydride } \\ \text { Tf } & \text { trifluoromethylsulfonyl } \\ \text { THF } & \text { tetrahydrofuran } \\ \text { THNA } & \text { 1,2,3,4-tetrahydro-1-naphthylamine } \\ \text { THP } & \text { tetrahydropyranyl } \\ \text { TMS } & \text { trimethylsilyl } \\ p \text { Tol } & p \text {-tolyl } \\ \text { Ts } & p \text {-tolylsulfonyl }\end{array}$

\section{Acknowledgements}

Financial support from the Ministerio de Economía y Competitividad (MINECO)FEDER (grant numbers CTQ2010-17436, CTQ2013-40855-R; predoctoral fellowship for P. L.) and Gobierno de Aragón-FSE (research group E40) is gratefully acknowledged.

[1] Compound $\mathbf{1}$ is more frequently referred to as $(1 S, 3 \mathrm{a} R, 6 \mathrm{a} S)$ octahydrocyclopenta[c]pyrrole-1-carboxylic acid rather than (1S,2S,5R)-3azabicyclo[3.3.0] octane-2-carboxylic acid. On the other hand, both $(1 R, 2 S, 5 S)-6,6-$ dimethyl-3-azabicyclo[3.1.0]hexane-2-carboxylic acid, and trans-6,6-dimethyl-3,4methano-L-proline are commonly employed to refer to compound 2. In Figure 2, the positions of chiral carbons are indicated with numerical locants that relate to the nomenclature system more commonly employed to refer to each compound.

[2] a) A. D. Kwong, R. S. Kauffman, P. Hurter, P. Mueller, Nat. Biotechnol. 2011, 29, 993-1003, and references cited therein; b) F. Victor, J. Lamar, N. Snyder, Y. Yip, D. Guo, N. Yumibe, R. B. Johnson, Q. M. Wang, J. I. Glass, S.-H. Chen, Bioorg. Med. Chem. Lett. 2004, 14, 257-261; c) J. Lamar, F. Victor, N. Snyder, R. B. Johnson, Q. M. Wang, J. I. Glass, S.-H. Chen, Bioorg. Med. Chem. Lett. 2004, 14, 263-266; d) D. X. Sun, L. Liu, B. Heinz, A. Kolykhalov, J. Lamar, R. B. Johnson, Q. M. Wang, Y. Yip, S.-H. Chen, Bioorg. Med. Chem. Lett. 2004, 14, 4333-4338; e) Y. Yip, F. Victor, J. Lamar, R. Johnson, Q. M. Wang, J. I. Glass, N. Yumibe, M. Wakulchik, J. Munroe, S.-H. Chen, Bioorg. Med. Chem. Lett. 2004, 14, 5007-5011; f) F. Maltais, 
Published in Eur. J. Org. Chem. 2015, 1633-1658 (doi: 10.1002/ejoc.201403121)

Y. C. Jung, M. Chen, J. Tanoury, R. B. Perni, N. Mani, L. Laitinen, H. Huang, S. Liao, H. Gao, H. Tsao, E. Block, C. Ma, R. S. Shawgo, C. Town, C. L. Brummel, D. Howe, S. Pazhanisamy, S. Raybuck, M. Namchuk, Y. L. Bennani, J. Med. Chem. 2009, 52, 7993-8001.

[3] a) S. Venkatraman, A. Prongay, F. G. Njoroge, "Discovery of Boceprevir and Narlaprevir: A Case Study for Role of Structure-Based Drug Design” in Analoguebased Drug Discovery III (Eds.: J. Fischer, C. R. Ganellin, D. P. Rotella), WileyVCH, 2013, pp 343-363; b) K. X. Chen, F. G. Njoroge, "Discovery of Boceprevir and Narlaprevir: the First and Second Generation of HCV NS3 Protease Inhibitors" in Case Studies in Modern Drug Discovery and Development (Eds.: X. Huang, R. G. Aslanian), John Wiley \& Sons, 2012, pp 296-335, and references cited therein.

[4] M. Boehringer, K. Groebke-Zbinden, W. Haap, N. Panday, F. Ricklin, M. Stahl, P. Schmitz, PCT Patent WO2007054453, 2007 [Chem. Abstr. 2007, 146, 521676].

[5] a) P.-P. Kung, B. Huang, G. Zhang, J. Z. Zhou, J. Wang, J. A. Digits, J. Skaptason, S. Yamazaki, D. Neul, M. Zientek, J. Elleraas, P. Mehta, M.-J. Yin, M. J. Hickey, K. S. Gajiwala, C. Rodgers, J. F. Davies, M. R. Gehring, J. Med. Chem. 2010, 53, 499503; b) P. Mehta, P.-P. Kung, S. Yamazaki, M. Walls, A. Shen, L. Nguyen, M. R. Gehring, G. Los, T. Smeal, M.-J. Yin, Cancer Lett. 2011, 300, 30-39.

[6] a) G. Cignarella, P. Sanna, J. Med. Chem. 1981, 24, 1003-1006; b) P. Sanna, G. Cignarella, V. Arania, R. Siri, M. S. Desole, Il Farmaco 1985, 40, 777-785.

[7] S. Klutchko, C. J. Blankley, R. W. Fleming, J. M. Hinkley, A. E. Werner, I. Nordin, A. Holmes, M. L. Hoefle, D. M. Cohen, A. D. Essenburg, H. R. Kaplan, J. Med. Chem. 1986, 29, 1953-1961.

[8] J. Chiba, G. Takayama, T. Takashi, M. Yokoyama, A. Nakayama, J. J. Baldwin, E. McDonald, K. J. Moriarty, C. R. Sarko, K. W. Saionz, R. Swanson, Z. Hussain, A. Wong, N. Machinaga, Bioorg. Med. Chem. 2006, 14, 2725-2746.

[9] D. R. Bolin, A. L. Swain, R. Sarabu, S. J. Berthel, P. Gillespie, N. J. S. Huby, R. Makofske, L. Orzechowski, P. Perrotta, K. Toth, J. P. Cooper, N. Jiang, F. Falcioni, R. Campbell, D. Cox, D. Gaizband, C. J. Belunis, D. Vidovic, K. Ito, R. Crowther, U. Kammlott, X. Zhang, R. Palermo, D. Weber, J. Guenot, Z. Nagy, G. L. Olson, J. Med. Chem. 2000, 43, 2135-2148. 
[10] S. Bourgault, D. Vaudry, I. Segalas-Milazzo, L. Guilhaudis, A. Couvineau, M. Laburthe, H. Vaudry, A. Fournier, J. Med. Chem. 2009, 52, 3308-3316.

[11]C. A. Luckhurst, L. A. Stein, M. Furber, N. Webb, M. J. Ratcliffe, G. Allenby, S. Botterell, W. Tomlinson, B. Martin, A. Walding, Bioorg. Med. Chem. Lett. 2011, 21, $492-496$.

[12]P. R. Guzzo, J. M. Hamby, M. R. Johnson, V.-D. Le, J. E. Mangette, R. A. Shenoy, M. A. Stier, PCT Patent WO2004092134, 2004 [Chem. Abstr. 2004, 141, 380131].

[13]C. J. Blankley, J. S. Kaltenbronn, D. E. DeJohn, A. Werner, L. R. Bennett, G. Bobowski, U. Krolls, D. R. Johnson, W. M. Pearlman, M. L. Hoefle, A. D. Essenburg, D. M. Cohen, H. R. Kaplan, J. Med. Chem. 1987, 30, 992-998.

[14]a) L. J. Farmer, S. D. Britt, K. M. Cottrell, J. J. Court, L. F. Courtney, D. D. Deininger, C. A. Gates, S. L. Harbeson, K. Lin, C. Lin, Y.-P. Luong, J. P. Maxwell, J. Pitlik, B. G. Rao, W. C. Schairer, J. A. Thomson, R. D. Tung, J. H. Van Drie, Y. Wei, R. B. Perni, Lett. Drug Des. Discovery 2005, 2, 497-502; b) Y. Yip, F. Victor, J. Lamar, R. Johnson, Q. M. Wang, D. Barket, J. Glass, L. Jin, L. Liu, D. Venable, M. Wakulchik, C. Xie, B. Heinz, E. Villarreal, J. Colacino, N. Yumibe, M. Tebbe, J. Munroe, S.-H. Chen, Bioorg. Med. Chem. Lett. 2004, 14, 251-256.

[15] S.-H. Chen, J. Lamar, F. Victor, N. Snyder, R. Johnson, B. A. Heinz, M. Wakulchik, Q. M. Wang, Bioorg. Med. Chem. Lett. 2003, 13, 3531-3536.

[16] a) D. R. Coleman, Z. Ren, P. K. Mandal, A. G. Cameron, G. A. Dyer, S. Muranjan, M. Campbell, X. Chen, J. S. McMurray, J. Med. Chem. 2005, 48, 6661-6670; b) P. K. Mandal, Z. Ren, X. Chen, C. Xiong, J. S. McMurray, J. Med. Chem. 2009, 52, 6126-6141; c) P. K. Mandal, F. Gao, Z. Lu, Z. Ren, R. Ramesh, J. S. Birtwistle, K. K. Kaluarachchi, X. Chen, R. C. Bast, Jr., W. S. Liao, J. S. McMurray, J. Med. Chem. 2011, 54, 3549-3563.

[17] I. Rowland, H. Tristram, Chem.-Biol. Interactions 1971, 4, 377-388.

[18] a) C. M. Anderson, R. J. Bridges, A. R. Chamberlin, K. Shimamoto, Y. YasudaKamatani, R. A. Swanson, J. Neurochem. 2001, 79, 1207-1216; b) T. Mennini, E. Fumagalli, M. Gobbi, C. Fattorusso, B. Catalanotti, G. Campiani, Eur. J. Pharmacol. 2003, 479, 291-296; c) C. E.-H. Moussa, C. Rae, W. A. Bubb, J. L. Griffin, N. A. 
Published in Eur. J. Org. Chem. 2015, 1633-1658 (doi: 10.1002/ejoc.201403121)

Deters, V. J. Balcar, J. Neurosci. Res. 2007, 85, 342-350; d) S. Huang, R. M. Ryan, R. J. Vandenberg, J. Biol. Chem. 2009, 284, 4510-4515.

[19] L. J. Beeley, C. J. M. Rockell, Tetrahedron Lett. 1990, 31, 417-420.

[20] R. E. Gawley, S. R. Chemburkar, A. L. Smith, T. V. Anklekar, J. Org. Chem. 1988, $53,5381-5383$.

[21] A. I. Meyers, B. Santiago, Tetrahedron Lett. 1995, 36, 5877-5880.

[22] J. E. Hernández, S. Fernández, G. Arias, Synth. Commun. 1988, 18, 2055-2061.

[23] a) J. A. Monn, K. C. Rice, Tetrahedron Lett. 1989, 30, 911-914; b) J. A. Monn, A. Thurkauf, M. V. Mattson, A. E. Jacobson, K. C. Rice, J. Med. Chem. 1990, 33, 10691076.

[24] T. Mita, M. Sugawara, H. Hasegawa, Y. Sato, J. Org. Chem. 2012, 77, 2159-2168.

[25] R. Morán-Ramallal, V. Gotor-Fernández, P. Laborda, F. J. Sayago, C. Cativiela, V. Gotor, Org. Lett. 2012, 14, 1696-1699.

[26] a) M. Ordóñez, G. D. Tibhe, A. Zamudio-Medina, J. L. Viveros-Ceballos, Synthesis 2012, 44, 569-574 and references cited therein; b) L. Shi, L. Hu, J. Wang, X. Cao, H. Gu, Org. Lett. 2012, 14, 1876-1879; c) A. A. Kilikli, C. Dengiz, S. Özcan, M. Balci, Synthesis 2011, 3697-3705; d) C. S. Cho, W. X. Ren, Tetrahedron Lett. 2009, 50, 2097-2099; e) M. H. Norman, D. J. Minick, G. C. Rigdon, J. Med. Chem. 1996, 39, 149-157; f) S. Das, D. Addis, L. R. Knöpke, U. Bentrup, K. Junge, A. Brückner, M. Beller, Angew. Chem. Int. Ed. 2011, 50, 9180-9184; Angew. Chem. 2011, 123, 9346-9350.

[27] For the synthesis of C3-substituted isoindolinones see: a) M. Lamblin, A. Couture, E. Deniau, P. Grandclaudon, Tetrahedron: Asymmetry 2008, 19, 111-123; b) E. Deniau, A. Couture, P. Grandclaudon, Tetrahedron: Asymmetry 2008, 19, 27352740; c) D. M. Shacklady-McAtee, S. Dasgupta, M. P. Watson, Org. Lett. 2011, 13, 3490-3493; d) D.-D. Li, T.-T. Yuan, G.-W. Wang, Chem. Commun. 2011, 47, 12789-12791; e) V. Agouridas, F. Capet, A. Couture, E. Deniau, P. Grandclaudon, Tetrahedron: Asymmetry 2011, 22, 1441-1447; f) M. A. Reyes-González, A. Zamudio-Medina, M. Ordóñez, Tetrahedron Lett. 2012, 53, 5756-5758; g) M. Fujioka, T. Morimoto, T. Tsumagari, H. Tanimoto, Y. Nishiyama, K. Kakiuchi, $J$. 
Published in Eur. J. Org. Chem. 2015, 1633-1658 (doi: 10.1002/ejoc.201403121)

Org. Chem. 2012, 77, 2911-2923; h) M.-W. Chen, Q.-A. Chen, Y. Duan, Z.-S. Ye, Y.-G. Zhou, Chem. Commun. 2012, 48, 1698-1700.

[28] a) G. Cignarella, R. Cerri, G. Grella, P. Sanna, Gazz. Chim. Ital. 1976, 106, 65-75;

b) J. S. New, J. P. Yevich, J. Heterocyclic Chem. 1984, 21, 1355-1360.

[29] G. Cignarella, F. Savelli, P. Sanna, Synthesis 1975, 252-253.

[30] S. Yao, D. Gallenkamp, K. Wölfel, B. Lüke, M. Schindler, J. Scherkenbeck, Bioorg. Med. Chem. 2011, 19, 4669-4678.

[31] O. Gaertzen, S. L. Buchwald, J. Org. Chem. 2002, 67, 465-475.

[32] D. Solé, O. Serrano, J. Org. Chem. 2010, 75, 6267-6270.

[33]H. Hussain, E. Kianmehr, T. Durst, Tetrahedron Lett. 2001, 42, 2245-2248.

[34]B. M. K. Tong, B. W.-Q. Hui, S. H. Chua, S. Chiba, Synthesis 2011, 3552-3562.

[35] a) K. A. Parker, I. D. Cohen, R. E. Babine, Tetrahedron Lett. 1984, 25, 3543-3546;

b) R. Grigg, H. Q. N. Gunaratne, V. Sridharan, Tetrahedron 1987, 43, 5887-5898;

c) C. Wang, X.-H. Chen, S.-M. Zhou, L.-Z. Gong, Chem. Commun. 2010, 46, 12751277; d) Z. He, T. Liu, H. Tao, C.-J. Wang, Org. Lett. 2012, 14, 6230-6233.

[36]D. Sémeril, J. Le Nôtre, C. Bruneau, P. H. Dixneuf, A. F. Kolomiets, S. N. Osipov, New. J. Chem. 2001, 25, 16-18.

[37] G. T. Shchetnikov, S. N. Osipov, C. Bruneau, P. H. Dixneuf, Synlett 2008, 578-582.

[38] M. R. Johnson, J. F. Gauuan, C. Guo, P. R. Guzzo, V.-D. Le, R. A. Shenoy, J. Hamby, H. Roark, M. Stier, J. E. Mangette, Synthetic Commun. 2011, 41, 2769-2793.

[39]S. Nieto, F. J. Sayago, P. Laborda, T. Soler, C. Cativiela, E. P. Urriolabeitia, Tetrahedron 2011, 67, 4185-4191.

[40] a) A. Couture, E. Deniau, D. Ionescu, P. Grandclaudon, Tetrahedron Lett. 1998, 39, 2319-2320; b) T. Kametani, H. Sugahara, K. Kanno, Chem. Pharm. Bull. 1967, 15, 1916-1921; c) J. A. Lowe III, F. E. Ewing, J. Heterocyclic Chem. 1987, 24, 877; d) M. M. Rammah, M. Othman, K. Ciamala, C. Strohmann, M. B. Rammah, Tetrahedron 2008, 64, 3505-3516 and references cited therein; e) S. Nieto, P. Arnau, E. Serrano, R. Navarro, T. Soler, C. Cativiela, E. P. Urriolabeitia, Inorg. Chem. 2009, 48, 11963-11975; f) E. P. Urriolabeitia, E. Laga, C. Cativiela, Beilstein J. Org. Chem. 2012, $8,1569-1575$. 
[41] For the synthesis of isoindolinone-3-carboxamide derivatives see: a) J. Zhang, A. Jacobson, J. R. Rusche, W. Herlihy, J. Org. Chem. 1999, 64, 1074-1076; b) D. L. Wright, C. V. Robotham, K. Aboud, Tetrahedron Lett. 2002, 43, 943-946.

[42] For the synthesis of C3-substituted isoindolinone-3-carboxylic acid derivatives see: a) S. Petersen, H. Heitzer, Liebigs Ann. Chem. 1978, 283-288; b) T. Fujimaki, H. Otomasu, Chem. Pharm. Bull. 1982, 30, 1215-1220; c) M. D. Andrews, A. G. Brewster, J. Chuhan, A. J. Ibbett, M. G. Moloney, K. Prout, D. Watkin, Synthesis 1997, 305-308; d) G. Yang, C. Shen, W. Zhang, Angew. Chem., Int. Ed. 2012, 51, 9141-9145; Angew. Chem. 2012, 124, 9275-9279; e) C. Zhu, J. R. Falck, Tetrahedron 2012, 68, 9192-9199; f) T. K. Hyster, K. E. Ruhl, T. Rovis, J. Am. Chem. Soc. 2013, 135, 5364-5367; g) J. Albert, X. Ariza, T. Calvet, M. Font-Bardia, J. Garcia, J. Granell, A. Lamela, B. López, M. Martinez, L. Ortega, A. Rodriguez, D. Santos, Organometallics 2013, 32, 649-659; h) H.-W. Lam, K.-Y. Man, W.-W. Chan, Z. Zhou, W.-Y. Yu, Org. Biomol. Chem. 2014, 12, 4112-4116.

[43] J. Clayden, D. W. Watson, M. Helliwell, M. Chambers, Chem. Commun. 2003, 2582-2583.

[44] a) J. Clayden, F. E. Knowles, C. J. Menet, Tetrahedron Lett. 2003, 44, 3397-3400; b) G. Lemiere, S. Sedehizadeh, J. Toueg, N. Fleary-Roberts, J. Clayden, Chem. Commun. 2011, 3745-3747 and references cited therein.

[45] V. Köhler, K. R. Bailey, A. Znabet, J. Raftery, M. Helliwell, N. J. Turner, Angew. Chem. Int. Ed. 2010, 49, 2182-2184.

[46] R. Hening, U. Urbach, US Patent 4,691,022, 1987 [Chem. Abstr. 1985, 103, 71186].

[47] A. Sasaoka, Md. I. Uddin, A. Shimomoto, Y. Ichikawa, M. Shiro, H. Kotsuki, Tetrahedron: Asymmetry 2006, 17, 2963-2969.

[48] a) S. Koep, H.-J. Gais, G. Raabe, J. Am. Chem. Soc. 2003, 125, 13243-13251; b) S. K. Tiwari, H.-J. Gais, A. Lindemaier, G. S. Babu, G. Raabe, L. R. Reddy, F. Köhler, M. Günter, S. Koep, V. B. R. Iska, J. Am. Chem. Soc. 2006, 128, 7360-7373.

[49]P. M. Esch, H. Hiemstra, R. F. De Boer, W. N. Speckamp, Tetrahedron 1992, 48, 4659-4676.

[50] J. H. Udding, C. J. M. Tuijp, H. Hiemstra, W. N. Speckamp, Tetrahedron 1994, 50, 1907-1918. 
[51] A. Orellana, S. K. Pandey, S. Carret, A. E. Greene, J.-F. Poisson, J. Org. Chem. 2012, $77,5286-5296$.

[52]K. Hashimoto, M. Horikawa, H. Shirahama, Tetrahedron Lett. 1990, 31, 7047-7050.

[53] a) R. Huisgen, W. Scheer, H. Mäder, E. Brunn, Angew. Chem. Int. Ed. 1969, 8, 604; b) R. Huisgen, W. Scheer, Tetrahedron Lett. 1971, 12, 481-484; c) K. Amornraksa, R. Grigg, H. Q. N. Gunaratne, J. Kemp, V. Sridharan, J. Chem. Soc, Perkin Trans. 1 1987, 2285-2296; d) A. Soret, R. Guillot, G. Rousseau, L. Blanco, S. Deloisy, Synlett 2007, 1284-1288; e) M. R. Chaulagain, Z. D. Aron, J. Org. Chem. 2010, 75, 82718274; f) M. Potowski, M. Schürmann, H. Preut, A. P. Antonchick, H. Waldmann, Nat. Chem. Biol. 2012, 8, 428-430; g) K. Liu, H.-L. Teng, L. Yao, H.-Y. Tao, C.-J. Wang, Org. Lett. 2013, 15, 2250-2253.

[54] S. C. Bergmeier, S. L. Fundy, P. P. Seth, Tetrahedron 1999, 55, 8025-8038.

[55] R. Henning, H. Urbach, Tetrahedron Lett. 1983, 24, 5339-5342.

[56]J. J. Lalonde, J. Liang, "Biocatalytic Asymmetric Oxidation for the Production of Bicyclic Proline Peptidomimetics" in Asymmetric Catalysis on Industrial Scale: Challenges, Approaches, and Solutions, $2^{\text {nd }}$ Ed. (Eds.: H.-U. Blaser, H.-J. Federsel), Wiley-VCH, 2010, pp 41-60.

[57] a) A. Znabet, E. Ruijter, F. J. J. de Kanter, V. Köhler, M. Helliwell, N. J. Turner, R. V. A. Orru, Angew. Chem. Int. Ed. 2010, 49, 5289-5292; Angew. Chem. 2010, 122, 5417-5420. b) A. Znabet, M. M. Polak, E. Janssen, F. J. J. de Kanter, N. J. Turner, R. V. A. Orru, E. Ruijter, Chem. Commun. 2010, 46, 7918-7920.

[58] a) G. J. Tanoury, M. Chen, J. E. Cochran, PCT Patent WO2007022459, 2007 [Chem. Abstr. 2007, 146, 252114]; b) G. J. Tanoury, M. Chen, Y. Dong, R. Forslund, V. Jurkauskas, A. D. Jones, D. Belmont, Org. Process Res. Dev. 2014, 18, 1234-1244.

[59] a) Y. Liu, A. Usui, S. Shirakawa, K. Maruoka, Asian J. Org. Chem. 2012, 1, 180186; b) S. Shirakawa, Y. Liu, A. Usui, K. Maruoka, ChemCatChem 2012, 4, 980982.

[60] L. Bunch, B. Nielsen, A. A. Jensen, H. Bräuner-Osborne, J. Med. Chem. 2006, 49, $172-178$.

[61]E. Jao, S. Bogen, A. K. Saksena, V. Girijavallabhan, Tetrahedron Lett. 2003, 44, 5033-5035. 
Published in Eur. J. Org. Chem. 2015, 1633-1658 (doi: 10.1002/ejoc.201403121)

[62] K. Hashimoto, Y. Ohfune, H. Shirahama, Tetrahedron Lett. 1995, 36, 6235-6238.

[63] Y. Arakawa, M. Ohnishi, N. Yoshimura, S. Yoshifuji, Chem. Pharm. Bull. 2003, 51, $1015-1020$.

[64] M.-C. P. Yeh, L.-W. Chuang, C.-C. Hwu, J.-M. Sheu, L.-C. Row, Organometallics 1995, 14, 3396-3407.

[65] a) B. Jiang, M. Xu, Org. Lett. 2002, 4, 4077-4080; b) K. M. Brummond, B. Mitasev, Org. Lett. 2004, 6, 2245-2248; c) K. M. Brummond, D. P. Curran, B. Mitasev, S. Fischer, J. Org. Chem. 2005, 70, 1745-1753; d) S. Werner, P. S. Iyer, M. D. Fodor, C. M. Coleman, L. A. Twining, B. Mitasev, K. M. Brummond, J. Comb. Chem. 2006, $8,368-380$.

[66] J. A. Monn, M. J. Valli, J. Org. Chem. 1994, 59, 2773-2778.

[67]J. L. García-Ruano, A. Tito, M. T. Peromingo, J. Org. Chem. 2003, 68, 10013-10019. [68] a) J. Hernández-Toribio, R. Gómez Arrayás, B. Martín-Matute, J. C. Carretero, Org. Lett. 2009, 11, 393-396; b) C. Zhang, S.-B. Yu, X.-P. Hu, D.-Y. Wang, Z. Zheng, Org. Lett. 2010, 12, 5542-5545; c) I. Oura, K. Shimizu, K. Ogata, S. Fukuzawa, Org. Lett. 2010, 12, 1752-1755; d) C. Nájera, M. G. Retamosa, M. Martín-Rodríguez, J. M. Sansano, A. Cózar, F. P. Cossío, Eur. J. Org. Chem. 2009, 5622-5634.

[69] J. Sançon, J. B. Sweeney, Synlett 2008, 2213-2214.

[70] a) T. Bach, C. Pelkmann, K. Harms, Tetrahedron Lett. 1999, 40, 2103-2104; b) T. Bach, C. Krüger, K. Harms, Synthesis 2000, 305-320.

[71] a) R. Flores, R. Alibés, M. Figueredo, J. Font, Tetrahedron Lett. 2009, 65, 69126917; b) V. André, M. Gras, H. Awada, R. Guillot, S. Robin, D. J. Aitken, Tetrahedron 2013, 69, 3571-3576.

[72] C. A. Maryanoff, C. B. Karash, I. J. Turchi, E. R. Corey, B. E. Marynoff, J. Org. Chem. 1989, 54, 3790-3792.

[73]F. Frébault, M. Luparia, M. T. Oliveira, R. Goddard, N. Maulide, Angew. Chem. Int. Ed. 2010, 49, 5672-5676; Angew. Chem. 2010, 122, 5807-5811.

[74] M. J. Milewska, Pol. J. Chem. 2000, 74, 447-467 and references cited therein.

[75]B. Bakonyi, M. Furegati, C. Kramer, L. La Vecchia, F. Ossola, J. Org. Chem. 2013, $78,9328-9339$. 
[76]a) W. D. Kollmeyer, US Patent 4,225,499, 1980 [Chem. Abstr. 1980, 93, 8011]; b) G. Wu, F. X. Chen, P. Rashatasakhon, J. M. Eckert, G. S. Wong, H.-C. Lee, N. C. Erikson, J. A. Vance, P. C. Nirchio, J. Weber, D. J.-S. Tsai, Z. Nanfei, PCT Patent WO2007075790, 2007 [Chem. Abstr. 2007, 147, 143273]; c) T. Berranger, P. Demonchaux, PCT Patent WO2008082508, 2008 [Chem. Abstr. 2008, 149, 152936]; d) B. Mijts, S. Muley, J. Liang, L. M. Newman, X. Zhang, J. Lalonde, M. D. Clay, J. Zhu, J. M. Gruber, J. Colbeck, J. D. Jr. Munger, J. Mavinhalli, R. Sheldon, PCT Patent WO2010008828, 2010 [Chem. Abstr. 2010, 152, 191938]; e) T. Li, J. Liang, A. Ambrogelly, T. Brennan, G. Gloor, G. Huisman, J. Lalonde, A. Lekhal, B. Mijts, S. Muley, L. Newman, M. Tobin, G. Wong, A. Zaks, X. Zhang, J. Am. Chem. Soc. 2012, 134, 6467-6472.

[77] a) Y. Fujimoto, F. Irreverre, J. M. Karle, I. L. Karle, B. Witkop, J. Am. Chem. Soc. 1971, 93, 3471-3477; b) P. K. Mykhailiuk, S. Afonin, G. V. Palamarchuk, O. V. Shishkin, A. S. Ulrich, I. V. Komarov, Angew. Chem. Int. Ed. 2008, 47, 5765-5767; c) K. X. Chen, B. Vibulbhan, W. Yang, K.-C. Cheng, R. Liu, J. Pichardo, N. Butkiewicz, F. G. Njoroge, Bioorg. Med. Chem. 2008, 16, 1874-1883.

[78]F. Brackmann, H. Schill, A. de Meijere, Chem. Eur. J. 2005, 11, 6593-6600.

[79]F. Brackmann, N. Colombo, C. Cabrele, A. de Meijere, Eur. J. Org. Chem. 2006, $4440-4450$.

[80] a) R. Zhang, A. Mamai, J. S. Madalengoitia, J. Org. Chem. 1999, 64, 547-555; b) R. Zhang, J. S. Madalengoitia, J. Org. Chem. 1999, 64, 330-331; c) A. Mamai, R. Zhang, A. Natarajan, J. S. Madalengoitia, J. Org. Chem. 2001, 66, 455-460; d) A. Mamai, J. S. Madalengoitia, Org. Lett. 2001, 3, 561-564; e) R. Ganorkar, A. Natarajan, A. Mamai, J. S. Madalengoitia, J. Org. Chem. 2006, 71, 5004-5007; f) S. Flemer, A. Wurthmann, A. Mamai, J. S. Madalengoitia, J. Org. Chem. 2008, 73, 7593-7602.

[81] S. Venkatraman, S. L. Bogen, A. Arasappan, F. Bennett, K. Chen, E. Jao, Y.-T. Liu, R. Lovey, S. Hendrata, Y. Huang, W. Pan, T. Parekh, P. Pinto, V. Popov, R. Pike, S. Ruan, B. Santhanam, B. Vibulbhan, W. Wu, W. Yang, J. Kong, X. Liang, J. Wong, R. Liu, N. Butkiewicz, R. Chase, A. Hart, S. Agrawal, P. Ingravallo, J. Pichardo, R. Kong, B. Baroudy, B. Malcolm, Z. Guo, A. Prongay, V. Madison, L. Broske, X. Cui, K.-C. Cheng, Y. Hsieh, J.-M. Brisson, D. Prelusky, W. Korfmacher, R. White, S. 
Published in Eur. J. Org. Chem. 2015, 1633-1658 (doi: 10.1002/ejoc.201403121)

Bogdanowich-Knipp, A. Pavlovsky, P. Bradley, A. K. Saksena, A. Ganguly, J. Piwinski, V. Girijavallabhan, F. G. Njoroge, J. Med. Chem. 2006, 49, 6074-6086.

[82] M. Oba, N. Nishiyama, K. Nishiyama, Tetrahedron 2005, 61, 8456-8464.

[83] A. J. Morgan, S. Nguyen, V. Uttamsingh, G. Bridson, S. Harbeson, R. Tung, C. E. Masse, J. Labelled Compd. Radiopharm. 2011, 54, 613-624.

[84] a) I. Collado, C. Pedregal, A. B. Bueno, A. Marcos, R. González, J. Blanco-Urgoiti, J. Pérez-Castells, D. D. Schoepp, R. A. Wright, B. G. Johnson, A. E. Kingston, E. D. Moher, D. W. Hoard, K. I. Griffey, J. P. Tizzano, J. Med. Chem. 2004, 47, 456-466; b) R. González, I. Collado, B. López de Uralde, A. Marcos, L. M. Martín-Cabrejas, C. Pedregal, J. Blanco-Urgoiti, J. Pérez-Castells, M. A. Fernández, S. L. Andis, B. G. Johnson, R. A. Wright, D. D. Schoepp, J. A. Monn, Bioorg. Med. Chem. 2005, 13, 6556-6570; c) A. Shibuya, A. Sato, T. Taguchi, Bioorg. Med. Chem. Lett. 1998, 8, 1979-1984; d) K. Shimamoto, Y. Ohfune, J. Med. Chem. 1996, 39, 407-423.

[85] I. Sagnard, N. A. Sasaki, A. Chiaroni, C. Riche, P. Potier, Tetrahedron Lett. 1995, $36,3149-3152$.

[86]L. G. Nair, A. Saksena, R. Lovey, M. Sannigrahi, J. Wong, J. Kong, X. Fu, V. Girijavallabhan, J. Org. Chem. 2010, 75, 1285-1288.

[87] T. Berranger, P. Demonchaux, FR2972453, 2012 [Chem. Abstr. 2012, 157, 492985].

[88] J. Park, A. Sudhakar, W. Tong, E. J. Vater, G. S. Wong, M. Chen, J. Weber, X. Yang, D.-J. Kwok, I. Jeon, R. R. Raghavan, M. Tamarez, US Patent 7,309,717, 2007 [Chem. Abstr. 2004, 142, 93671].

[89] V. V. Tverezovsky, M. S. Baird, I. G. Bolesov, Tetrahedron 1997, 53, 14773-14792.

[90] S. Hendrata, F. Bennett, Y. Huang, M. Sannigrahi, P. A. Pinto, T.-M. Chan, C. A. Evans, R. Osterman, A. Buevich, A. T. McPhail, Tetrahedron Lett. 2006, 47, 64696472 .

[91] a) M. Eckert, F. Monnier, G. T. Shchetnikov, I. D. Titanyuk, S. N. Osipov, L. Toupet, S. Dérien, P. H. Dixneuf, Org. Lett. 2005, 7, 3741-3743; b) M. Eckert, S. Moulin, F. Monnier, I. D. Titanyuk, S. N. Osipov, T. Roisnel, S. Dérien, P. H. Dixneuf, Chem. Eur. J. 2011, 17, 9456-9462; c) C. V.-L. Bray, H. Klein, P. H. Dixneuf, A. Macé, F. Berrée, B. Carboni, S. Dérien, Adv. Synth. Catal. 2012, 354, 1919-1925. 
Published in Eur. J. Org. Chem. 2015, 1633-1658 (doi: 10.1002/ejoc.201403121)

[92] S. P. Fritz, J. V. Matlock, E. M. McGarrigle, V. K. Aggarwal, Chem. Eur. J. 2013, 19, 10827-10831. 
M. Isabel Calaza obtained her $\mathrm{PhD}$ in Chemistry from the University of Santiago de Compostela in 2000 in the field of organolithium reagents derived from amino acids. She conducted a two-year postdoctoral stay in the group of Prof. P. Knochel at the Ludwig Maximilians University of Munich. In 2004, she joined AstraZeneca R\&D Mölndal as synthetic chemist of the Medicinal Chemistry Department. In 2007, she moved to the University of Zaragoza where she is an Assistant Professor. Her research interests include the synthesis of proline analogues and NMR conformational analysis.

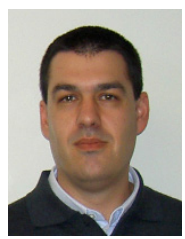

Francisco J. Sayago received his PhD in Chemistry from the University of Sevilla in 2006 in the field of carbohydrate synthesis. He conducted postdoctoral research in the laboratories of Prof. C. Cativiela at the University of Zaragoza. He is currently an Assistant Professor at this University and his research is oriented to the synthesis of bicyclic proline analogues and aminophosphonic acids.

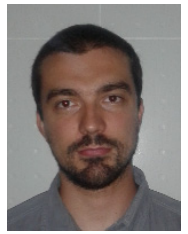

Pedro Laborda graduated in Chemistry at the University of Zaragoza in 2009 and completed his Master Thesis in Organic Chemistry one year later. He received his $\mathrm{PhD}$ in Chemistry from the same University in 2014 under the guidance of Prof. C. Cativiela. His work involved the synthesis of proline surrogates containing an octahydroindole or octahydroisoindole core.

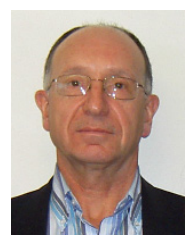

Carlos Cativiela is Full Professor of Organic Chemistry at the University of Zaragoza since 1996. His scientific activity is oriented to the synthesis of non-proteinogenic amino acids in enantiomerically pure form. He has developed different methodologies for the synthesis of a wide variety of non-coded constrained amino acids in enantiomerically pure form either by enantio-/diastereoselective syntheses or by chromatographic resolution procedures. Current research interests also involve the incorporation of such amino acids into peptides of structural, medical or agrochemical interest. He is author of more than 400 papers, including several reviews on the synthesis of amino acids. 